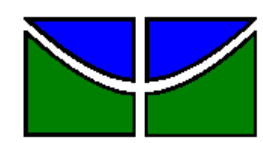

Universidade de Brasília

Faculdade de Economia, Administração e Contabilidade

Departamento de Administração

THAÍS SILVA OLIVEIRA LIMA

\title{
O USO DA ANÁLISE ENVOLTÓRIA DE DADOS PARA A AVALIAÇÃO DA EFICIÊNCIA DE CARTEIRAS DE INVESTIMENTO
}

Brasília - DF 
THAÍS SILVA OLIVEIRA LIMA

\section{O USO DA ANÁLISE ENVOLTÓRIA DE DADOS PARA A AVALIAÇÃO DA EFICIÊNCIA DE CARTEIRAS DE INVESTIMENTO}

Monografia apresentada ao Departamento de Administração como requisito parcial à obtenção do título de Bacharel em Administração.

Professor Orientador: Dr. Carlos Rosano Peña 
Lima, Thaís Silva Oliveira.

O uso da Análise Envoltória de Dados para a Avaliação de Eficiência de Carteiras de Investimento / Thaís Silva Oliveira Lima. Brasília, 2010.

94 f. : il.

Monografia (bacharelado) - Universidade de Brasília, Departamento de Administração, 2010.

Orientador: Prof. Dr. Carlos Rosano Peña, Departamento de Administração.

1. Análise Envoltória de Dados. 2. Carteiras de Investimento. 3. Eficiência. I. Título. 


\title{
O USO DA ANÁLISE ENVOLTÓRIA DE DADOS PARA A AVALIAÇÃO DA EFICIÊNCIA DE CARTEIRAS DE INVESTIMENTO
}

A Comissão Examinadora, abaixo identificada, aprova o Trabalho de Conclusão do Curso de Administração da Universidade de Brasília do (a) aluno (a)

\section{Thaís Silva Oliveira Lima}

\author{
Dr., Carlos Rosano Peña \\ Professor-Orientador \\ Ms., José Carneiro da Cunha Oliveira Neto \\ Professor-Examinador \\ Dra., Geovana Lorena Bertussi \\ Professora-Examinadora
}




\section{AGRADECIMENTOS}

A Deus, por ter me dado forças para a realização desse trabalho e ter me sustentado em todos os momentos;

Aos meus pais por estarem sempre presentes e por terem me dado a condição de estudar onde sempre desejei;

Às grandes amigas de longa data pela presença, força, amizade e por me incentivarem sempre;

Aos amigos e colegas de curso pelo companheirismo e apoio durante todos esses anos;

Ao meu namorado, pela paciência e por acreditar sempre em mim;

Às pessoas que me ajudaram e foram essenciais para a minha coleta de dados. 


\section{RESUMO}

A Análise Envoltória de Dados (DEA) é uma ferramenta utilizada para avaliar a eficiência de unidades produtivas considerando a relação insumo/produto e acreditase que ela pode ser aplicada em carteiras de investimento. O mercado financeiro é marcado pela instabilidade e necessita de métodos precisos para a tomada de decisão frente a cenários diversos, tais como a recente crise financeira mundial de 2008. Com esta monografia objetiva-se descobrir quais as potencialidades da ferramenta DEA na avaliação do desempenho de carteiras de investimento no mercado de renda variável brasileiro. Para isso foi realizada uma revisão de literatura contemplando alguns métodos usuais do mercado financeiro para avaliação de carteiras de investimento e introduzindo conceitos relacionados com a ferramenta DEA. A partir do método dedutivo, foi feita uma pesquisa quantitativa, com fins descritivos e meios de investigação documental; os índices financeiros e fundamentalistas foram analisados para se chegar às variáveis necessárias inerentes ao método DEA. A população e a amostra foram definidas a partir de uma série de passos aplicados por outros autores, chegando-se a uma amostra de 35 carteiras de investimento. Procedeu-se a análise a partir do modelo CCR orientado aos insumos e aos produtos para os anos de 2008 e 2009. Além disso, fez-se uma análise com a projeção não orientada e outra conjunta dos dois anos. Os resultados mostraram que o DEA foi capaz de retratar maior desempenho nas carteiras em 2008 ao contrário do que aconteceu em 2009, o que corrobora a realidade do momento analisado em que no ano de 2008 o mundo atravessava a crise financeira e em 2009 os mercados ainda estavam sofrendo as consequências dela. Dessa forma o DEA se mostrou uma ferramenta útil no contexto de carteiras de investimento. Além disso, com a análise é possível dizer quais foram as variáveis de destaque, quais carteiras foram mais eficientes que outras e quais serviram de referência para as demais, aspecto de suma importância para a realização de benchmarking e tomada de decisão dos agentes do mercado financeiro.

Palavras-chave: 1. Análise Envoltória de Dados 2. Carteiras de Investimento 3. Eficiência 


\section{LISTA DE ILUSTRAÇÕES}

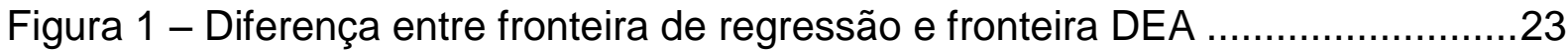

Figura 2 - DEA com retornos constantes de escala ........................................26

Figura 3 - Fronteira CRS com orientação aos inputs.......................................29

Figura 4 - Fronteira CRS com orientação aos outputs ...................................... 31

Figura 5 - DEA com retornos variáveis de escala. .......................................... 32

Figura 6 - Projeções das orientações na Fronteira VRS .....................................34

Figura 7 - Fronteira de Produção para retornos de escala constantes e variáveis....35

Figura 8 - Classificação entre ganhos de escala e orientação. .............................36

Figura 9 - Etapas da pesquisa .............................................................. 42

\section{LISTA DE QUADROS}

Quadro 1 - Indicadores utilizados na análise da eficiência de carteiras. .45

\section{LISTA DE GRÁFICOS}

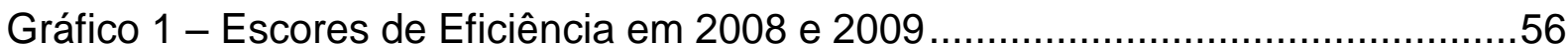

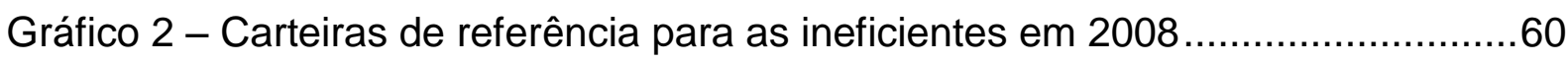

Gráfico 3 - Carteira de referência para as demais .........................................62

Gráfico 4 - Projeção da Carteira 1 em 2008 .....................................................66

Gráfico 5 - Projeção da Carteira 20 em 2009 ..............................................67

Gráfico 6 - Projeção não orientada da Carteira 20 ..........................................69

Gráfico 7 - Pesos dos Inputs ........................................................................ 70

Gráfico 8 - Pesos dos Produtos.......................................................... 72

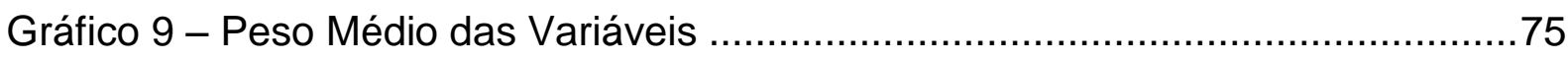




\section{LISTA DE TABELAS}

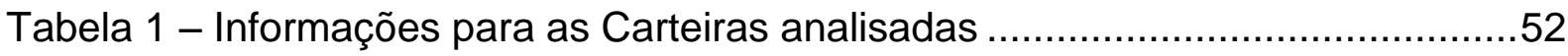

Tabela 2 - Ordenamento das Carteiras de Investimento - Modelo DEA-CCR ..........54

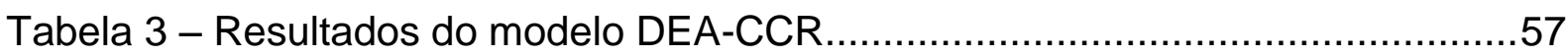

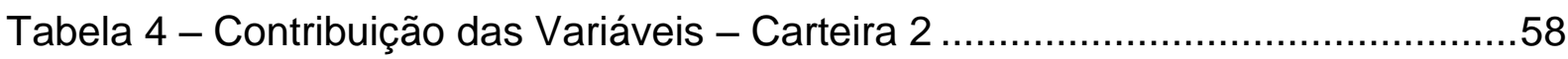

Tabela 5 - Contribuição das Variáveis - Carteira 23 .............................................59

Tabela 6 - Contribuição das Variáveis - Carteira 6 ..............................................61

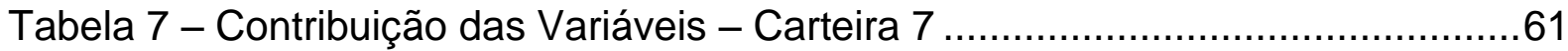

Tabela 8 - Contribuição das Variáveis - Carteira 11 ...........................................62

Tabela 9 - Indicadores e Metas Radiais de Eficiência ..........................................64

Tabela 10 - Projeção radial das variáveis nas carteiras ineficientes em 2008 .........65

Tabela 11 - Projeção radial das variáveis ineficientes em 2009 ............................66

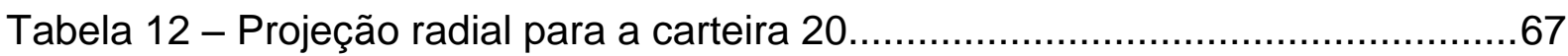

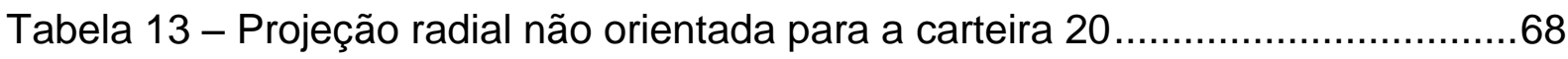

Tabela 14 - Comparação dos escores entre as eficientes.....................................73

Tabela 15 - Comparação dos escores entre as ineficientes ....................................74

Tabela 16 - Comparação dos resultados ...........................................................74 


\section{LISTA DE ABREVIATURAS E SIGLAS}

BCC - Banker, Charnes e Cooper

BMF\&BOVESPA - Bolsa de Valores, Mercadorias e Futuros

BOVESPA - Bolsa de Valores de São Paulo

CAPM - Capital Asset Pricing Model

CCR - Charnes, Cooper e Rhodes

CRS - Constant Returns to Scale ou Retorno Constante de Escala

CVM - Comissão de Valores Mobiliários

DEA - Data Envelopment Analysis ou Análise Envoltória de Dados

DMU - Decision Making Units ou Unidades Tomadoras de Decisão

EE - Eficiência de Escala

EP - Eficiência Produtiva

ET - Eficiência Técnica Pura

IBOVESPA - índice da Bolsa de Valores de São Paulo

LPA - Lucro por Ação

MACD - Moving Average Convergence-Divergence

Ol - Orientação aos insumos

OO - Orientação aos Produtos

$\mathrm{P} / \mathrm{L}$ - Preço sobre Lucro

PCA - Principal Component Analysis

PPL - Problema de Programação Linear

PTF - Índice de Produtividade Total dos Fatores

SBPE - Sistema de Poupança e Empréstimo

SFA - Stochastic Frontier Analysis ou Análise de Fronteiras Estocásticas

SFN - Sistema Financeiro Nacional

VRS - Variable Returns to Scale ou Retorno Variável de Escala 


\section{SUMÁRIO}

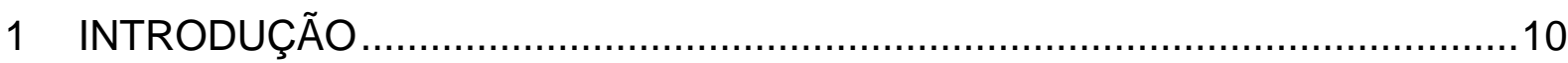

1.1 Contextualização do assunto ...........................................................10

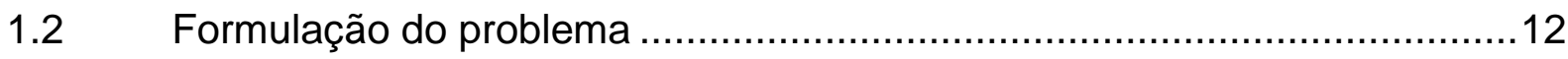

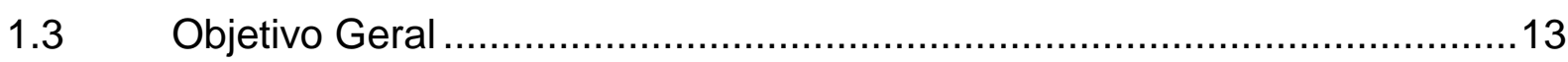

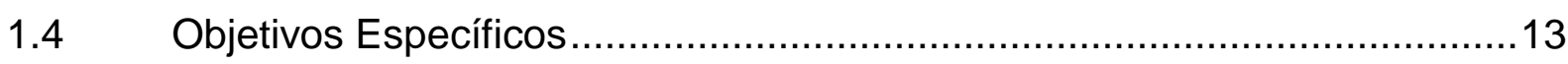

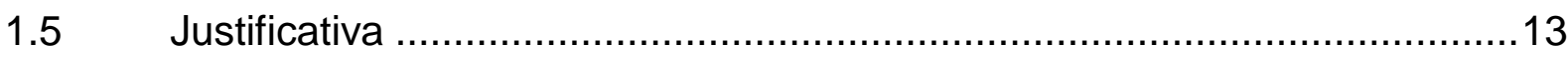

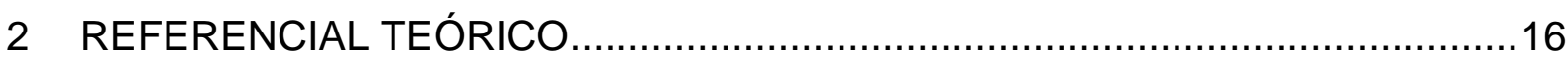

2.1 Mercado Financeiro e Ferramentas de Decisão ......................................16

$2.2 \quad$ Análise Envoltória de Dados - DEA …………...................................21

2.2.1 Conceitos e Avaliação de Eficiência …………………………….....21

2.2.2 Definição da Ferramenta DEA ………….....................................24

2.2.3 Histórico, Modelos DEA e Estudos Realizados ....................................25

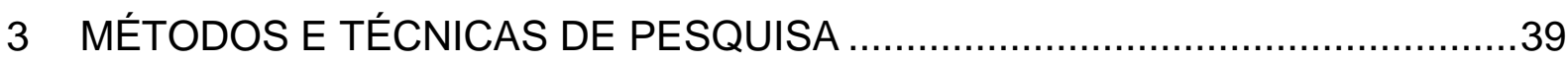

3.1 Tipo e descrição geral da pesquisa............................................................39

3.2 Caracterização da organização ……………....................................... 40

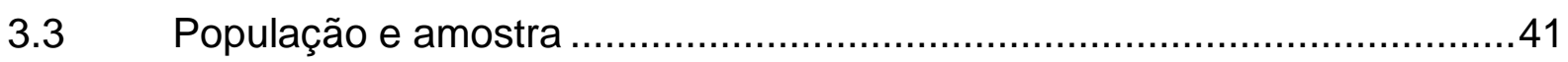

3.4 Caracterização dos instrumentos de pesquisa ........................................48

3.5 Procedimentos de coleta e de análise de dados.......................................49

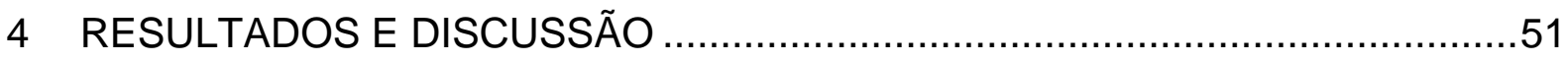

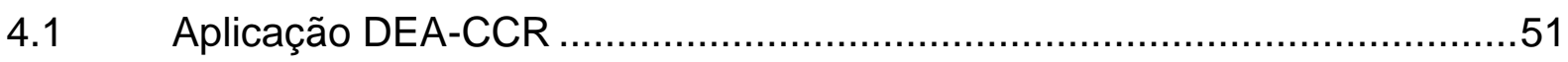

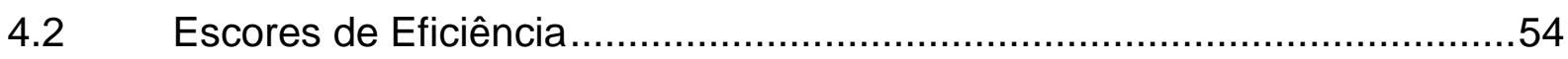

4.3 Interpretação das Carteiras Eficientes …………................................58

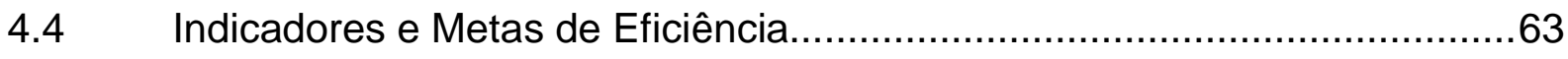

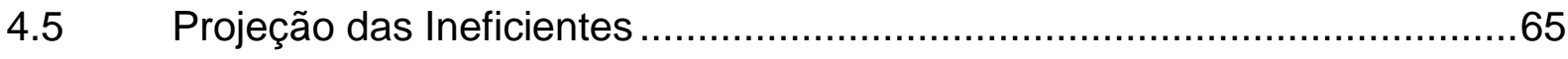

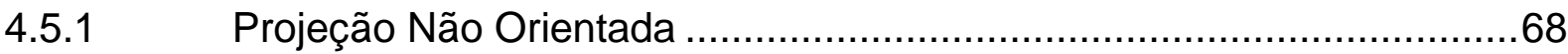




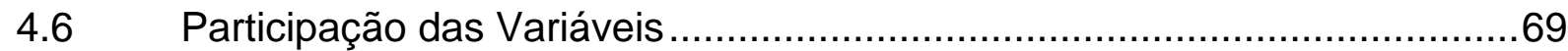

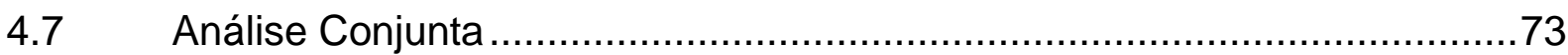

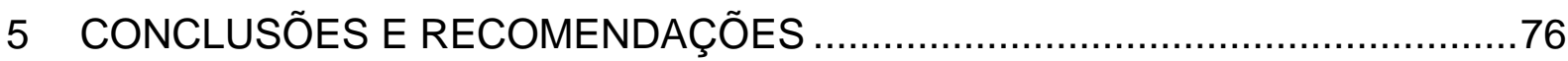

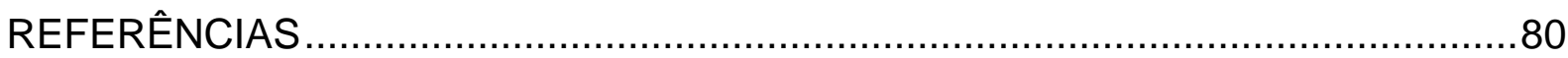

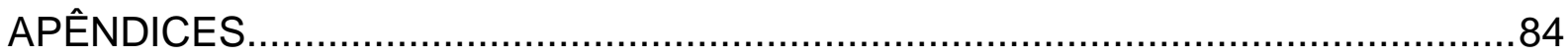

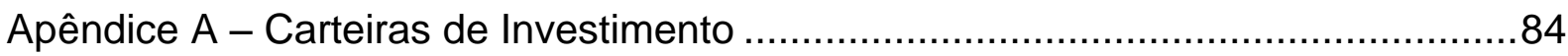

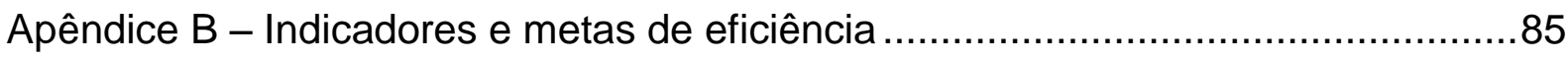

Apêndice C - Projeção das variáveis para as unidades ineficientes em 2008 ...........86

Apêndice D - Projeção das variáveis para as unidades ineficientes em 2009..........87

Apêndice E - Pesos das variáveis CCR- OI 2008................................................ 88

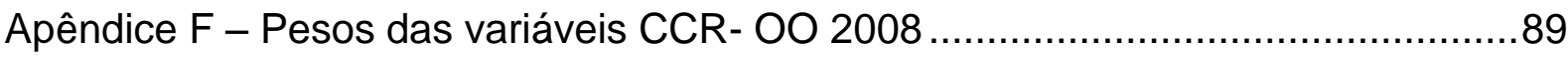

Apêndice G - Pesos das variáveis CCR- OI 2009 ...................................................

Apêndice H - Pesos das variáveis CCR- OO 2009.............................................91

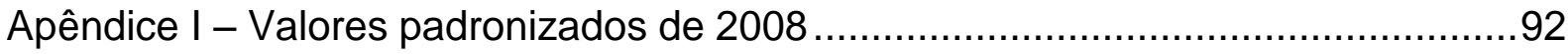

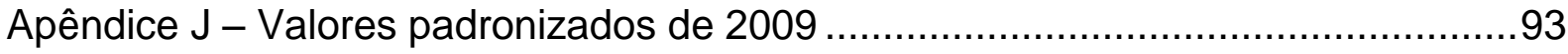

Apêndice K - Valores padronizados da média de 2008 e 2009 ...............................94 


\section{INTRODUÇÃO}

Este capítulo inicia-se com a contextualização do assunto mercado financeiro em que se destacam seus aspectos principais e a relevância de se utilizar ferramentas que auxiliem a tomada de decisão. A partir dessa situação, considerase a ferramenta DEA na avaliação de carteiras de investimento o que culminará para a formulação do problema, bem como dos objetivos principais e específicos. Além disso, apresentam-se as razões teóricas e práticas para a realização dessa pesquisa e a importância desse tema no contexto atual.

\subsection{Contextualização do assunto}

As relações econômicas e financeiras existentes em diversos países estão marcadas pela forte globalização; é cada vez mais imperativo se deparar com nações que mantém relação de trocas, favores e mutualismo para seu próprio desenvolvimento. O mundo percebeu a necessidade de modernização no sentido de interagir por meio de diversos fatores; um que merece destaque especial é o mercado financeiro, pois como afirma Assaf Neto (2008), "o sucesso empresarial passa, necessariamente, pela dinâmica dos mercados financeiros, avaliando as diversas estratégias e decisões de investimentos, financiamentos e gestão de risco". Dessa forma, o autor confirma que o estudo do mercado financeiro vem assumindo crescente importância no contemporâneo ambiente econômico mundial.

Para Silva (2003), o aumento do interesse pelo mercado financeiro se dá, principalmente, pelo alto volume de recursos movimentados no mundo todo e pelo papel exercido pelo mercado de capitais: canalizar recursos das unidades superavitárias para unidades deficitárias. Com isso o mercado financeiro agiliza o processo de transferência de recursos, facilitando atividades e criando melhores oportunidades de poupança e investimento. (SILVA, 2003, p. 3).

Para Lima (1999 apud SILVA, 2003) já há uma aceitação generalizada que um sistema financeiro desenvolvido na economia proporciona, em tempos de produtividade, acumulação do capital, aumento de poupança e investimentos e crescimento econômico. 
Hoje em dia percebem-se bolsas de valores integradas em todo o sistema econômico e circulação de moeda e informação em tempo recorde. O crescimento das bolsas de valores e dos investimentos é percebido no Brasil diante do alto volume de ativos negociados. Como mostra Silva (2003, p.1) no caso do Brasil, no ano de 2002, o valor de mercado das ações de companhias brasileiras, cotadas na Bolsa de Valores de São Paulo (BOVESPA), atingia a cifra de 192,9 bilhões de dólares.

Vidotto, Migliato e Zambon (2009, p.293) confirmam a elevação da participação de empresas nas bolsas de valores e o crescimento de novos investidores, segundo os autores:

\begin{abstract}
isso tem sido motivado particularmente pela estabilidade da economia brasileira, que envolve desde o controle da inflação na casa de um dígito anual, a valorização do Real perante o dólar, a queda contínua da taxa de juros (SELIC), entre outros. Esses fatores não motivaram apenas as empresas a ingressarem na bolsa de valores, pois se verifica também um reflexo no aumento de novos investidores, que buscam novas formas de investimento, em detrimento da queda nas taxas de retorno de aplicações financeiras mais convencionais, como: Poupança, fundos de Renda Fixa e fundos DI.
\end{abstract}

Lopes et al. (2008, p.1) também corroboram o fato do crescimento de novos investidores no mercado financeiro, "em 5 anos o índice Bovespa - Ibovespa cresceu 476\%", isso se deve, segundo os autores, pela elevação do grau de confiança do investidor na economia brasileira e, por consequência, nas empresas que fazem parte da bolsa de valores.

Diante do exposto percebe-se o crescimento potencial desse mercado. Embora exista esse aumento, há a preocupação com a eficiência nos investimentos em ativos negociados em bolsas de valores, principalmente nos critérios de seleção de carteiras de investimento, objeto desse estudo. "Apesar da inclusão crescente do número de investidores neste mercado modelos de seleção de carteiras ainda parecem extremamente complexos" (LOPES et al., 2008, p. 1). É nesse sentido que aparece um recente modelo para medir a eficiência e, logo auxiliar na tomada de decisão.

A Análise Envoltória de Dados - Data Envelopment Analysis (DEA) surge como um complemento para sanar as falhas de modelos conhecidos para seleção de carteiras, como a Teoria das Carteiras de Markowitz (1952), pois como mostram Ceretta e Costa Jr. (2001, p.1) "a análise por envoltório de dados permite incorporar outros atributos importantes ao investidor, além dos tradicionais atributos risco e 
retorno calculados sobre um determinado intervalo de tempo". O DEA também se constitui como uma poderosa ferramenta de auxílio na tomada de decisão para a busca da eficiência nas carteiras de investimento, pois ela "permite ao investidor não somente tomar decisões sobre em quais fundos investir, mas também mostra as razões de não se investir em outros fundos". (CERETTA; COSTA Jr., 2001, p. 20).

A utilização do método DEA para a seleção de carteiras de investimento foi influenciada pela abordagem de Powers e McMullen (2000) aonde, o método de programação matemática DEA foi proposto para a construção de carteiras no mercado de renda variável americano.

\subsection{Formulação do problema}

Diante da alta competitividade empresarial e da volatilidade do mercado financeiro se faz mister um bom diferencial no momento de investir em ações. As ferramentas para otimização de carteiras e busca pela eficiência estão cada vez mais em alta nos profissionais do mercado financeiro. A seleção de eficientes ativos para compor uma carteira de investimento se torna uma necessidade para melhores desempenhos perante a competitividade de empresas; dessa forma, procura-se um auxílio para a tomada de decisões a fim de diminuir os riscos e aumentar os retornos face às incertezas do futuro.

Nesse sentido a ferramenta DEA, que é utilizada para a avaliação da eficiência, aparece como uma resposta a que métodos devem ser empregados para se avaliar esse desempenho. Assim, algumas questões práticas auxiliam a construção da problemática principal: Por que o DEA deve ser utilizado para avaliar o desempenho das carteiras de investimentos? Como auxiliar a decisão dos investidores sobre qual carteira escolher? O uso da Análise Envoltória de Dados servirá para responder essas questões e embasará a questão fundamental desse trabalho: A medida de eficiência DEA é um bom indicativo do desempenho de carteiras de investimento no mercado de renda variável brasileiro? 


\subsection{Objetivo Geral}

Ao final desse trabalho será possível avaliar a eficiência das carteiras de investimento, dado que isso reflete a uma propriedade da ferramenta DEA. Porém o objetivo principal desse estudo consiste em, a partir da aplicação e avaliação da ferramenta Análise Envoltória de Dados:

Evidenciar as potencialidades da ferramenta DEA na análise de desempenho de carteiras de investimento no mercado de renda variável brasileiro.

\subsection{Objetivos Específicos}

a) Discutir os principais estudos sobre ferramentas de decisão e seleção de carteiras;

b) Revisar os principais conceitos para a avaliação de desempenho;

c) Caracterizar o histórico e os conceitos relacionados com a ferramenta DEA; e

d) Avaliar a eficiência das carteiras de investimento.

\subsection{Justificativa}

A Análise Envoltória de Dados é a tradução do conceito Data Envelopment Analysis (DEA). Para Lopes et al. (2009 p. 1) o DEA "consiste em um modelo de programação linear que avalia a eficiência relativa de Unidades Tomadores de Decisão (DMUs) que utilizam múltiplos insumos na produção de múltiplos produtos." Os autores ainda complementam que o DEA é uma técnica de mensuração de desempenho que tem como objetivo principal determinar a eficiência relativa de unidades de produção considerando sua proximidade à uma fronteira de eficiência.

Charnes et al. (1997, p. 10) afirmam que "entre 1978 e 1992 mais de 4000 artigos, livros e dissertações foram publicados envolvendo DEA". Para os autores, esse rápido desenvolvimento foi em virtude, principalmente, de problemas que surgiram no processo de aplicação do método, o que possibilitou que várias extensões do DEA surgissem. Como mostra Charnes et al. $(1997$, p. 11) a 
bibliografia sobre aplicações do DEA envolve uma grande variedade de contextos, como a educação (escolas e universidades públicas), saúde (hospitais, clínicas, médicos), bancos, forças armadas, auditoria, esportes, agricultura, meios de transporte, etc. Onusic, Casa Nova e Almeida (2007, p.83) afirmam que essa repercussão do DEA se dá em virtude de que os pesquisadores em diversos campos rapidamente reconheceram que a DEA é uma excelente metodologia para processos de modelagem operacional. Esse dado evidencia o crescente uso da ferramenta DEA na solução de problemas organizacionais.

Segundo Lopes et al. (2008, p. 2) alguns estudos mais recentes na literatura nacional vêm demonstrando a aplicabilidade de DEA na área de finanças. Dentre esses estudos, pode ser encontrada a utilização do DEA para avaliação do desempenho de fundos de ações e fundos de investimento em geral. Há também a avaliação da rentabilidade e eficiência do setor bancário brasileiro e alguns trabalhos que constroem modelos para análise de demonstrações contábeis. Aplicações que mais se aproximam com a atual pesquisa são encontradas na utilização de DEA para construção de carteiras de investimento. $O$ presente trabalho se diferencia desses estudos, pois ele envolve a aplicação do DEA em uma realidade já existente, por meio da avaliação de carteiras de investimento reais de uma empresa específica. Nesse sentido, a pesquisa contribuíra para desenvolver linhas de pesquisa no âmbito do mercado financeiro, visto que este se apresenta promissor, mas ao mesmo tempo de grande risco, necessitando assim de medidas e indicadores que permitam avaliar a eficiência nesses setores.

Com isso, o DEA pode ser mais explorado em áreas financeiras específicas; tal fato e sua comprovada eficiência justificam a escolha do presente trabalho, que irá colaborar para aprofundar o estudo na aplicação do DEA em carteiras de investimento, bem como ser um auxílio à tomada de decisão de empresários, como corretores de bolsa de valores, agentes autônomos de investimentos e demais profissionais ligados ao mercado financeiro.

Além desses benefícios, cabe destacar que a empresa de onde serão tirados os dados é um agente autônomo de investimento e que esta depende da alta eficiência de suas carteiras para obter sucesso profissional. $O$ resultado desse trabalho proporcionará uma contribuição prática no sentido de melhorar a tomada de decisão, uma vez que os gestores conhecerão os riscos e retornos envolvidos na administração de carteiras de investimento e poderão assim criar estratégias que 
otimizem a futura gestão de carteiras de seus clientes. Além disso, na prática, a pesquisa funcionará como um benchmarking no negócio, uma vez que, como apontam Macedo, Casa Nova e Almeida (2007, p.2) a ferramenta DEA "vem sendo usada como um instrumento analítico e quantitativo de benchmarking para avaliar a eficiência relativa entre empresas/instituições". Onusic, Casa Nova e Almeida (2007, p.94) corroboram isso e afirmam que "um aspecto relevante da técnica DEA é a possibilidade de comparar as empresas eficientes com as empresas ineficientes (benchmarking), indicando possibilidades de melhoria para seu desempenho." 


\section{REFERENCIAL TEÓRICO}

Neste capítulo se apresenta uma revisão de literatura dos principais elementos teóricos considerados relevantes para a realização e o entendimento desse trabalho. Inicia-se com uma introdução ao mercado financeiro e os componentes do Sistema Financeiro Nacional (SFN), são mostradas as principais formas de se avaliar e tomar decisões sobre investimentos; e selecionar carteiras de investimento. Por fim apresentam-se conceitos existentes para avaliar desempenho, as principais formas de medi-los e aspectos relacionados com DEA como: definição da ferramenta, caracterização do histórico, dos principais modelos existentes, da metodologia dessa ferramenta e principais estudos envolvendo o DEA.

\subsection{Mercado Financeiro e Ferramentas de Decisão}

Diante da crescente relevância que o mercado financeiro exerce na economia e da alta complexidade em suas operações, faz-se necessário compreender melhor o SFN. De acordo com a Comissão de Valores Mobiliários (CVM, 2010) ele pode ser entendido como o conjunto de instrumentos, mecanismos e instituições que asseguram a canalização da poupança para o investimento, ou seja, dos setores que possuem recursos financeiros superavitários para os desejam ou necessitam de recursos (deficitários). O SFN é segmentado em quatro grandes mercados: monetário, de crédito, de câmbio e de capitais. Para Assa Neto (2008) o Sistema Financeiro Nacional envolve dois grandes subsistemas:

1) O Normativo, formado por entidades fiscalizadoras e reguladoras;

2) $O$ de Intermediação Financeira, onde está o mercado de capitais.

O mercado de capitais é constituído pelas instituições financeiras não bancárias, instituições componentes do sistema de poupança e empréstimo (SBPE) e diversas instituições auxiliares. (ASSAF NETO, 2008, p.67). Segundo a CVM (2010) esse mercado tem como objetivo canalizar recursos de médio e longo prazo para agentes deficitários, através das operações de compra e de venda de títulos e valores mobiliários, efetuadas entre empresas, investidores e intermediários; ela é o 
principal órgão responsável pelo controle, normatização e fiscalização deste mercado.

Vários são os títulos e valores mobiliários negociados no mercado financeiro, tanto produtos de renda fixa quanto de renda variável. Para a CVM (2010), "nos investimentos em renda fixa, a remuneração, ou sua forma de cálculo, é previamente definida no momento da aplicação." Já em renda variável "o investidor não tem como saber, previamente, qual será a rentabilidade da aplicação". As diferenças principais entre esses produtos estão ligadas, também, aos processos de formação de preços em seus respectivos mercados. Enquanto os preços de produtos de renda variável são formados pela interação entre ofertas e demandas propostas por um número diversificado de investidores, em renda fixa o preço depende da rentabilidade implícita prevista para o papel (CVM, 2010). Os investimentos mais populares em renda fixa são a Caderneta de Poupança e os Fundos DI, e em renda variável são as ações, os fundos de ações e os clubes de investimento. Para fins desse estudo, serão analisadas somente as ações.

A Bolsa de Valores, Mercadorias e Futuros (BM\&FBOVESPA, 2010) define ações como "títulos nominativos negociáveis que representam, para quem as possui, uma fração do capital social de uma empresa". Para Assaf Neto (2008, p. 158) "o sucesso dos investimentos produtivos está cada vez mais dependente da participação dos acionistas, cujos interesses de participação impulsionam o crescimento das empresas." Nesse sentido o mercado acionário se mostra muito promissor, mas ao mesmo tempo de considerável risco diante da incerteza que ele oferece aos investidores. Portugal Neto (2005, p. 67) afirma que "as ações constituem os principais ativos, e os títulos mais negociáveis e indicados à estruturação de operações, voltados às necessidades de captação de recursos financeiros de uma empresa". Em suma, as ações são valores caracteristicamente negociáveis, em mercados primários e em bolsas de valores e mercados de balcão, e distribuídos aos acionistas de acordo com a participação monetária efetiva. (ASSAF NETO, 2008, p. 159).

As bolsas de valores, por sua vez, são instituições administradoras de mercados e também são os centros de negociação de valores mobiliários, que utilizam sistemas eletrônicos de negociação para efetuar compras e vendas desses valores. (CMV, 2010). Lins et al.(2007, p.1) mostram que 
os estudos e modelos que procuram encontrar estratégias de investimento em ações, de modo a formar carteiras capazes de apresentar retornos superiores aos índices de mercado com riscos dentro de um padrão tolerável, são tão antigos quanto às próprias Bolsas de Valores.

Os autores ainda afirmam que a partir daí, se originou o conceito de carteira de investimentos, que é definido "como um grupo de ativos que pertence a um investidor, pessoa física ou jurídica que busca a maximização da relação entre risco incorrido e retorno esperado".

Como visto anteriormente na seção 1, é notável o alto crescimento de novos investidores no mercado acionário e a grande participação de empresas nas bolsas de valores, por isso, é necessário buscar instrumentos que melhorem as decisões e a eficiência dos negócios. Várias são as ferramentas que auxiliam a tomada de decisão sobre investimento em ações; e os modelos de seleção de carteiras estão cada vez mais em alta nos profissionais do mercado financeiro.

Segundo Assaf Neto (2008) existem basicamente dois critérios básicos de análise para investimento em ações: a análise técnica e a análise fundamentalista. $A$ análise técnica é aquela também conhecida por análise gráfica, pois a partir da análise de gráficos têm-se projeções de um provável comportamento das ações, proveniente de padrões observados no desempenho passado do mercado. Vidotto, Migliato e Zambon (2009) apresentam em seu trabalho o Moving Average Convergence-Divergence (MACD) como ferramenta alternativa para a decisão de investimentos. O MACD é um indicador de tendência da análise técnica, dentre outros citados pelos autores e utilizados para o mesmo fim.

Outra forma da avaliação das ações se dá pela análise fundamentalista que está baseada no desempenho econômico e financeiro da empresa; ela considera as variáveis internas e externas à empresa, as quais exercem influência sobre o seu desempenho e, logo, sobre o valor intrínseco de suas ações. Os principais subsídios desse critério de análise são os demonstrativos financeiros da empresa, os diversos dados e informações referentes ao setor econômico de atividade, ao mercado acionário e a conjuntura econômica. (ASSAF NETO, 2008, p.195). É importante considerar essas duas formas de avaliar as ações, pois algumas variáveis utilizadas na metodologia DEA são indicadores provenientes da análise fundamentalista de ações.

Ao que tange a otimização e a seleção de carteiras de investimento, Markowitz (1952) merece destaque na relação risco versus retorno na composição 
das mesmas. Desde a divulgação da Teoria das Carteiras, várias são as vertentes que convergem para a pesquisa de técnicas de seleção de carteiras.

A teoria introduzida por Markowitz em 1952 é um modelo de programação quadrática para a formação de portfólios. Busca maximizar a utilidade de um investidor que deve escolher um conjunto de ativos para compor uma carteira. (LOPES et al., 2009, p.5). Markowitz afirma que o retorno esperado de uma carteira de ativos é a média ponderada do retorno de cada ativo em relação a sua participação no total da carteira e a soma dessa participação dos ativos da carteira deve ser igual a um. O risco da carteira depende não apenas do risco e da participação de cada ativo, mas também da forma como se relacionam (covariam) entre si. Dessa forma, o risco é medido por meio da variância dos retornos dos ativos e da covariância entre eles. (ASSAF NETO, 2008, p. 221).

Outros modelos para a seleção de carteiras de investimento podem ser encontrados nos trabalhos de Lins et al. (2007) e Matsumoto, Pinheiro e Santos (2007). Lins et al. (2007, p. 3) sugerem uma abordagem que, além de levar em consideração a diversificação proposta por Markowitz, também analisem os preços dos ativos e outros fatores, sem os quais, podem tornar a diversificação supérflua. Nesse sentido, o trabalho de Lins et al. (2007 p. 1) "reside na busca de uma métrica alternativa que auxilie um determinado investidor a formular grupos de ações onde possam alocar seu capital disponível para investimento de forma a conhecer o risco potencial e o retorno possível". Para isso eles utilizam a técnica de análise de Clusters para a formulação de carteiras hipotéticas de ativos financeiros.

Matsumoto, Pinheiro e Santos (2007) aplicaram as técnicas de programação de compromisso no mercado de ações no Brasil com base na utilidade do investidor. Para eles essa foi a metodologia adotada, pois "a maioria dos portfólios de ações, indexados ao índice da bolsa e construídos sobre o mercado brasileiro, podem não apresentar eficiência e otimização da utilidade totalmente garantida conforme a preferência do investidor" (MATSUMOTO; PINHEIRO; SANTOS, 2007, p.3).

Lopes et al. $(2006,2008,2009)$ em seus trabalhos utilizam a ferramenta DEA para construção de carteiras de investimento, e ainda para a construção de sua metodologia também fazem referencia ao trabalho de Powers e McMullen (2000). No presente trabalho, a ferramenta DEA será utilizada para analisar carteiras de investimento já existentes, pois o propósito não é a construção de carteiras, mas sim evidenciar a potencialidade dessa ferramenta no contexto de mercado acionário; e 
isso será obtido por meio da avaliação da eficiência de cada carteira de investimento. A seguir, algumas das principais características relacionadas com a ferramenta DEA. 


\subsection{Análise Envoltória de Dados - DEA}

\subsubsection{Conceitos e Avaliação de Eficiência}

Sabe-se que a ferramenta DEA é utilizada para avaliar eficiência, porém para compreender essa funcionalidade, é importante revisar e diferenciar alguns conceitos básicos comumente usados para avaliar o desempenho de organizações: Eficiência, Eficácia e Produtividade. Kassai (2002) corrobora a definição de Rosano (2008) para eficácia, no sentido de que esta está relacionada ao cumprimento dos objetivos traçados, ou seja, diz respeito aos fins e à obtenção dos resultados desejados. Rosano (2008, p. 85) define eficiência como "a combinação ótima dos insumos e métodos necessários (inputs) no processo produtivo de modo que gerem o máximo de produto (output)." O autor ainda complementa que a eficiência "visa assegurar a otimização da utilização dos recursos e, portanto, relaciona-se com os meios e não com os fins."

Coelli et al. (2005) mostram que frequentemente produtividade e eficiência são usadas como sinônimos, o que é lamentável para os autores, pois essas medidas não são exatamente a mesma coisa. De uma maneira simples, os autores definem a produtividade como a razão entre um output e um input, porém quando existem múltiplos inputs e outputs, deve haver um método para agregá-los em um único valor para se obter a razão de medida da produtividade. Quando se faz referencia a produtividade, essa é em relação à produtividade total dos fatores, que, por sua vez, é a medida de produtividade envolvendo todos os fatores de produção. Coelli et al. (2005) afirmam que uma unidade pode ser tecnicamente eficiente, mas ainda pode ser capaz de aumentar sua produtividade, explorando economias de escala. Kassai (2002, p. 36) expõe que a produtividade "se difere da eficiência apenas pelo fato de esta última expressar uma relação ótima entre os recursos consumidos e os produtos gerados." A relação ótima é no sentido de otimização, ou seja, minimização dos insumos, maximização dos produtos.

De acordo com Possamai (2006, p. 49) a Análise Envoltória de Dados pode ser classificada conforme o tipo de variáveis disponíveis: calcula-se a eficiência técnica, quando se tem somente unidades físicas de medidas; ou calcula-se a eficiência econômica (que pode ser decomposta em suas componentes: técnicas e 
alocativas), quando se tem quantidades e preços. Rosano (2008, p.85) confirma a existência desses dois tipos de eficiência (técnica e econômica) e explica:

Um método de produção é eficiente do ponto de vista tecnológico, quando
se emprega o menor nível de insumos possível para produzir um nível dado
de produção. [...] E um método produtivo é mais eficiente do ponto de vista
econômico que outro, quando o primeiro consegue uma quantidade de
produto maior ou igual ao do segundo com menor custo.

Apresentados os conceitos relacionados com a avaliação do desempenho, é necessário conhecer as formas existentes para medi-lo. Coelli et al. (2005) exibem em seu livro quatro métodos de se avaliar a eficiência e a produtividade. São eles:

1) Mínimos Quadrados - Modelos Econométricos de Produção;

2) Índice de Produtividade Total dos Fatores (PTF);

3) Análise Envoltória de Dados (DEA); e

4) Análise de Fronteiras Estocásticas (SFA).

Os autores apresentam uma forma alternativa de agrupar os modelos: enquanto os modelos 1 e 4 envolvem a estimativa econométrica das funções paramétricas, os métodos 2 e 3 envolvem a estimativa não paramétricas que utiliza programação matemática. Estes dois grupos podem ser denominados de métodos "paramétricos" e "não paramétricos", respectivamente. Rosano (2008, p. 91) explica que esses métodos estão entre as técnicas mais utilizadas para determinar as fronteiras eficientes e os níveis de eficiência de unidades produtivas homogêneas. $O$ autor ainda explica cada um: o método paramétrico é o mais comum e requer uma relação funcional entre as variáveis envolvidas. A análise de regressão entra nesse método e utiliza como referência os valores médios, o que gera uma medida imprecisa das melhores práticas. (ROSANO, 2008, p.91)

Já o método não-paramétrico determina a fronteira de eficiência através de programação matemática de otimização, não requerendo a especificação de nenhuma relação funcional entre os insumos e produtos. Porém, sendo determinística, esta técnica é muito susceptível às observações extremas e aos erros de medidas.

Dessa forma, considerando o DEA, a relação ótima insumo/produto é usada para construir a fronteira de melhores práticas; fronteira essa que é construída pela solução de Problemas de Programação Linear (PPL). Oro, Beuren e Hein (2009, p.9) também contribuem ao mostrar que de forma geral, 
o modelo DEA permite a inclusão de variáveis múltiplas de entrada e saída que são calculadas simultaneamente. Essa característica a diferencia de outras técnicas analíticas com uma única dimensão, usadas geralmente na análise comparativa, como, por exemplo, análise de regressão e correlação.

Segundo Greene (1993, apud Possamai, 2006, p. 47), nos anos 60, o uso de análises de regressão foi generalizado, com base em métodos estatísticos onde se estimavam funções para ajustar os dados. Após a consolidação da teoria das fronteiras, aumentou o interesse em substituir a prática de atravessar os dados, pela de circundá-los (o que mostrava as melhores práticas e não a média), por meio de técnicas de programação matemática. A diferença entre os métodos de fronteiras e os de análise de regressão linear, para um output (produto) e um input (insumo) é apresentada de forma simples na figura a seguir:

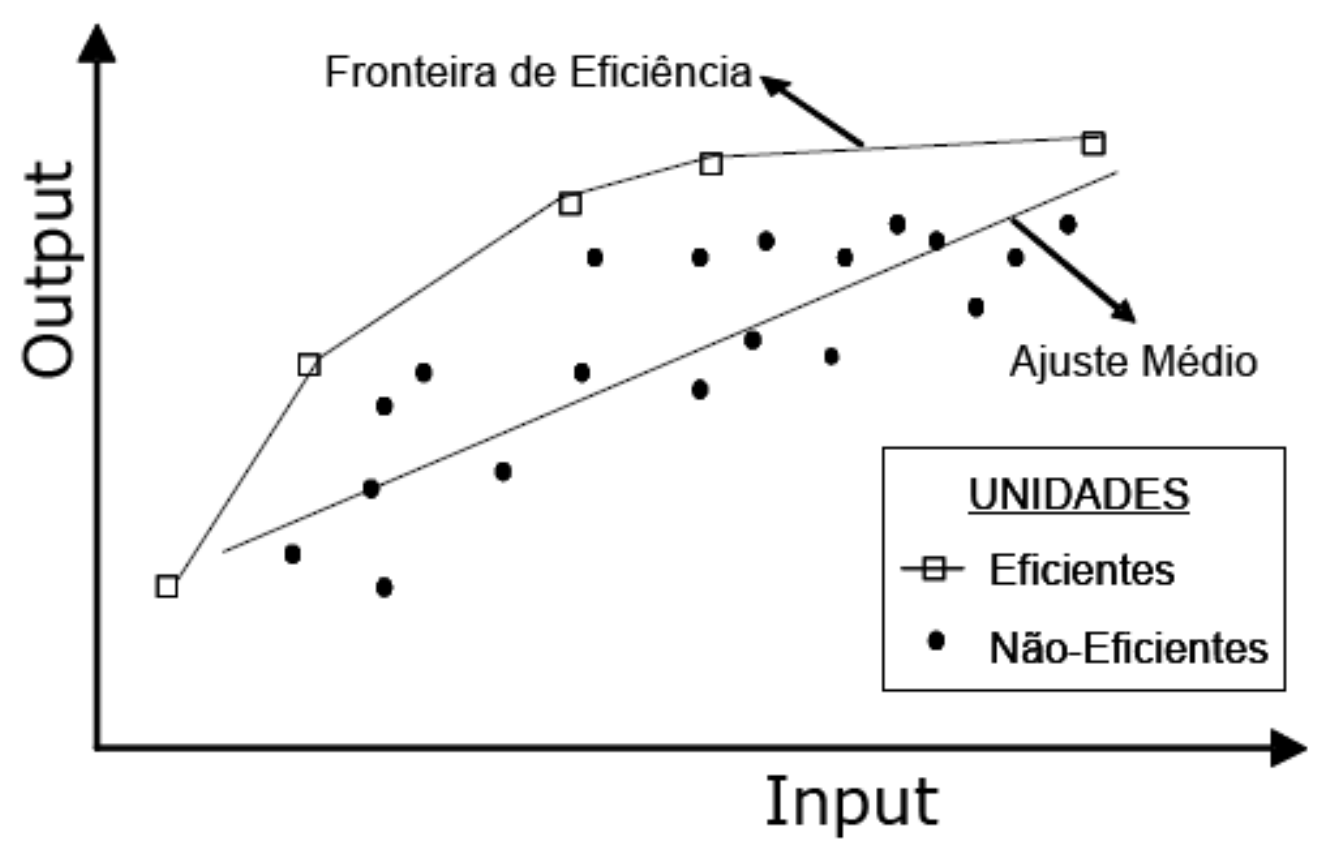

Figura 1 - Diferença entre fronteira de regressão e fronteira DEA

Fonte: Possamai (2006, p.47)

De forma clara, Greene (1993, apud Possamai, 2006, p. 47) mostra as principais diferenças entre os métodos da Figura 1: enquanto a abordagem econométrica é estocástica, paramétrica baseada em métodos estatísticos; a abordagem de programação matemática é não estocástica, não paramétrica e baseada em métodos determinísticos, construída empiricamente. Nessa última abordagem se insere a Análise Envoltória de Dados. 


\subsubsection{Definição da Ferramenta DEA}

Para Kassai (2002, p.70) a Análise Envoltória de Dados é uma técnica de construção de fronteiras de produção e indicadores da eficiência produtiva. A Figura 1 ajuda a visualizar o que essa autora expõe em sua tese, que "a Análise Envoltória de Dados define a curva de eficiência (ou de máxima produtividade), considerando a relação ótima insumo/produto". Assim são identificadas as unidades que obtiveram a alocação ótima entre inputs e outputs, que são, então, chamadas de eficientes e estão posicionadas na curva de máxima eficiência relativa. É importante notar que as demais unidades, não eficientes, estão posicionadas abaixo da curva, "envolvidas" pelo desempenho das unidades eficientes (KASSAI, 2002, p.80). A unidade "envolvida" para melhorar sua eficiência, de uma forma ideal, deve reduzir o consumo de seus inputs e/ou aumentar a produção dos outputs, movendo-se para atingir a fronteira eficiente e o desempenho das unidades benchmark (MACEDO; CASA NOVA; ALMEIDA, 2007, p.3).

O DEA é um método não paramétrico utilizado para medir a eficiência relativa de organizações homogêneas ou Unidades Tomadoras de Decisão (referenciadas na literatura como Decision Making Units - DMUs) que utilizando um conjunto de insumos, produzem um vetor produto. "Utiliza, para cada organização, técnicas de programação linear no cálculo de indicador de eficiência que compara seu desempenho com a combinação convexa mais eficiente das outras observações (produto/insumo virtual)". (SANTOS; CASA NOVA, 2005, p.5). De acordo com Kassai (2002, p.81) as DMUs podem ser grupos empresariais, empresas individuais, departamentos, divisões ou unidades administrativas. Macedo, Casa Nova e Almeida (2007, p.3) generalizam e afirmam que as DMUs são as unidades operacionais sob avaliação em uma organização ou setor econômico. É preciso que as unidades sejam homogêneas, comparáveis, ou seja, obtenham os mesmos resultados (produtos) utilizando os mesmo recursos (insumos) com variação apenas de quantidade ou intensidade, ou seja, os produtos e insumos podem ser variáveis contínuas, ordinais ou categóricas; e igualmente podem ser medidas em diferentes unidades (reais, números de alunos, metros quadrados, tempo médio de formação etc.) (ROSANO, 2008, p.92). 
Os resultados obtidos pelas DMUs são os chamados Outputs (Produtos) que compõem o numerador do quociente de eficiência devendo, portanto, respeitar ao critério de quanto maior, melhor. Já os recursos utilizados pelas DMUs para obter os resultados (produtos) desejados são chamados de Inputs (Insumos). Eles devem obedecer ao critério de quanto menor, melhor, e compõem o denominador do quociente de eficiência. (MACEDO; CASA NOVA; ALMEIDA, 2007, p.3).

\subsubsection{Histórico, Modelos DEA e Estudos Realizados}

De acordo com Santos e Casa Nova (2005 p.5) o histórico de desenvolvimento da Análise Envoltória de Dados inicia com a tese de doutoramento de Edwardo Rhodes, apresentada à Carnegie Mellon University em 1978, sob a orientação de W. W. Cooper. Onusic, Casa Nova e Almeida (2007, p.78 e 79) explicam no que consistia esse trabalho:

A tese tinha o objetivo de analisar os resultados de experimento educacional de larga escala em escolas públicas americanas (Program Follow-Through), e para isso foi desenvolvido um modelo matemático que relacionava resultados (produtos), como, por exemplo, aumento da autoestima (medido por testes psicológicos) com insumos, como tempo gasto pelos pais em exercícios de leitura com os filhos.

O estudo que resultou no modelo DEA original teve a publicação de seu primeiro artigo no European Journal of Operations Research em 1978 e foi apresentado por Charnes, Cooper e Rhodes. Esse trabalho foi construído sobre o estudo anterior de Farrell que em 1957 desenvolveu o conceito de "fronteira de melhores práticas", que representa a fronteira técnica realizável, ou seja, indica, para cada nível de entrada a saída máxima atingível e para cada nível de saída a entrada mínima necessária, respectivamente. (ELING, 2006, p.6). Esse estudo foi motivado pela necessidade de desenvolver melhores métodos e modelos de avaliação de produtividade. Segundo Possamai (2006, p.50) as bases teóricas para medir eficiência, a partir de uma abordagem não paramétrica, iniciaram com a análise de eficiência técnica de Farrell, essa análise considerava casos de um único produto/insumo. "Farrell (1957) ampliou o conceito de "produtividade" com o conceito mais geral de "eficiência", mas ainda não conseguia combinar as medidas de 
múltiplas entradas em qualquer medida global satisfatória de eficiência". (COOPER; SEIFORD; ZHU, 2004, p.4)

Posteriormente o trabalho de Farrell foi aperfeiçoado e transformado em um algoritmo de solução baseado em programação linear. Utilizou-se a análise da eficiência relativa, ao invés de absoluta, e em 1978 surgiu o método original DEA chamado de CCR que são as iniciais dos seus autores (Charnes, Cooper e Rhodes); esse modelo também é conhecido por CRS (Constant Returns to Scale) que considera retornos constantes de escala.

O modelo CCR utiliza o método de otimização de programação matemática, para, partindo da medida de eficiência técnica em casos de único produto/insumo proposta por Farrell em 1957, desenvolver um modelo que atenda a casos com múltiplos produtos/insumos, com a construção de um único produto "virtual" e um único insumo "virtual" para medir a eficiência relativa. (CHARNES et al., 1997, p.4). De forma simples a Figura 2 a seguir ilustra o CCR no caso de um insumo e um produto:

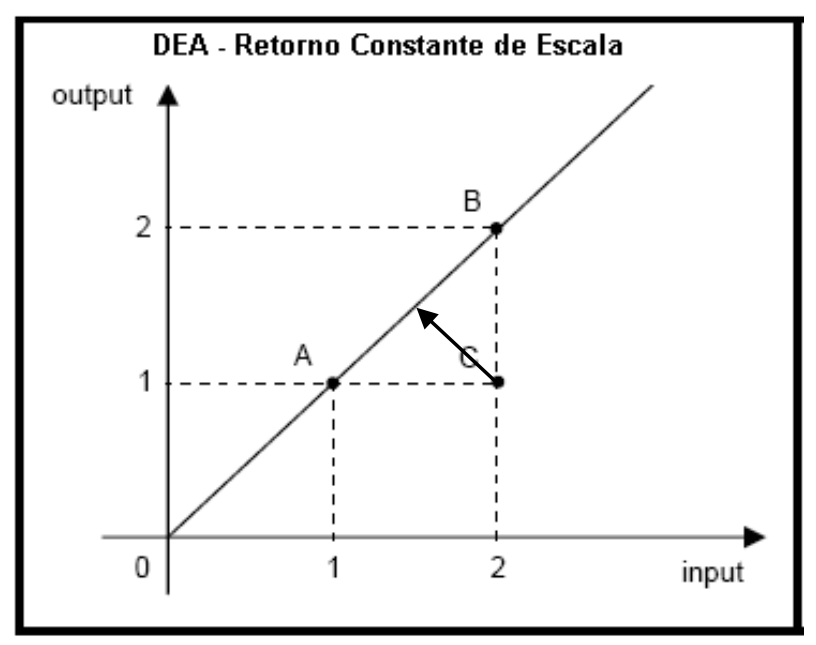

Figura 2 - DEA com retornos constantes de escala Fonte: Adaptado de Eling (2006, p.7)

O modelo DEA CCR, apresentado na Figura 2, é representado pela formulação 1 por meio de um PPL. A medida da eficiência relativa do modelo CCR para qualquer DMU é obtida pela maior razão entre outputs ponderados e inputs ponderados, representada por:

$$
\operatorname{Max} h_{o}=\frac{\sum_{r=1}^{m} u_{r} y_{r o}}{\sum_{i=1}^{n} v_{i} x_{i o}}
$$

Sujeito a: 
$\frac{\sum_{r=1}^{m} u_{r} y_{r j}}{\sum_{i=1}^{n} v_{i} x_{i j}} \leq 1 \quad j=1, \ldots, N$

$u_{r}, v_{i} \geq 0 \quad r=1, \ldots, m ; \quad i=1, \ldots, m$

Segundo Rosano (2008, p.92) esse problema resolvido para cada DMU pode ser apresentado considerando $\mathrm{N}$ unidades, produzindo $m$ quantidade de produtos $y$, a partir de $n$ quantidades de insumo $x$. Uma unidade $o$ qualquer produz $y_{r o}$ quantidades de produtos, utilizando xio insumos. A solução envolve a obtenção dos valores para $v_{i}$ e $u_{r}$ - o peso específico de cada insumo $i$ e produto $r$ - de tal forma que a medida de eficiência para a unidade produtiva analisada $h_{\circ}$ seja maximizada sujeita à restrição de que as medidas de eficiência de todas as unidades sejam menor ou igual a um, devido à orientação do problema.

A partir da resolução do $\mathrm{PPL}$, o método determina quais são as melhores práticas observadas que formam a fronteira eficiente. A eficiência das outras unidades analisadas, localizadas abaixo da fronteira, é medida a partir das posições relativas por elas, ocupadas em relação à fronteira. (ROSANO, 2008, p. 93). Essa distância entre a fronteira de produção e a unidade avaliada pode ser medida por duas situações, ou seja, a forma como é feita a projeção destas unidades na fronteira de eficiência determina a orientação do modelo: orientação a insumos (OI), quando se deseja minimizar os recursos, mantendo-se os valores dos produtos constantes; e orientação a produtos (OO), quando se deseja maximizar os produtos sem diminuir ou aumentar os insumos. (LINS; ALMEIDA; BARTHOLO Jr., 2004, p. 47).

Cooper, Seiford e Tone (2007) procedem a outra análise a partir das orientações, procedendo-se a uma combinação entre insumos e produtos, ou seja, uma projeção não orientada. Ela é obtida pela média simples entre as projeções orientadas aos insumos e aos produtos e assim é possível obter outra solução ótima reduzindo insumos e, também, aumentando produtos. Importante frisar que essa projeção só é cabível em retornos constantes de escala, essa situação pode ser exemplificada com a Figura 2 em que o ponto $C$ encontraria sua projeção não orientada exatamente no meio do segmento $A B$. 
A relação insumo/produto, dependendo da orientação do modelo, vai gerar um indicador de eficiência diferente para cada DMU. No caso de orientação aos insumos, $O$ indicador varia de 0 (máxima ineficiência) a 1 (máxima eficiência). (ONUSIC; CASA NOVA; ALMEIDA, 2007, p.79). No caso de orientação aos produtos, o índice é sempre igual ou maior que um, sendo mais ineficiente quanto maior o valor. (ROSANO, 2008). As DMUs com indicador igual a 1 formam a fronteira de eficiência e servem de benchmark para as demais, ineficientes.

Possamai (2006, p. 52) ainda afirma que além desses escores serem definidos através da relação entre insumos e produtos, eles possibilitam a identificação de folgas (excesso de insumos ou folgas de produtos). Surco e Wilhelm (2006, p.47) complementam que a avaliação que considera as folgas é chamada de medida não radial; e a que não considera é a medida radial. $O$ escore representa a distância entre a fronteira de produção e a unidade avaliada, correspondendo ao mínimo decréscimo proporcional em insumos que torna a DMU eficiente. Essa situação pode ser ilustrada na Figura 2, em que o ponto $C$ para se tornar eficiente precisa avançar para o ponto $\mathrm{A}$ ou $\mathrm{B}$ caso se proceda a $\mathrm{Ol}$ ou $\mathrm{OO}$, respectivamente. Em DEA, os insumos e produtos são ponderados por pesos, calculados livremente ou de forma restrita através de programação linear, objetivando maximizar a eficiência de cada DMU em relação ao conjunto de referência. (SENRA, et al., 2007, p.192).

A primeira situação do modelo DEA, o CCR - OI, pode ser resolvida mais facilmente pela linearização equivalente da formulação anterior:

$$
\operatorname{Max} h_{o}=\sum_{r=1}^{m} u_{r} y_{r o}
$$

Sujeito a:

$\sum_{i=1}^{n} v_{i} x_{i o}=1$ 
$\sum_{r=1}^{m} u_{r} y_{r j} \leq \sum_{i=1}^{n} v_{i} x_{i j ;} j=1, \ldots N$

$u_{r}, v_{i} \geq \varepsilon ; \quad r=1, \ldots, m ; \quad i=1, \ldots, n$

Considera-se $\mathrm{N}$ unidades $(\mathrm{j}=1,2, . ., \mathrm{N})$ que utilizam os mesmos insumos, $x$, (em diferentes quantidades) para gerar os mesmos produtos, $y$ (em diferentes quantidades);

Onde:

$\mathrm{x}_{\mathrm{ij}}=$ as quantidades do insumo $\mathrm{i}(\mathrm{i}=1,2, . ., \mathrm{n})$ consumido pela $\mathrm{j}$-ésima unidade;

$\mathrm{y}_{\mathrm{rj}}=$ as quantidades do produto $\mathrm{r}(\mathrm{r}=1,2, . ., \mathrm{m})$ produzido pela j-ésima unidade;

$\mathrm{u}_{\mathrm{r}}$ e $\mathrm{v}_{\mathrm{i}}=$ os pesos dos insumos e produtos respectivamente; e

$\varepsilon=$ equivale a um valor muito pequeno, $10^{-6}$ para evitar que os pesos sejam iguais a zero e que algumas variáveis fiquem marginalizadas do estudo.

A forma como as unidades ineficientes são projetadas no modelo CCR - OI é visualizada abaixo:

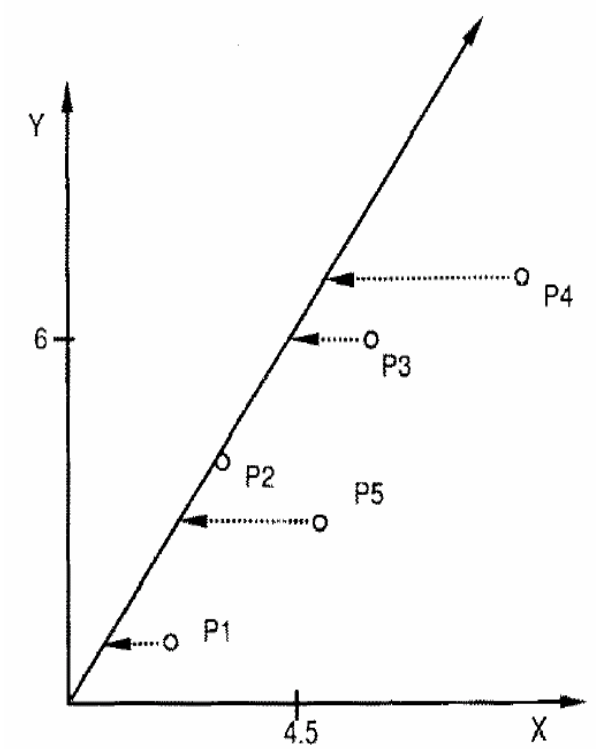

Figura 3 - Fronteira CRS com orientação aos inputs Fonte: Cooper, Seiford e Zhu (2004, p. 16)

$\mathrm{Na}$ Figura 3 os eixos $x$ e $y$ representam os inputs e os outputs, respectivamente; dessa forma para as unidades acima se tornarem eficientes é preciso orientá-las horizontalmente no caso de OI. Como visto, por ter orientação 
aos insumos, a eficiência relativa da unidade analisada, sempre tomará valores entre 0 e 1. Por exemplo, se o coeficiente encontrado da unidade P3 é 0,80 sua interpretação indicará que essa unidade produtiva deverá reduzir equiproporcionalmente o consumo de insumos em $20 \%$ para ser eficiente. (ROSANO, 2008, p.94).

Em outra situação, caso se queira aumentar os outputs, considerando o nível de insumos disponíveis, deve-se utilizar o modelo CCR com orientação aos produtos, cuja formulação é dada por:

$$
\operatorname{Min} h_{o}=\sum_{r=1}^{m} v_{r} x_{r o}
$$

Sujeito a:

$$
\begin{aligned}
& \sum_{i=1}^{n} u_{i} y_{i o}=1 \\
& \sum_{r=1}^{m} u_{i} y_{r j} \geq \sum_{i=1}^{n} v_{i} x_{i j} ; j=1, \ldots N ; \\
& u_{r}, v_{i} \geq 0 ; \quad r=1, \ldots, m ; \quad i=1, \ldots, n
\end{aligned}
$$

Essa situação é representada graficamente por: 


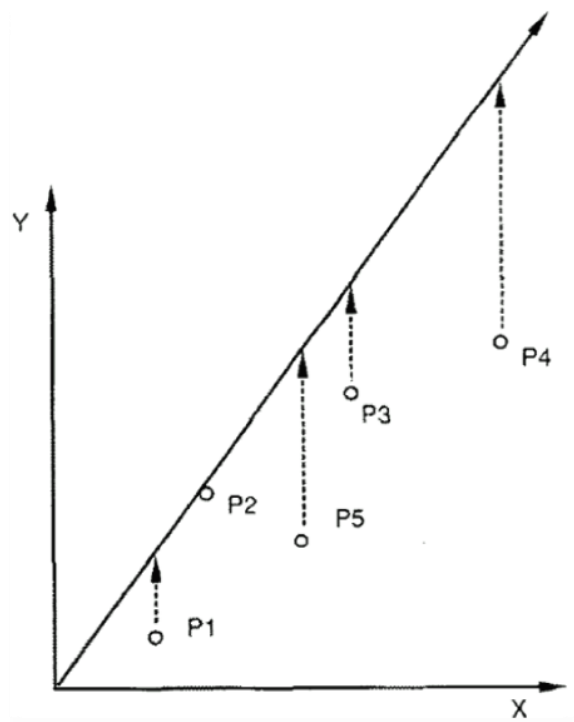

Figura 4 - Fronteira CRS com orientação aos outputs Fonte: Cooper, Seiford e Zhu (2004, p. 16)

Na Figura 4, as unidades ineficientes são deslocadas verticalmente, dado que os inputs representados pelo eixo $x$ se mantêm constante. Aqui o indicador de eficiência das unidades ineficientes será o inverso do indicador calculado pelo modelo com orientação aos insumos. Assim, o índice da unidade do exemplo anterior será $1,25=1 / 0,8$. Sua interpretação indicará que essa unidade produtiva deverá aumentar equiproporcionalmente os bens e serviços produzidos em $25 \%$ para ser eficiente (ROSANO, 2008, p.94). O modelo CCR-OI deve dar resultados equivalentes ao modelo CCR-OO, posto que ambos consideram retornos constantes de escala, ou seja, "incrementos proporcionais em inputs cobrem um mesmo incremento proporcional de todos os outputs em toda a linha de fronteira que define a eficiência e vice versa." (POSSAMAI, 2006, p. 50).

Outro modelo de DEA foi desenvolvido mais tarde e é chamado de BCC, abreviatura de Banker, Charnes e Cooper, que o desenvolveram e apresentaram em artigo publicado na Management Science em 1984. (SANTOS; CASA NOVA, 2005, p.5). Onusic, Casa Nova e Almeida (2007 p. 78 e 79) expõem que o modelo BCC permite que as unidades avaliadas apresentem retornos variáveis de escala (Variable Returns to Scale - VRS), ou seja, existe a possibilidade de retornos crescentes ou decrescentes. Esse retorno variável significa que o acréscimo em uma unidade de insumo possa gerar um acréscimo não proporcional no volume de produtos. É importante ressaltar que de acordo com Coelli et al. (2005), Eling (2006) e Cooper, Seiford e Zhu (2004) existem vários modelos DEA, como os modelos 
aditivos e multiplicativos; porém para fins desse estudo serão abordados apenas os dois modelos principais DEA: CCR e BCC. Esse último pode ser representado de maneira simples na Figura abaixo:

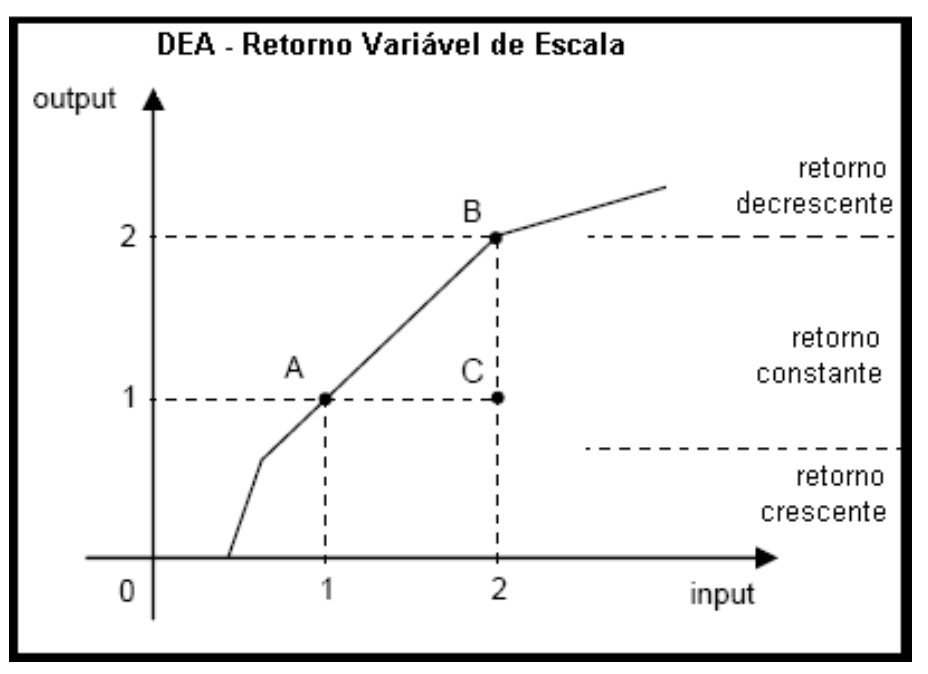

Figura 5 - DEA com retornos variáveis de escala.

Fonte: Adaptado de Eling (2006, p.7)

A Figura 5 mostra a fronteira eficiente DEA com retornos variáveis de escala no caso em que uma entrada é utilizada para a produção de uma saída.

Assim como no modelo CCR, o modelo BCC também admite duas orientações possíveis para se atingir a fronteira de eficiência: aos insumos ou aos produtos. Matematicamente, o modelo BCC inclui a variável adicional " $\mathrm{k}_{0}$ " ou " $\mathrm{w}_{0}$ " para retratar o retorno variável de escala, cada uma dependendo da orientação do modelo. Kassai (2002) mostra que os termos $k_{0}$ e $w_{0}$, por representarem a possibilidade de retornos variáveis de escada, podem assumir valores negativos ou positivos: quando são positivos apresentam retornos decrescentes de escala, quando são nulos, retornos constantes de escala, e quando são negativos, retornos crescentes de escala. No caso de orientação aos insumos, ou seja, caso se prefira minimizar os insumos a formulação matemática é:

$$
\operatorname{Max} h_{o}=\sum_{r=1}^{m} u_{r} y_{r o}-\mathrm{k}_{\mathrm{o}}
$$

Sujeito a: 
$\sum_{i=1}^{n} v_{i} x_{i o}=1$

$\sum_{r=1}^{m} u_{i} y_{r j}-\sum_{i=1}^{n} v_{i} x_{i j}-k_{o} \leq 0 j=1, \ldots N$

$u_{r}, v_{i} \geq 0 ; \quad r=1, \ldots, m ; \quad i=1, \ldots, n$

E caso se pretenda maximizar a produção dados os níveis de insumos (orientação ao produto), a formulação do Modelo BCC é:

$$
\operatorname{Min} h_{o}=\sum_{r=1}^{m} v_{r} x_{r o}+\mathrm{w}_{\mathrm{o}}
$$

Sujeito a:

$\sum_{i=1}^{n} u_{i} y_{i o}=1$

$\sum_{r=1}^{m} u_{i} y_{r j}-\sum_{i=1}^{n} v_{i} x_{i j}-w_{o} \leq 0 \quad j=1, \ldots N$

$u_{r}, v_{i} \geq 0 \quad r=1, \ldots, m ; \quad i=1, \ldots, n$

A forma como são projetadas as unidades orientadas aos insumos e aos produtos são representadas na Figura 6 a seguir: 


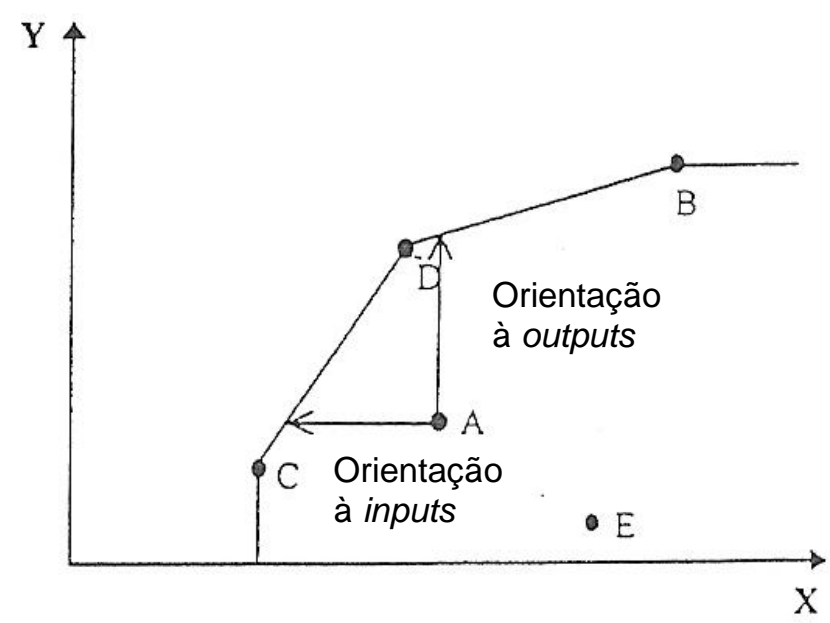

Figura 6 - Projeções das orientações na Fronteira VRS Fonte: Adaptado de Lins e Meza (2000, p.35)

A Figura 6 ilustra que para a unidade A se tornar eficiente, faz-se a orientação vertical $(\mathrm{OO})$ ou a orientação horizontal $(\mathrm{OI})$ dado que os eixos $x$ e $y$ também representam os insumos e produtos, respectivamente.

Visto os dois modelos DEA principais e suas possíveis orientações, Kassai (2002, p.76) afirma que a possibilidade de retornos de escala variáveis do modelo BCC admite que a produtividade máxima varie em função da escala de produção; e que, portanto, esse modelo permite a utilização de unidades de portes distintos. A variação mencionada ocorre pela convexidade decorrente dos retornos variáveis de escala, que pode ser ilustrado na Figura 4 e na Figura 6. Segundo Rosano (2008, p.94) o Modelo BCC com retornos variáveis de escala (VRS) forma uma fronteira convexa eficiente com as melhores unidades, independentemente da escala de operação e, dessa forma, passa a "envelopar" as unidades ineficientes para cada escala de produção. Ao trabalhar com uma fronteira convexa, considera as unidades com baixos níveis de consumo de insumos como unidades operadas com retornos crescentes de escalas e vice-versa. Essa situação é representada por: 


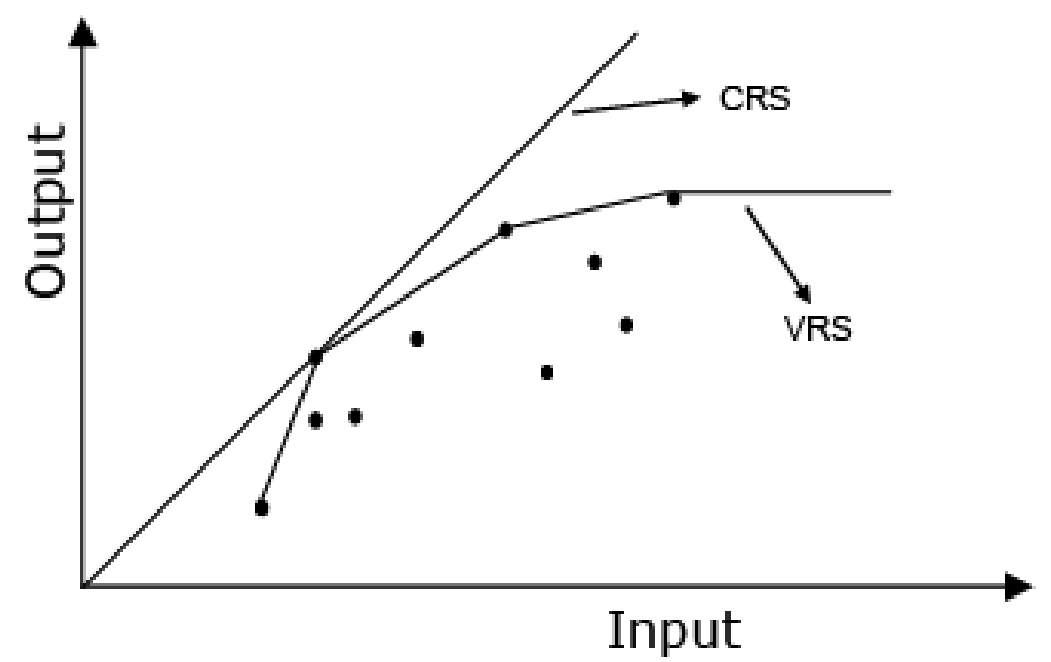

Figura 7 - Fronteira de Produção para retornos de escala constantes e variáveis Fonte: Possamai (2006, p.62)

Diante da convexidade na Figura 7, percebe-se que o modelo VRS envolve maior número de pontos, o que leva a concluir que pequenas e grandes DMUs são beneficiadas no cálculo de eficiência, dessa forma os modelos CRS e VRS, sob a ótica do produto, geram indicadores de eficiência técnica que se diferem. (Possamai, 2006, p.62).

Segundo Charnes et al. (1997, p.23) o modelo CCR permite uma avaliação objetiva da eficiência global e identifica as fontes e estimativas de montantes das ineficiências identificadas. Já o modelo BCC distingue entre ineficiências técnicas e de escala, estimando a eficiência técnica pura, a uma dada escala de operações, e identificando se estão presentes ganhos de escala crescentes, decrescentes e constantes, para futura exploração. Ainda considerando o modelo BCC, Possamai (2006, p. 53) enfatiza e complementa que a eficiência técnica pode ser decomposta em eficiência de escala, que mede a perda do produto por não estar trabalhando na escala ótima e, eficiência técnica pura, que mede a perda de produto resultante da forma de produção utilizada, refletindo aspectos de gerenciamento. Sobre o modelo BCC, Kassai (2002, p.95) afirma que em decorrência da possibilidade de retornos variáveis de escala e da segregação das ineficiências de escala e técnica os efeitos decorrentes do porte das DMUs são isolados, ou seja, esse modelo é indicado em casos que o porte das DMUs tenha relação com as variáveis em estudo.

$O$ modelo CCR envolve $O$ indicador de eficiência produtiva (EP) também chamado de eficiência técnica global, enquanto o modelo BCC envolve um indicador 
de eficiência técnica pura (ET). A relação entre os dois é definida como eficiência de escala (EE) e representada por:

$$
\mathrm{EE}_{\mathrm{SC}}=\frac{\mathrm{EP}_{\mathrm{CR}}}{\mathrm{ET}_{\mathrm{VR}}}
$$

Onde:

$E E=$ Eficiência de Escala

EP = Eficiência Produtiva

$\mathrm{ET}=$ Eficiência Técnica

Deste modo, EP pode ser de origem tanto pura quanto de escala $(E P=$ $\left.E E^{\star} E T\right)$. A EE identifica a distância existente entre as fronteiras EP e ET.

Resumidamente, a Figura 8 ilustra os modelos DEA apresentados:

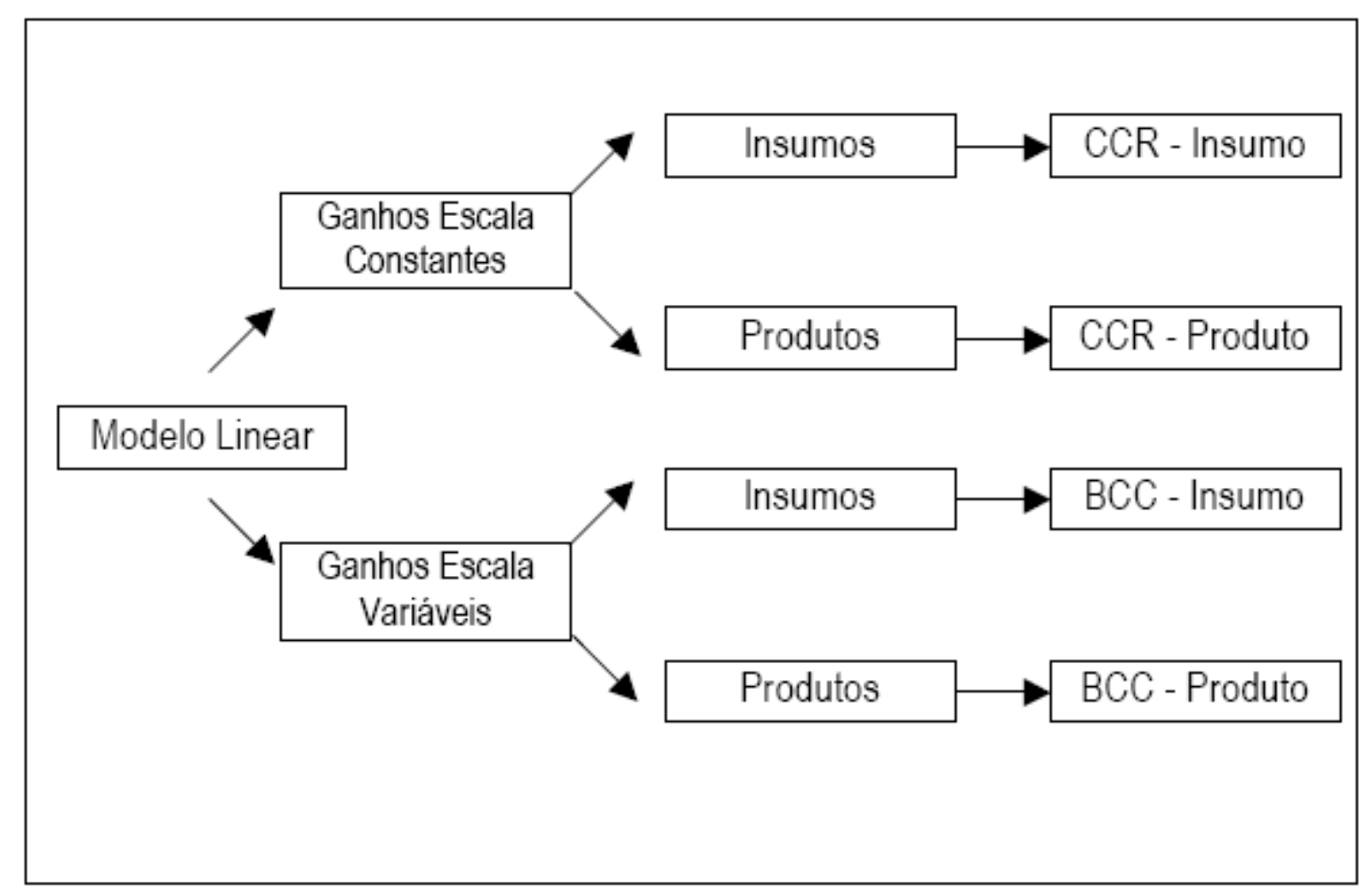

Figura 8 - Classificação entre ganhos de escala e orientação.

Fonte: Kassai (2002, p. 66)

De acordo com os ganhos de escala, a Figura 8 ilustra possíveis usos dos modelos DEA principais e as possibilidades de orientações de cada um. A escolha dentre eles depende de avaliação do desempenho que se pretende fazer, o que pode variar de negócio e abrangência, possibilitando assim encontrar diversas produções científicas utilizando o DEA. 
A partir do levantamento bibliográfico pôde-se perceber a extensão da literatura sobre DEA no exterior, porém no Brasil essa ferramenta pode ser melhor utilizada e aplicada nos mais diversos setores. Kassai (2002, p. 124) afirma que a pesquisa no Brasil, utilizando o DEA, ainda é recente e pouco explorada, porém a partir de 2000 já é notável o uso crescente do DEA em instituições financeiras e pode ser encontrado em alguns trabalhos recentes. Estudos na temática de seleção de carteiras estão em voga nos trabalhos de Powers \& McMullen (2000), utilizando DEA para construção de carteiras no mercado de renda variável americano; e nos trabalhos de Lopes, et al. (2008, 2009), aplicando a metodologia desses autores, no mercado de renda variável brasileiro.

Macedo, Casa Nova e Almeida (2007, p.9) com sua pesquisa bibliométrica, analisam as publicações em eventos e periódicos brasileiros Qualis Nacional ou Internacional - conceito A (CAPES) das áreas de Contabilidade e Administração que utilizaram o método DEA. A pesquisa mostrou que "no período de 1998 a 2006 foram recuperados 36 artigos em periódicos e 39 trabalhos em eventos, totalizando 75 pesquisas utilizando DEA." Os resultados ainda apontam para o fato de que existem mais publicações com a autoria de Engenheiros de Produção "o que pode indicar que o tema DEA esteja mais maduro na área de Engenharia de Produção e nas áreas de Contabilidade e Administração a metodologia ainda se encontra em fase de expansão." (MACEDO; CASA NOVA; ALMEIDA, 2007, p.12).

Segundo Lopes et al. (2009 p. 2) aplicações de DEA em finanças podem ser encontradas nos estudos de Gregouriou em 2007, Choi e Murthi; Ceretta e Costa Junior; e Basso e Funari em 2001 e Machado-Santos e Rocha Armada em 1997. "Estes estudos buscaram avaliar o desempenho de fundos e gestores de investimento enquanto que Santos e Casa Nova (2005) propuseram um modelo de análise das demonstrações financeiras por meio de DEA" (LOPES et al., 2009, p. 2). Os trabalhos existentes utilizando o DEA sugerem a potencialidade dessa ferramenta, diante do seu crescimento e aplicabilidade nos mais diversos setores.

Como apresentado, a avaliação de desempenho das carteiras de investimento depende de ferramentas que auxiliem na decisão para sua construção e interpretação de seus resultados no que tange à eficiência. A partir disso, o presente trabalho apresenta a DEA como uma possível ferramenta para a determinação da eficiência de carteiras de investimento e, dessa forma, utilizando-se 
das fórmulas e conceitos básicos apresentados, buscará atingir os objetivos traçados e sanar o atual problema de pesquisa. 


\section{MÉTODOS E TÉCNICAS DE PESQUISA}

Neste capítulo é apresentada, em seções, a metodologia utilizada para a realização do trabalho. Na primeira seção se apresenta a classificação dos métodos e técnicas da pesquisa, nas seções seguintes faz-se a caracterização da organização de onde foi realizada a pesquisa e definem-se a população e a amostra do estudo. Na seção 3.4 apresentam-se os instrumentos necessários para a realização da pesquisa, no caso estudado os instrumentos foram retirados dentre os modelos DEA. Por fim, na última seção será mostrado detalhadamente o procedimento realizado para a coleta e a análise dos dados.

\subsection{Tipo e descrição geral da pesquisa}

Os tipos de pesquisa podem ser classificados de várias formas, de acordo com diferentes enfoques. Do ponto de vista da forma de abordagem do problema a pesquisa foi quantitativa; como mostra Silva e Menezes (2001, p. 20) a pesquisa quantitativa "considera que tudo pode ser quantificável, o que significa traduzir em números opiniões e informações para classificá-las e analisá-las, e ainda requer o uso de recursos e de técnicas estatísticas". Conforme o tipo de raciocínio empregado, o método de abordagem utilizado foi o método dedutivo, segundo Andrade (1999, p.111) ele surgiu das concepções de Descartes, cuja técnica se fundamenta em esclarecer as ideias através de cadeias de raciocínio, ou seja, "partindo-se de teorias e leis gerais, pode-se chegar à determinação ou previsão de fenômenos particulares". (ANDRADE, 1999, p. 113). Contextualizando isso no presente trabalho, a dedução aconteceu da aplicação da técnica matemática DEA no estudo de uma realidade concreta, no caso o desempenho de um conjunto de carteiras de investimento. Isso determina e confirma o caráter empírico-quantitativo da pesquisa.

Vergara (2000) classifica o tipo de pesquisa em dois critérios básicos: quanto aos fins e quanto aos meios. Quanto aos fins, essa pesquisa foi descritiva, que de acordo com Vergara (2000, p.47) "expõe características de determinada população ou determinado fenômeno", que no caso estudado é o comportamento dos índices 
financeiros e fundamentalistas das carteiras de investimento, e a partir deles medir a eficiência dessas.

Quanto aos meios de investigação foi utilizado o método de investigação documental, ou seja, uma avaliação dos índices financeiros dos ativos que compõe as carteiras de investimentos para se chegar aos valores das variáveis inputs e outputs do modelo DEA; para assim fazer a avaliação das próprias carteiras de investimentos. E também foi utilizado o método bibliográfico, que consiste no "estudo sistematizado desenvolvido com base em material publicado em livros, revistas, jornais, redes eletrônicas, isto é, material acessível ao público em geral." (VERGARA, 2000, p. 48). Andrade (1999, p. 107) mostra que a diferença principal entre a pesquisa documental e bibliográfica está na espécie de documentos que constituem fontes de pesquisa: "enquanto a pesquisa bibliográfica utiliza fontes secundárias, ou seja, livros e outros documentos bibliográficos, a pesquisa documental baseia-se em documentos primários, originais, [...] que ainda não foram utilizados em nenhum estudo ou pesquisa".

Essas informações foram disponibilizadas pela Empresa, por meio de seus documentos e também foram retiradas de sites que disponibilizam informações econômico-financeiras, como BM\&FBOVESPA, Guialnvest, Infomoney e Corretora Fator. As principais redes eletrônicas consultadas foram as bases de dados científicas como Proquest e Scielo e as revistas eletrônicas como Revista de Administração de Empresas (RAE) e Revista de Administração Contemporânea (RAC). Ainda quanto aos meios foi feita uma pesquisa de campo para a coleta de dados.

\subsection{Caracterização da organização}

A organização, de onde os dados foram coletados para a realização dessa pesquisa, é uma micro empresa de agente autônomo de investimento - pessoa jurídica. Agentes Autônomos de Investimento são Instituições Auxiliares no mercado de capitais. Para Assaf Neto (2008, p.45),

os agentes autônomos de investimento são pessoas físicas credenciadas pelas instituições financeiras intermediadoras (corretoras, distribuidoras, bancos e financeiras) para atuarem na colocação de títulos e valores 
mobiliários outros serviços financeiros no mercado, operando em troca do recebimento de uma comissão.

Para a CVM (2010), o agente autônomo de investimento pode também ser pessoa jurídica que obtém registro nessa Comissão para exercer a atividade de distribuição e mediação de valores mobiliários, sob a responsabilidade e como preposto de instituição integrante do sistema de distribuição de valores mobiliários. Portugal Neto (2005 p. 76) acredita que esses atores possam alavancar negócios em micro e pequenas empresas, tendo em vista que seus custos de transação serem menores em função da utilização de estruturas consideravelmente mais enxutas, se comparadas às praticadas pelas demais instituições financeiras.

A empresa atua no ramo de atividades comerciais, prestando serviço aos seus clientes, representa duas Corretoras com sede em São Paulo e reconhecidas nacionalmente. Esse agente autônomo de investimento atua no Mercado de Capitais há mais de 15 anos, proporciona aos clientes uma vasta gama de serviços, tais como: Operações na Bovespa: mercado à vista, termo e opções, Operações na Bolsa de Mercadorias e Futuros - BM\&F: derivativos, Operações em Renda Fixa, Administração e Gestão de Clubes de Investimentos, Oferta Pública de Ações, Homebroker, Operações na Bovespa e BM\&F via Internet e Recuperação de Ativos. Está localizada no Setor Comercial Sul e conta com uma estrutura de cinco funcionários, dentre os quais, quatro são operadores da bolsa de valores e um é o próprio dono. Por motivo de sigilo a organização não permitiu a sua identificação, sendo, nesse sentido, atribuído um nome fictício, como a Empresa $\mathbf{A}$.

\subsection{População e amostra}

Para a definição da população e da amostra da pesquisa foi feita uma investigação documental, dessa forma a população inicial do estudo foi composta por todas as carteiras de investimentos de todos os clientes existentes na Empresa A. Por ser uma micro empresa, o número de clientes que possuem carteiras de investimento é reduzido, somando um total de 300 carteiras. A definição da amostra foi não probabilística e deu-se pelo critério de tipicidade, que segundo Vergara (2000, p.51) "é constituída pela seleção de elementos que o pesquisador considere representativos da população alvo, o que requer profundo conhecimento dessa 
população". Isso ocorreu devido à limitação de tempo e a necessidade de selecionar carteiras que contém ativos atualmente negociados no mercado financeiro e que possuam os dados necessários para a credibilidade da pesquisa.

A realização dessa metodologia foi influenciada pela abordagem adotada por Rosano (2008, p. 97) e pela sequência de etapas das pesquisas realizadas por Lopes et al. (2008, 2009). Rosano (2008, p.97) afirma que

A aplicação da DEA exige uma seqüência de passos. Inicialmente se
selecionam as unidades produtivas (DMUs), Posteriormente, descreve-se o
processo produtivo das unidades analisadas para identificar e classificar os
insumos e produtos. Realizado isso, passa-se a executar o método,
utilizando os softwares disponíveis.

Lopes et al.(2009, p. 6 e 2008, p.7) em suas análises propõem algumas etapas para a construção de carteiras de investimento no mercado de renda variável brasileiro. É importante reforçar que na presente pesquisa não há o propósito de construir carteiras, mas apenas analisá-las, como mostrado na seção 1.2. Apesar dessa diferença entre a atual pesquisa e aquela feita por esses autores, a metodologia nessa ocasião empregada pode coincidir com aquela adotada por Lopes et al. (2008, 2009), assim algumas dessas etapas usadas pelos autores foram utilizadas no presente contexto. São elas:

Etapa 1: Levantamento dos indicadores

Etapa 2: Levantamento de seus ativos e seus dados

Etapa 3: Retirada dos ativos que não possuem informações completas

Etapa 4: Tratamento matemático dos dados

Etapa 5: Escolha dos modelos DEA a serem utilizados

Etapa 6: Aplicação dos modelos DEA escolhidos

Etapa 7: Avaliação do desempenho da carteira

Figura 9 - Etapas da pesquisa

Adaptado de Lopes et al. $(2008$, p. $7 ; 2009$, p. 6)

Para a realização da Etapa 1 da Figura 9 foi importante que antes se tivessem as DMUs definidas, assim, seguiu-se o primeiro passo da metodologia de Rosano 
(2008). Para fins de amostra as DMUs devem atender a alguns pré requisitos; como expostos na seção 2.2.2.; nesse estudo as DMUs selecionadas foram as carteiras de investimento de renda variável, ou seja, somente carteiras compostas por ações. Como feito por alguns autores, a amostra do estudo, ou seja, a quantidade de DMUs analisadas foi definida após a escolha das variáveis insumos e produtos, dessa forma fez-se necessário conhecer as diferentes visões que a literatura apresenta no que tange aos critérios de seleção dos insumos e dos produtos. no qual

Primeiramente, Senra et al. (2007, p.193) atentam para um fato importante,

\begin{abstract}
Em qualquer método [de seleção de variáveis] usado o decisor deve ser confrontado com o resultado e verificar a sua coerência. Por exemplo, deve verificar se não foi omitida nenhuma variável que considere imprescindível, e se há relação causal entre todos os pares input output selecionados. Pode ainda ser recomendável fazer a seleção por mais de um método para comparar resultados e tomar a decisão com mais embasamento.
\end{abstract}

Dessa forma é preciso adotar uma metodologia criteriosa na escolha das variáveis, para garantir a confiabilidade da análise. Pela limitação do estudo, foi escolhida apenas uma metodologia, apesar da pertinente recomendação acima dos autores.

Os autores apresentam o método I-O Stepwise Exaustivo Completo e explicam que "métodos da família I-O Stepwise partem da premissa que a seleção de variáveis deve obedecer ao princípio de máxima relação causal entre inputs e output'. Além disso, esse método calcula a eficiência média de cada par input/output e escolhe a alternativa com maior valor. Nesse mesmo trabalho os autores apresentam o Método Multicritério, tanto nessa forma simples quanto em Método Multicritério Combinatório Inicial e Combinatório por Cenários. Basicamente, esses três combinam a boa relação causal e boa discriminação entre as DMUs, porém em alguns casos exige opinião do decisor para o processo de seleção das variáveis e em outros exige um custo de cálculo elevado. (SENRA et al., 2007, p.205)

Eling (2006) em seu trabalho sobre o desempenho de fundos de investimento utilizando DEA mostra que a seleção de variáveis para os casos de investimento é resultado da teoria básica do mercado de capitais, em que existe uma relação funcional entre risco e retorno. Os investidores preferem riscos reduzidos e retornos elevados em seus investimentos, o que levaria o primeiro a ser um input e o segundo um output. Porém, Eling (2006) apresenta autores que chamam atenção para o fato de que existem investidores que estão preocupados com outros fatores que não apenas risco e retorno, ou seja, consideram diferentes medidas pertinentes, 
como a tendência central (média, desvio-padrão), outros valores extremos, a ética na tomada de decisão, a preferência do investidor, etc.

Eling (2006) apresenta duas opções de seleção das variáveis: a primeira é baseada na regra de correlação de Spearman, que consiste em selecionar as entradas e saídas que são correlacionadas o mínimo possível; e a segunda regra considera a Análise de Componentes Principais (Principal Component Analysis $P C A)$, que é um procedimento de redução do número de variáveis. Essa técnica é empregada quando existe redundância nos dados de uma amostra e tem por finalidade básica a redução de dados a partir de combinações lineares das variáveis originais.

Outra abordagem para a seleção de variáveis foi apresentada no trabalho de Powers e McMullen (2000) que propõem construção de carteiras no mercado de renda variável americano. Lopes et al. $(2008,2009)$ também utilizam os indicadores propostos por esses autores para a execução de seu trabalho sobre construção de carteiras no mercado variável brasileiro. Powers e McMullen (2000) em sua pesquisa analisam 185 ações de maior valor de mercado. Um total de oito atributos são considerado, cinco dos atributos são considerados outputs: 1, 3, 5 e 10 anos de retorno e lucro por ação, enquanto os restantes três atributos são considerados inputs: relação preço/lucro, beta e sigma (volatilidade). Os autores ainda explicam em seu estudo que os investidores buscam ativos que proporcionem os maiores valores de retornos e de lucro por ação enquanto que apresentem o menor preço $(\mathrm{P} / \mathrm{L})$ e risco e, assim eles justificam a escolha destes indicadores para compor 0 conjunto de variáveis outputs e inputs. O risco está representado no modelo pelos indicadores beta e volatilidade. O Quadro 1 a seguir mostra a disposição das variáveis e suas características. 


\begin{tabular}{|c|c|c|}
\hline Indicador & Descrição & Classificação \\
\hline $\begin{array}{l}\text { Preço/Lucro } \\
(\mathrm{P} / \mathrm{L})\end{array}$ & Cotação da ação/lucro por ação & Insumo \\
\hline Beta & $\begin{array}{l}\text { Relação entre o retorno do ativo e o } \\
\text { retorno da carteira de mercado }\end{array}$ & Insumo \\
\hline Volatilidade & $\begin{array}{l}\text { Desvio-padrão dos retornos de } 36 \\
\text { meses }\end{array}$ & Insumo \\
\hline $\begin{array}{l}\text { Lucro por Ação } \\
\text { (LPA) }\end{array}$ & Lucro por ação da carteira & Produto \\
\hline$\% 12$ & $\begin{array}{l}\text { Retorno dos } 12 \text { meses anteriores ao } \\
\text { período da carteira }\end{array}$ & Produto \\
\hline$\% 36$ & $\begin{array}{l}\text { Retorno dos } 36 \text { meses anteriores ao } \\
\text { período da carteira }\end{array}$ & Produto \\
\hline$\% 60$ & $\begin{array}{l}\text { Retorno dos } 60 \text { meses anteriores ao } \\
\text { período da carteira }\end{array}$ & Produto \\
\hline
\end{tabular}

Quadro 1 - Indicadores utilizados na análise da eficiência de carteiras.

Fonte: Adaptado de Powers e McMullen (2000, p.3)

Conhecidas algumas visões a respeito de critérios de seleção de variáveis, optou-se pela utilização da metodologia de Powers e McMullen (2000) para a realização do presente trabalho. A escolha por essa metodologia se realizou pela credibilidade das variáveis escolhidas por esses autores, e da comprovada medida de risco e retorno que esses indicadores proporcionam. Os outputs representam as maiores quantidades desejáveis por um investidor, enquanto os inputs representam as menores quantidades desejáveis, como mostram os autores. Após uma criteriosa análise a respeito da seleção das variáveis, foi possível levantar os indicadores do estudo, o que corresponde à Etapa 1 da Figura 9.

Para a coerência da análise, o indicador "Retorno de 10 anos" foi excluído das variáveis estudadas, pois assim como afirma Lopes et al. (2006, p.2) muitas ações presentes nas carteiras analisadas não estão no mercado de ações há mais de cinco anos. Dessa forma, a análise do estudo engloba carteiras anuais no período Dezembro de 2008 a Dezembro de 2009. A triagem de tempo também foi selecionada pela amostragem não probabilística por tipicidade, como já explicitado por Vergara (2000), devido a limitação de tempo disponível para a realização da pesquisa e da disponibilidade de dados no período estudado. A quantidade de ações em cada carteira não é de grande relevância, pois as unidades analisadas são as 
carteiras de ações existentes, e não cada ativo separadamente. Sua composição pouco interfere na análise da eficiência, contudo para fins de constatação a quantidade de ativos em cada DMU varia de 1 a 12 ações.

As DMUs já foram definidas e correspondem às carteiras de investimento, porém era preciso definir a quantidade dessas, ou seja, a amostra da pesquisa. Eling (2006) se posiciona ao indicar quantas variáveis devem ser escolhidas e alega que a utilização de uma grande quantidade de entradas e saídas não é muito útil, porque quando o número de entradas e saídas aumenta, mais unidades de decisão tendem a ter uma eficiência máxima, ou seja, pontuação igual a um. A regra geral é que "deve haver um mínimo de três unidades, por entrada e saída da aplicação de um modelo DEA". (BOWLIN, 1998, p. 18 apud ELING, 2006, p.14). Gonzáles-Araya (2003 apud Rosano, 2008, p. 97) já diz que "o número de unidades avaliadas deve ser maior do que cinco vezes o número de variáveis estudadas, principalmente em casos que se pretende fazer benchmarking". Dessa forma, considerando a metodologia de Gonzáles-Araya, a soma total de variáveis é igual a sete: três insumos e quatro produtos, o que levou a uma amostra de, no mínimo, 35 carteiras de investimento.

A partir da definição do tamanho da amostra, foi possível realizar a Etapa 2 da Figura 9, que consiste no levantamento dos ativos e seus dados. Os critérios considerados de relevância para o levantamento dos dados disponíveis a respeito dos ativos de cada carteira envolveram verificar se os ativos estavam no mercado há mais de 5 anos, se continham informações à respeito das variáveis inputs e outputs e se havia relevância de negociação e participação no mercado financeiro. As carteiras cujos ativos não se encaixaram nesses critérios foram descartadas para a composição da amostra, o que corresponde a Etapa 3 da Figura 9.

Após definidas as 35 carteiras destinadas à análise e suas respectivas variáveis foi possível escolher os modelos DEA para a realização da análise. Porém antes dessa fase, Lopes et al. $(2008,2009)$ sugerem a Etapa 4 da Figura 9 que consiste no tratamento matemático dos indicadores, principalmente no que tange aos possíveis valores negativos, posto que riscos e lucro são medidas que aceitam valores negativos. A respeito disso Santos e Casa Nova (2005) se posicionam:

É importante ressaltar que os modelos DEA são invariantes à escala, podendo incluir indicadores de diferentes medidas de mensuração. Os indicadores devem, no entanto, [...] manter valores positivos, pois apenas alguns modelos permitem o ajuste para transformar as variáveis negativas 
em positivas sem alteração dos escores de eficiência. (SANTOS; CASA NOVA, 2005, p.11)

Nesse sentido, foi preciso fazer um ajuste matemático a fim de garantir a eficácia dos escores de eficiência. Seguindo Powers e McMullen (2000), os dados dos indicadores utilizados foram padronizados. Este procedimento foi aplicado para que a interpretação dos resultados se mantivesse o mais universal possível. Inicialmente todos os indicadores foram padronizados por:

$$
Z_{i j}=\frac{\left(X_{i j}-\bar{X}_{j}\right)}{\widehat{\sigma}_{j}}
$$

Onde:

$\mathrm{Zij}=0$ resultado padronizado para o indicador $\mathrm{j}$ da ação $\mathrm{i}$;

$X i j=0$ valor do indicador $j$ da ação $i$;

$\mathrm{Xj}=\mathrm{a}$ média do indicador $\mathrm{j}$ para todas as ações;

$\sigma j=0$ desvio padrão do indicador $j$ para todas ações

Após a padronização, os autores recomendam fazer um reescalonamento de acordo com a Equação 8; isso evita a inclusão de dados negativos no modelo, de maneira que o menor valor de cada indicador foi transformado em zero.

$$
R Z_{i j}=\operatorname{Abs}\left(\operatorname{Min} Z_{j}\right)+Z_{i j}
$$

Onde:

$\mathrm{RZ} \mathrm{ij}=$ resultado do reescalonamento para cada indicador $\mathrm{j}$.

Powers e McMullen (2000) procedem, ainda, a uma normalização (Equação 9) dos valores resultantes das Equações 7 e 8, processo este seguido por este trabalho.

$$
M R Z_{i j}=\frac{R Z_{i j}}{M A ́ X I M O d e ~ R Z_{j}}
$$

Onde:

MRZij = normalização da ação $\mathrm{i}$ no indicador $\mathrm{j}$ realizada dividindo todos os indicadores pelo valor máximo apresentado, conforme Equação (8). 
Estes procedimentos tornam as instâncias numéricas mais balanceadas, reduzindo o risco de imprecisão computacional. (LOPES et al., 2008;2009). Feita a padronização e a normalização para cada ativo, foi realizada a média ponderada das ações e suas quantidades para se achar valores adaptados para as Carteiras.

Posteriormente ao ajuste matemático, pôde-se seguir para a etapa de escolha dos modelos DEA que foram utilizados, dentre aqueles apresentados na seção 2.2.3. Pelo caráter dessa pesquisa, a execução desses modelos corresponde aos instrumentos de pesquisa, o que será abordado na seção posterior.

\subsection{Caracterização dos instrumentos de pesquisa}

Por se tratar de uma investigação documental de caráter quantitativo, os instrumentos de pesquisa foram selecionados dentre os próprios modelos DEA apresentados nesse trabalho. Como visto na seção 2.2.2, pode-se avaliar a eficiência das carteiras pelos modelos $\mathrm{CCR}$ ou BCC, caso queira fazer uma análise constante ou variável, respectivamente. Além da escolha do modelo deve-se proceder também quanto à orientação do estudo, se Ol ou OO. Essa etapa corresponde a Etapa 5 da Figura 9. Como o estudo se aplica para a avaliação das carteiras de investimento, se orientado aos inputs, pretende-se diminuir os riscos (a volatilidade e o Beta) e o P/L. Caso se deseje aumentar o retorno e o LPA o modelo seria orientado aos outputs.

Segundo Lopes et al. (2008, p.8) "deve-se escolher dentre os vários modelos existentes, DEA-CCR, DEA-VRS, supereficiência, entre outros, aquele que é mais adequado à avaliação de desempenho que se pretende." Como o objetivo principal da pesquisa é evidenciar a potencialidade da ferramenta DEA, foi recomendável realizar uma diversificação na escolha dos modelos a fim de obter um resultado consistente e amplo. Porém é preciso atentar para o fato que as DMUs analisadas são carteiras de investimento e que suas variáveis em questão se relacionam de, uma forma geral, com medidas de risco e retorno. Desse modo, a análise é invariável ao porte das carteiras, e como exposto na literatura, o modelo BCC é o recomendável em caso de distinção de porte das DMUs analisadas. Assim, optou-se somente pela utilização do modelo CCR. 
De acordo com as orientações, Macedo, Casa Nova e Almeida (2007, p.4) afirmam que "sempre que os outputs forem não controláveis pelos gestores, deve-se escolher uma orientação input. No contrário, deve-se preferir uma ótica output". Seguindo essa metodologia, o primeiro modelo escolhido foi o CCR orientado aos inputs, posto que os retornos das carteiras e seu Lucro por Ação são variáveis não controláveis pelos gestores.

Apesar dessa recomendação dos autores, o segundo modelo DEA escolhido foi o CCR-OO, basicamente pelo critério aleatório para uma melhor diversificação da análise, dessa forma foi possível testar diferentes orientações a fim de buscar 0 melhor desempenho e compará-los. Por fim fez a análise do modelo CCR com a projeção não orientada. O modelo e orientações utilizados foram aplicados anualmente no período de Dezembro de 2008 a Dezembro de 2009. Após definidos os modelos que integraram a análise, executou-se a Etapa 6 da Figura 9: aplicação dos modelos DEA escolhidos, onde se encaixa a última etapa proposta por Rosano (2008): execução dos modelos por meio dos softwares disponíveis. Para essa realização foi utilizado o software DEA-SEAD, que será detalhado na seção a seguir.

\subsection{Procedimentos de coleta e de análise de dados}

Quanto aos procedimentos de coleta de dados utilizou-se a técnica de pesquisa documental e pesquisa bibliográfica. Com relação aos documentos para fins de população e amostra, eles foram obtidos pela própria pesquisadora, por meio do acesso a intranet da Empresa $\mathbf{A}$ e aos dados dos clientes, que fornecem detalhes de suas carteiras de investimento, tais como, quais ativos compõem a carteira, em que quantidade e qual a porcentagem de participação de cada ativo na carteira.

Para o acesso às variáveis insumos e produtos de cada ação que compõe as 35 DMUs, foi feita uma pesquisa bibliográfica. As informações sobre os índices financeiros e fundamentalistas como P/L, LPA, Beta e Volatilidade, foram retirados dos sites como Guiainvest, Infomoney, BM\&FBOVESPA e também de materiais fornecidos pela Corretora Fator. Nesses sites e materiais, os índices são disponibilizados por ativos e já são calculados mensalmente, trimestralmente ou anualmente dependendo da necessidade do usuário. Para essa pesquisa, os dados 
utilizados foram aqueles calculados para o período de Dezembro de 2008 e de Dezembro de 2009, época necessária para a execução da análise.

As únicas variáveis que não são previamente calculadas pelos sites são as que representam os retornos de 1, 3 e 5 anos. Desse modo, esses outputs foram calculados pela pesquisadora, a partir de informações sobre cotações de preços de cada ativo no final de cada ano e da porcentagem de participação deles na carteira. A metodologia de cálculo para se chegar ao output retorno foi ajustada daquela adotada por Lopes et al. (2006), segundo os autores, para o cálculo do retorno de cada ação foi utilizado o valor de fechamento do dia inicial do trimestre. Tendo o retorno percentual individual de cada ação em cada um dos doze trimestres, foi calculada a média da carteira. (LOPES et al., 2006, p.5). Para o presente contexto, a adaptação consistiu no período da análise, dado que esta foi realizada anualmente e não trimestralmente, como executado pelos autores acima.

Após essa coleta dos dados, foi realizada uma média ponderada para encontrar os inputs e outputs das carteiras, dado que os índices disponíveis coletados são para cada ativo separadamente. As carteiras disponibilizadas pela Empresa contêm informações sobre quais ativos e qual a participação deles, o que possibilitou e facilitou a realização de uma média ponderada para se encontrar inputs e outputs das carteiras. Com a ajuda do software Excel foi possível encontrar de forma ágil as variáveis das 35 DMUs, dado que já estavam disponíveis todas as informações necessárias para a realização da média ponderada.

Os dados foram analisados por meio de softwares específicos para a Análise Envoltória de Dados. De acordo com Surco e Wilhelm (2006) existem vários aplicativos "na literatura e na Internet, gratuitos e pagos, destinados a usuários que desejam calcular índices de eficiência através de modelos DEA". Para fins desse estudo foi utilizado o software DEA-SEAD, que é uma ferramenta para avaliação da eficiência técnica e de produtividade baseada em DEA. O programa computacional possui interface amigável, uma grande gama de modelos DEA, é gratuito e apresenta os resultados com considerável nível de detalhamento. (SURCO; WILHELM, 2006, p.50). Além disso, os autores ainda apontam funções que o DEASEAD possui como ordenamento, referência cruzada, projeção e gráficos que auxiliam a análise dos resultados. 


\section{RESULTADOS E DISCUSSÃO}

Neste capítulo serão apresentados os resultados obtidos com a aplicação do modelo DEA - CCR utilizando-se o software DEA-SEAD. Foram realizadas 4 análises principais, aplicando o modelo CCR com as duas orientações, inputs e outputs, em cada ano da análise: 2008 e 2009. Além disso, obteve-se a média das variáveis para os anos 2008 e 2009, que foi aplicada para a duas orientações. Por fim fez-se para cada ano e para a média a análise não orientada, combinando as orientações aos insumos e aos produtos. Os resultados gerados são evidenciados ao longo dessa sessão em forma de tabelas e gráficos para facilitar o entendimento e visualização dos resultados. Seu conteúdo será discutido e conterá as principais potencialidades da ferramenta DEA aplicados em carteiras de investimento, indo ao encontro do objetivo principal do trabalho.

\subsection{Aplicação DEA-CCR}

Como exposto no Referencial Teórico, Kassai (2002) afirma que casos em que o porte das DMUs tenham relação com as variáveis em estudo, recomenda-se usar o modelo BCC, que considera os retornos variáveis de escala e, portanto permite analisar os efeitos isolados decorrente do porte de cada unidade analisada. Por se tratar de carteiras de investimento, as variáveis envolvidas tais como risco e retorno não tem relação com o tamanho da carteira, podendo esta ter 1 ou 30 ativos, fato que não afetaria direta ou inversamente proporcional o valor dessas variáveis. Dessa forma, para a análise dos dados considerou-se apenas o modelo CCR, pois ele é invariável ao porte das DMUs. Primeiramente utilizou-se o modelo CCR com orientação aos insumos, representado pela Equação 2; e com orientação aos produtos, representado pela Equação 3.

Conforme a coleta dos dados, a Tabela 1 reúne as informações dos 2 anos a respeito das carteiras analisadas. É apresentado o valor das variáveis insumos e produtos antes de proceder-se à normalização feita na etapa 3.3 da Metodologia. Os valores padronizados estão disponíveis nos Apêndices I e J. 
Tabela 1 - Informações para as Carteiras analisadas

\begin{tabular}{|c|c|c|c|c|c|c|c|c|c|c|c|c|c|c|}
\hline \multirow{2}{*}{ Carteira } & \multicolumn{2}{|c|}{$P / L$} & \multicolumn{2}{|c|}{ Beta } & \multicolumn{2}{|c|}{ Volatilidade } & \multicolumn{2}{|c|}{ Retorno 1 ano } & \multicolumn{2}{|c|}{ Retorno 3 anos } & \multicolumn{2}{|c|}{ Retorno 5 anos } & \multicolumn{2}{|c|}{ LPA } \\
\hline & 2008 & 2009 & 2008 & 2009 & 2008 & 2009 & 2008 & 2009 & 2008 & 2009 & 2008 & 2009 & 2008 & 2009 \\
\hline 1 & 75,40 & 05,20 & 0,95 & 1,00 & 4,80 & 31,80 & $-37,67$ & 30,58 & 21,12 & 35,00 & 75,14 & 61,06 & 0,09 & 0,11 \\
\hline 2 & $-2,00$ & 32,80 & 0,95 & 1,20 & 70,85 & 46,70 & $-200,72$ & 49,24 & $-46,51$ & $-17,69$ & $-68,48$ & 5,29 & $-2,65$ & 1,19 \\
\hline 3 & $-3,60$ & 10,40 & 1,00 & 0,60 & 48,60 & 48,40 & $-136,51$ & 44,74 & $-128,57$ & $-7,02$ & $-141,27$ & $-135,96$ & $-0,18$ & $-0,82$ \\
\hline 4 & 6,10 & 11,10 & 1,00 & 1,10 & 63,20 & 56,40 & $-73,44$ & 36,32 & 31,87 & 38,29 & 7,44 & 73,00 & 3,76 & 3,30 \\
\hline 5 & 6,60 & 8,10 & 0,70 & 0,70 & 47,50 & 32,70 & $-22,57$ & 23,72 & 20,29 & 18,85 & וד, שט & 59,64 & 3,04 & 3,00 \\
\hline 6 & $-2,10$ & 8,10 & 0,80 & 0,90 & 81,00 & 57,60 & $-323,92$ & 61,26 & $-511,40$ & $-135,24$ & $-184,50$ & $-51,83$ & $-4,70$ & 3,24 \\
\hline 7 & 5,20 & 10,60 & 1,00 & 1,10 & 65,50 & 27,10 & $-19,02$ & 50,12 & 55,61 & 48,30 & 73,17 & 79,20 & 0,91 & 0,82 \\
\hline 8 & 7,03 & 33,05 & 1,03 & 1,23 & 96,50 & 50,55 & $-69,13$ & 45,73 & 25,48 & 42,39 & 63,77 & 69,53 & 2,54 & 1,08 \\
\hline 9 & 6,01 & 15,72 & 1,04 & 1,06 & 67,20 & 51,47 & $-85,00$ & 40,00 & 26,72 & 39,35 & 62,32 & 70,54 & 3,90 & 2,71 \\
\hline 10 & 6,14 & 11,84 & 1,00 & 1,11 & 64,38 & 56,28 & $-73,03$ & 36,60 & 31,73 & 38,42 & 67,41 & 92 & 3,71 & 3,23 \\
\hline 11 & 13,41 & 17,19 & 0,99 & 1,00 & 69,06 & 28,08 & $-26,26$ & 35,14 & 27,01 & 32,90 & 77,47 & 67,35 & 1,76 & 2,23 \\
\hline 12 & 4,75 & 18,60 & 1,15 & 1,10 & 82,85 & 47,50 & $-81,92$ & 46,32 & 38,19 & 3ర,उర & 04,31 & 74,02 & 4,04 & 1,87 \\
\hline 13 & 2,74 & 11,02 & 0,89 & 0,73 & 61,76 & 39,33 & $-49,18$ & 40,63 & 35,00 & 36,54 & 66,45 & 64,09 & 1,89 & 0,79 \\
\hline 14 & 5,76 & 11,91 & 1,07 & 1,12 & 66,27 & 49,47 & $-81,06$ & 40,51 & 28,19 & 38,52 & 64,5 & 72,07 & 3,75 & 3,23 \\
\hline 15 & 5,93 & 18,50 & 1,10 & 1,23 & 80,53 & 44,60 & $-76,42$ & 45,48 & 26,30 & 39,66 & 64,55 & 71,76 & 3,07 & 2,68 \\
\hline 16 & 5,78 & 14,37 & 1,03 & 1,07 & 66,79 & 44,60 & $-66,80$ & 42,88 & 34,09 & 41,86 & $00,<0$ & 91 & 3,07 & 2,17 \\
\hline 17 & $-1,53$ & 13,23 & 1,02 & 0,68 & 53,39 & 47,77 & $-128,39$ & 44,27 & $-97,77$ & 2,40 & $-100,98$ & $-94,89$ & 0,68 & $-0,25$ \\
\hline 18 & 5,11 & 11,69 & 1,18 & 1,18 & 70,90 & 37,35 & $-91,87$ & 47,57 & 22,80 & 38,57 & 60,71 & 71,19 & 3,66 & 3,32 \\
\hline 19 & 6,71 & 16,01 & 1,04 & 1,06 & 66,71 & 52,07 & $-89,61$ & 39,38 & 26,95 & 40,43 & 63,04 & 70,74 & 3,89 & 2,78 \\
\hline
\end{tabular}




\begin{tabular}{|c|c|c|c|c|c|c|c|c|c|c|c|c|c|c|}
\hline 20 & 8,00 & 16,27 & 1,13 & 1,03 & 57,71 & 52,44 & $-102,07$ & 23,61 & $-32,61$ & $-42,58$ & $-17,05$ & 9,42 & 2,06 & 1,92 \\
\hline 21 & 5,73 & 13,89 & 1,05 & 1,09 & 69,08 & 53,18 & $-77,73$ & 39,60 & 32,62 & 42,45 & 65,70 & 72,83 & 3,86 & 2,82 \\
\hline 22 & 7,98 & 16,65 & 0,95 & 0,93 & 63,99 & 31,72 & $-61,55$ & 35,18 & 18,29 & 29,86 & 61,58 & 66,38 & 3,32 & 2,43 \\
\hline 23 & 4,16 & 9,26 & 0,76 & 0,78 & 59,07 & 36,82 & $-90,48$ & 32,04 & 18,90 & 18,13 & 47,46 & 59,34 & 0,42 & 2,88 \\
\hline 24 & 4,06 & 18,49 & 1,02 & 0,96 & 74,00 & 44,36 & $-139,24$ & 46,55 & $-33,68$ & 18,46 & 24,65 & 53,48 & 1,76 & 2,17 \\
\hline 25 & 5,15 & 12,01 & 1,01 & 1,09 & 65,97 & 31,25 & $-33,78$ & 48,60 & 48,62 & 45,37 & 68,04 & 75,81 & 1,30 & 1,11 \\
\hline 26 & 5,58 & 15,82 & 1,06 & 1,12 & 74,45 & 52,47 & $-75,50$ & 41,20 & 34,80 & 45,33 & 66,33 & 73,46 & 3,76 & 2,54 \\
\hline 27 & 5,43 & 20,29 & 1,16 & 1,15 & 88,09 & 48,95 & $-91,65$ & 46,43 & 24,13 & 38,36 & 59,43 & 65,97 & 5,80 & 2,61 \\
\hline 28 & 6,02 & 20,39 & 1,01 & 1,08 & 64,25 & 54,26 & $-73,79$ & 37,28 & 30,34 & 38,57 & 64,12 & 71,60 & 3,86 & 3,02 \\
\hline 29 & 6,45 & 36,49 & 1,04 & 1,15 & 82,70 & 51,20 & $-73,12$ & 42,37 & 25,69 & 40,36 & 60,96 & 68,04 & 3,56 & 1,92 \\
\hline 30 & 7,93 & 101,14 & 0,90 & 0,90 & 58,23 & 40,49 & $-30,43$ & 31,74 & 26,30 & 32,54 & 49,66 & 61,70 & 4,13 & 1,73 \\
\hline 31 & 5,70 & 23,09 & 1,09 & 1,15 & 73,66 & 47,86 & $-107,01$ & 37,74 & $-11,90$ & $-4,71$ & 7,07 & 31,70 & 1,55 & 1,78 \\
\hline 32 & $-2,38$ & 18,48 & 0,99 & 0,65 & 50,62 & 47,42 & $-123,59$ & 43,21 & $-108,09$ & $-1,81$ & $-114,95$ & $-109,47$ & 0,43 & $-0,43$ \\
\hline 33 & 5,70 & 23,09 & 1,09 & 1,15 & 73,66 & 47,86 & $-107,01$ & 37,74 & $-11,90$ & $-4,71$ & 7,07 & 31,70 & 1,55 & 1,78 \\
\hline 34 & 8,00 & 15,51 & 1,03 & 1,05 & 71,54 & 37,95 & $-61,53$ & 40,13 & 25,51 & 36,86 & 67,35 & 71,53 & 3,15 & 2,28 \\
\hline 35 & 5,33 & 12,98 & 1,01 & 1,10 & 67,40 & 33,98 & $-38,88$ & 47,63 & 46,22 & 44,91 & 68,06 & 75,45 & 1,62 & 1,28 \\
\hline Média & 6,92 & 24,38 & 1,01 & 1,02 & 68,06 & 44,63 & $-86,28$ & 40,90 & $-5,69$ & 22,92 & 31,20 & 44,03 & 2,24 & 1,96 \\
\hline $\begin{array}{l}\text { Desvio } \\
\text { Padrão }\end{array}$ & 12,40 & 35,20 & 0,10 & 0,17 & 10,68 & 8,69 & 55,89 & 7,47 & 98,29 & 35,16 & 68,31 & 55,91 & 2,05 & 1,12 \\
\hline
\end{tabular}


A Tabela 1 refere-se aos dados coletados para cada carteira. Comparando os valores de um ano para outro tem-se, de forma geral dado pela Média na primeira coluna, aumento do P/L, o que caracteriza um cenário desfavorável; a diminuição da volatilidade e crescimento do retorno em todos os anos, que apontam condições favoráveis. Além disso, a partir do Desvio Padrão percebe-se um maior valor desse nos anos de 2008 e a grande quantidade de valores negativos para esse ano. Essas informações derivam da crise econômica mundial que o Brasil atravessava no ano de 2008; esse cenário teve reflexo no mercado financeiro, que está demonstrado na Tabela 1 com os altos valores negativos nesse período, indicando maior instabilidade no mercado e no desempenho das carteiras. O fato de em 2009 os retornos aumentarem e a volatilidade diminuir indicam uma recuperação do mercado financeiro e, logo de suas carteiras, mesmo diante de algumas instabilidades herdadas de 2008. Após feita a normalização dos dados, submeteu-os ao software DEA-SEAD com aplicação do modelo DEA CCR para os anos 2008 e 2009. Procedeu-se com a análise de eficiência não radial, com epslon $(\varepsilon)$ previamente calculado pelo software, escolha pelo cálculo do retorno constante, orientado aos insumos e aos produtos.

\subsection{Escores de Eficiência}

Primeiramente são apresentados o resultado do escore de eficiência decrescente para cada Carteira.

Tabela 2 - Ordenamento das Carteiras de Investimento - Modelo DEA-CCR

\begin{tabular}{c|c|c|c|c|c}
\hline \multicolumn{3}{c|}{2008} & \multicolumn{3}{c}{ 2009 } \\
\hline ORDEM & CARTEIRA & EFICIÊNCIA & ORDEM & CARTEIRA & EFICIÊNCIA \\
\hline $\mathbf{1}$ & Carteira 3 & $100 \%$ & $\mathbf{1}$ & Carteira 7 & $100 \%$ \\
\hline $\mathbf{1}$ & Carteira 5 & $100 \%$ & $\mathbf{1}$ & Carteira 13 & $100 \%$ \\
\hline $\mathbf{1}$ & Carteira 13 & $100 \%$ & $\mathbf{1}$ & Carteira 5 & $100 \%$ \\
\hline $\mathbf{1}$ & Carteira 2 & $100 \%$ & $\mathbf{1}$ & Carteira 3 & $100 \%$ \\
\hline $\mathbf{1}$ & Carteira 23 & $100 \%$ & $\mathbf{1}$ & Carteira 11 & $100 \%$ \\
\hline $\mathbf{2}$ & Carteira 32 & $92 \%$ & $\mathbf{1}$ & Carteira 6 & $100 \%$ \\
\hline $\mathbf{3}$ & Carteira 17 & $80 \%$ & $\mathbf{2}$ & Carteira 23 & $92 \%$ \\
\hline $\mathbf{4}$ & Carteira 27 & $80 \%$ & $\mathbf{3}$ & Carteira 32 & $88 \%$ \\
\hline $\mathbf{5}$ & Carteira 4 & $77 \%$ & $\mathbf{4}$ & Carteira 22 & $87 \%$ \\
\hline $\mathbf{6}$ & Carteira 28 & $77 \%$ & $\mathbf{5}$ & Carteira 25 & $86 \%$ \\
\hline $\mathbf{7}$ & Carteira 10 & $77 \%$ & $\mathbf{6}$ & Carteira 17 & $86 \%$ \\
\hline
\end{tabular}




\begin{tabular}{c|c|c|c|c|c}
\hline $\mathbf{8}$ & Carteira 7 & $75 \%$ & $\mathbf{7}$ & Carteira 35 & $78 \%$ \\
\hline $\mathbf{9}$ & Carteira 21 & $74 \%$ & $\mathbf{8}$ & Carteira 24 & $78 \%$ \\
\hline $\mathbf{1 0}$ & Carteira 30 & $74 \%$ & $\mathbf{9}$ & Carteira 18 & $78 \%$ \\
\hline $\mathbf{1 1}$ & Carteira 9 & $74 \%$ & $\mathbf{1 0}$ & Carteira 1 & $69 \%$ \\
\hline $\mathbf{1 2}$ & Carteira 25 & $72 \%$ & $\mathbf{1 1}$ & Carteira 34 & $65 \%$ \\
\hline $\mathbf{1 3}$ & Carteira 26 & $72 \%$ & $\mathbf{1 2}$ & Carteira 16 & $59 \%$ \\
\hline $\mathbf{1 4}$ & Carteira 14 & $71 \%$ & $\mathbf{1 3}$ & Carteira 12 & $57 \%$ \\
\hline $\mathbf{1 5}$ & Carteira 35 & $71 \%$ & $\mathbf{1 4}$ & Carteira 27 & $57 \%$ \\
\hline $\mathbf{1 6}$ & Carteira 19 & $71 \%$ & $\mathbf{1 5}$ & Carteira 15 & $56 \%$ \\
\hline $\mathbf{1 7}$ & Carteira 12 & $71 \%$ & $\mathbf{1 6}$ & Carteira 2 & $54 \%$ \\
\hline $\mathbf{1 8}$ & Carteira 16 & $70 \%$ & $\mathbf{1 7}$ & Carteira 30 & $53 \%$ \\
\hline $\mathbf{1 9}$ & Carteira 29 & $69 \%$ & $\mathbf{1 8}$ & Carteira 14 & $52 \%$ \\
\hline $\mathbf{2 0}$ & Carteira 18 & $67 \%$ & $\mathbf{1 9}$ & Carteira 9 & $50 \%$ \\
\hline $\mathbf{2 1}$ & Carteira 24 & $67 \%$ & $\mathbf{2 0}$ & Carteira 19 & $48 \%$ \\
\hline $\mathbf{2 2}$ & Carteira 22 & $66 \%$ & $\mathbf{2 1}$ & Carteira 26 & $47 \%$ \\
\hline $\mathbf{2 3}$ & Carteira 15 & $65 \%$ & $\mathbf{2 2}$ & Carteira 21 & $46 \%$ \\
\hline $\mathbf{2 4}$ & Carteira 8 & $64 \%$ & $\mathbf{2 3}$ & Carteira 29 & $45 \%$ \\
\hline $\mathbf{2 5}$ & Carteira 34 & $61 \%$ & $\mathbf{2 4}$ & Carteira 8 & $43 \%$ \\
\hline $\mathbf{2 6}$ & Carteira 31 & $52 \%$ & $\mathbf{2 5}$ & Carteira 28 & $43 \%$ \\
\hline $\mathbf{2 6}$ & Carteira 33 & $52 \%$ & $\mathbf{2 6}$ & Carteira 4 & $41 \%$ \\
\hline $\mathbf{2 7}$ & Carteira 11 & $46 \%$ & $\mathbf{2 7}$ & Carteira 10 & $40 \%$ \\
\hline $\mathbf{2 8}$ & Carteira 20 & $44 \%$ & $\mathbf{2 8}$ & Carteira 31 & $39 \%$ \\
\hline $\mathbf{2 9}$ & Carteira 6 & $39 \%$ & $\mathbf{2 8}$ & Carteira 33 & $39 \%$ \\
\hline $\mathbf{3 0}$ & Carteira 1 & $13 \%$ & $\mathbf{2 9}$ & Carteira 20 & $18 \%$ \\
\hline & & & & &
\end{tabular}

Como discutido anteriormente na seção 2.2.3 do Referencial Teórico os escores de eficiência para os modelos CCR-OI e CCR-OO são equivalentes, dado que ambos consideram retornos constantes de escala, ou seja, os incrementos relativos em inputs e outputs são iguais, o que vai gerar os mesmos escores de eficiência apresentados na Tabela 2. A partir do ordenamento das DMUs percebe-se que em 2008, exceto as carteiras 2, 3, 5, 13 e 23, as demais são ineficientes, ou seja, apresentam insumos superdimensionados e produtos subdimensionados, que precisam ser alterados para alcançar a eficiência: no caso estudado, reduzir o $\mathrm{P} / \mathrm{L}$ e o risco ou aumentar seus retornos e LPA. Já em 2009 os resultados apontam 6 carteiras eficientes, uma carteira eficiente a mais que em 2008; e dentre as eficientes de 2008 apenas três permaneceram eficientes: as carteiras 3, 5 e 13 . Além dessas em comum nos 2 anos, as carteiras 2 e 23 aparecem eficientes em 2008; e as carteiras 6, 7 e 11 em 2009. A carteira 2 reduziu seu indicador de 100\% em 2008 para 54\% em 2009, ocupando a 16ำ posição. De maneira similar a carteira 23 diminuiu seu escore de 100\% para 92\% em 2009. Pelo ranking ainda é possível observar que, dentre as eficientes em 2009, a carteira 7 é uma unidade de 
referência para as demais, enquanto que em 2008 ela ocupava o 8 lugar com uma ineficiência de 25\%. A carteira 6 também chama atenção, pois em 2008 possuía indicador de eficiência igual a 39\% sendo considerada uma das mais ineficientes nesse ano, e no ano seguinte está na fronteira de eficiência. É interessante notar também que a carteira 1 em 2008 ocupava a última posição com apenas 13\% de eficiência, ao par que em 2009 essa unidade aumentou seu escore de eficiência para $69 \%$. Por outro lado a carteira 20 que possuía $44 \%$ de eficiência em 2008 , passou para 18\% em 2009, mostrando-se como a mais ineficiente desse ano. Dentre os extremos, percebe-se que o maior aumento de eficiência deu-se com a carteira 6, passando de 39\% em 2008 para eficiente em 2009, representando um aumento de $61 \%$. Por outro lado, a carteira 2 deixou de ser eficiente em 2009, obtendo um escore de $54 \%$ em média, o que representa uma redução de $46 \%$.

De forma a comparar a eficiência nos 2 anos, o Gráfico 1 ilustra em ordem decrescente a eficiência das carteiras em 2008 e as compara com o desempenho das mesmas em 2009.

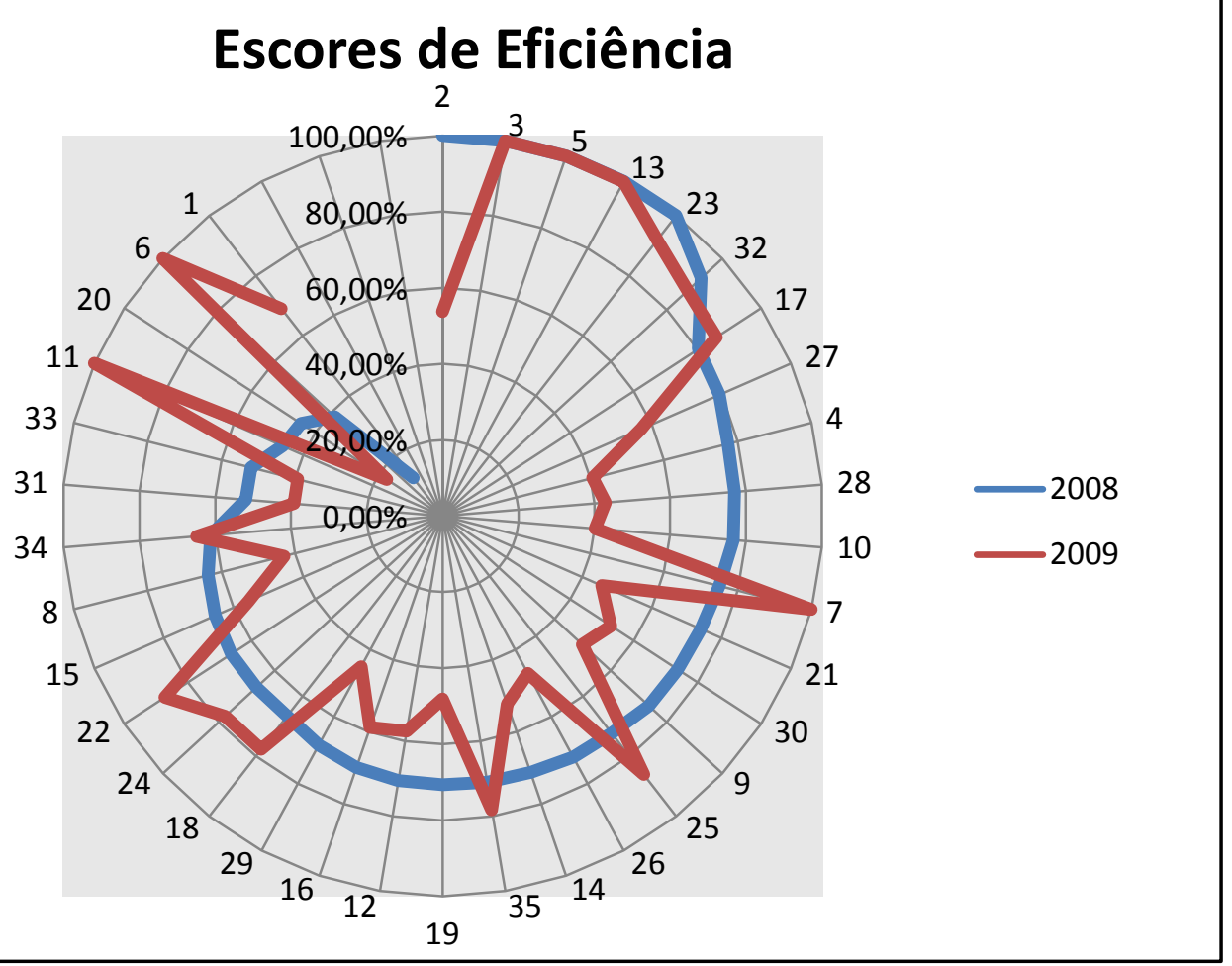

Gráfico 1 - Escores de Eficiência em 2008 e 2009

Fonte: Elaborado pela autora

A análise inicia-se com a carteira 2 que possui eficiência máxima em 2008 e em 2009 verifica-se com a linha vermelha a queda dessa eficiência para 55\% em 
média. Dessa forma, a ilustração permite examinar a variação da eficiência de um ano para o outro e ainda detectar o maior desvio padrão em 2009, dado a dispersão no formato dos traços em vermelho. Percebe-se que as carteiras 3,5 e 13 se mantiveram eficientes nos 2 anos, dado à posição das 2 linhas na fronteira máxima; e que as maiores variações ocorreram com as carteiras 1, 6 e 11, conforme maior distância entre a linha azul e vermelha para essas Carteiras.

De forma a resumir os dados acima, a Tabela seguinte relaciona resultados passíveis de comparação de acordo com algumas variáveis

Tabela 3 - Resultados do modelo DEA-CCR

\begin{tabular}{l|c|c|c}
\hline & $\mathbf{2 0 0 8}$ & $\mathbf{2 0 0 9}$ & Diferença \\
\hline Média & 71 & 65 & 6 \\
\hline Desvio Padrão & 18 & 23 & -5 \\
\hline Mínimo & 13 & 18 & $-46 \%$ \\
\hline Máximo & 100 & 100 & $61 \%$ \\
\hline Carteiras Eficientes & 5 & 6 & -1 \\
\hline Carteiras com ineficiência $>\mathbf{5 0 \%}$ & 4 & 12 & -8 \\
\hline
\end{tabular}

Os resultados para as análises de eficiência nos 2 anos são parecidas, com 2008 apresentando eficiência média de $71 \%$, obtendo 5 carteiras na fronteira de eficiência e apenas 4 carteiras que possuem eficiência menor que $50 \%$. Para o ano 2009 o desempenho das carteiras mostra-se aparentemente pior com relação a 2008, obtendo em média $65 \%$ de eficiência, 6 carteiras eficientes e 12 com indicador de eficiência inferior a $50 \%$. Para considerar um retrocesso no desempenho das carteiras de 2008 a 2009, é preciso ponderar o contexto mundial nesses anos; em 2009 muitas empresas se encontravam em período de recessão e recuperação, ainda sofrendo os reflexos da crise financeira em 2008, aspecto que será de suma importância para a interpretação dos dados desse trabalho. Como exemplo tem-se o maior desvio padrão em 2009, também ilustrado no Gráfico 1, que pode indicar a dispersão de acordo com a reação de cada carteira às consequências dessa crise, umas se recuperando mais rapidamente e outras não. 


\subsection{Interpretação das Carteiras Eficientes}

Para o entendimento dos resultados de DEA, a análise dessas informações pode ser feita a partir da participação de cada variável na determinação da eficiência e na variação nos dois anos. Essa participação corresponde aos pesos atribuídos pelo DEA-CCR que, a luz do referencial teórico, são calculados livremente ou de forma restrita através de PPL, e ponderam os insumos e produtos. O peso específico de cada insumo $i$ e produto $r$ são representados por $v i$ e $u r$, respectivamente e eles objetivam maximizar a eficiência de cada DMU em relação ao conjunto de referência. Esses pesos e seus respectivos PPL podem ser vistos nas Equações 2 e 3, da seção 2.2.3. Analisou-se a contribuição de cada insumo e produto, de maneira relativa, nas carteiras eficientes a fim de apontar as causas principais da eficiência máxima. No caso da carteira 2, pela Tabela 1 verifica-se aumento da importância ou peso nos indicadores $P / L$, Beta, Retornos 1, 3, 5 anos e LPA e redução apenas na Volatilidade. Considerando ambas as orientações, a Tabela a seguir ilustra a participação de cada variável nos anos de 2008 e 2009, a partir dos pesos estabelecidos pelo DEA. Para se chegar ao valor percentual da participação de cada variável foi feita uma análise relativa dos pesos calculados pelo DEA, que está disponível no Apêndices de $\mathrm{E}$ a $\mathrm{H}$.

Tabela 4 - Contribuição das Variáveis - Carteira 2

\begin{tabular}{l|c|c|l|c|c}
\hline \multicolumn{3}{c|}{ CCR - OI } & \multicolumn{3}{c}{ CCR - OO } \\
\hline \multicolumn{1}{c|}{ Carteira 2 } & $\mathbf{2 0 0 8}$ & $\mathbf{2 0 0 9}$ & \multicolumn{1}{|c}{ Carteira 2 } & $\mathbf{2 0 0 8}$ & $\mathbf{2 0 0 9}$ \\
\hline P/L & $76,8 \%$ & $0,2 \%$ & P/L & $86,8 \%$ & $0,1 \%$ \\
\hline Beta & $11,0 \%$ & $33,1 \%$ & Beta & $3,6 \%$ & $33,0 \%$ \\
\hline Volatilidade & $2,1 \%$ & $27,0 \%$ & Volatilidade & $0,0 \%$ & $27,0 \%$ \\
\hline Retorno 1 ano & $0,0 \%$ & $33,5 \%$ & Retorno 1 ano & $0,0 \%$ & $33,5 \%$ \\
\hline Retorno 3 anos & $10,0 \%$ & $0,2 \%$ & Retorno 3 anos & $0,0 \%$ & $0,1 \%$ \\
\hline Retorno 5 anos & $0,0 \%$ & $0,2 \%$ & Retorno 5 anos & $7,1 \%$ & $0,1 \%$ \\
\hline LPA & $0,0 \%$ & $5,8 \%$ & LPA & $2,4 \%$ & $6,2 \%$ \\
\hline
\end{tabular}

Dessa forma, tanto na orientação ao insumo quanto na orientação ao produto, maior peso foi dado à variável de maior alteração: o P/L. Em 2008 seu valor nominal era baixo, porém teve maior peso exibido na Tabela 4, o que aponta para uma causa de eficiência nesse ano. Em 2009 o indicador P/L quase não apresentou 
participação, dado o peso médio, a partir das duas orientações, de $0,15 \%$ o que explica ter afetado a posição de eficiência da unidade.

A carteira 23 caiu uma posição de um ano para o outro, ficando em $2^{\circ}$ lugar no ordenamento das carteiras eficientes com um escore de 92\%. Na Tabela 1 verifica-se que a situação dessa carteira se mantém favorável para os insumos e produtos, exceto para o indicador $P / L$ que sofreu um aumento de $121,4 \%$. A provável causa dessa queda na eficiência pode ser encontrada de acordo com a contribuição dessas variáveis em cada ano dados pela Tabela 5:

Tabela 5 - Contribuição das Variáveis - Carteira 23

\begin{tabular}{l|r|r|l|r|r}
\hline \multicolumn{3}{c|}{ CCR - OI } & \multicolumn{2}{c}{ CCR - OO } \\
\hline \multicolumn{1}{c|}{ Carteira 23 } & $\mathbf{2 0 0 8}$ & $\mathbf{2 0 0 9}$ & Carteira 23 & \multicolumn{1}{c}{$\mathbf{2 0 0 8}$} & \multicolumn{1}{c}{$\mathbf{2 0 0 9}$} \\
\hline P/L & $78,0 \%$ & $0,1 \%$ & P/L & $79,9 \%$ & $0,1 \%$ \\
\hline Beta & $6,8 \%$ & $31,8 \%$ & Beta & $9,4 \%$ & $31,8 \%$ \\
\hline Volatilidade & $4,6 \%$ & $27,5 \%$ & Volatilidade & $0,0 \%$ & $27,5 \%$ \\
\hline Retorno 1 ano & $0,0 \%$ & $29,7 \%$ & Retorno 1 ano & $3,3 \%$ & $29,7 \%$ \\
\hline Retorno 3 anos & $4,8 \%$ & $0,1 \%$ & Retorno 3 anos & $0,0 \%$ & $0,1 \%$ \\
\hline Retorno 5 anos & $5,7 \%$ & $0,1 \%$ & Retorno 5 anos & $7,3 \%$ & $0,1 \%$ \\
\hline LPA & $0,0 \%$ & $10,8 \%$ & LPA & $0,0 \%$ & $10,8 \%$ \\
\hline
\end{tabular}

Como se vê em 2008 a contribuição do indicador P/L é em torno de $80 \%$ para as duas orientações ao passo que em 2009 esse indicador além de ter aumentado em valores nominais visto na Tabela 1 , teve também participação quase nula, o que explica a queda de $8 \%$ na eficiência.

Além dessas análises, outra informação é pertinente para o entendimento do ranking de eficiência e está disponível no Gráfico 2 a seguir que apresenta as carteiras eficientes pelo número de vezes, tanto nominal quanto percentual, que servem como referência para as demais ineficientes. 


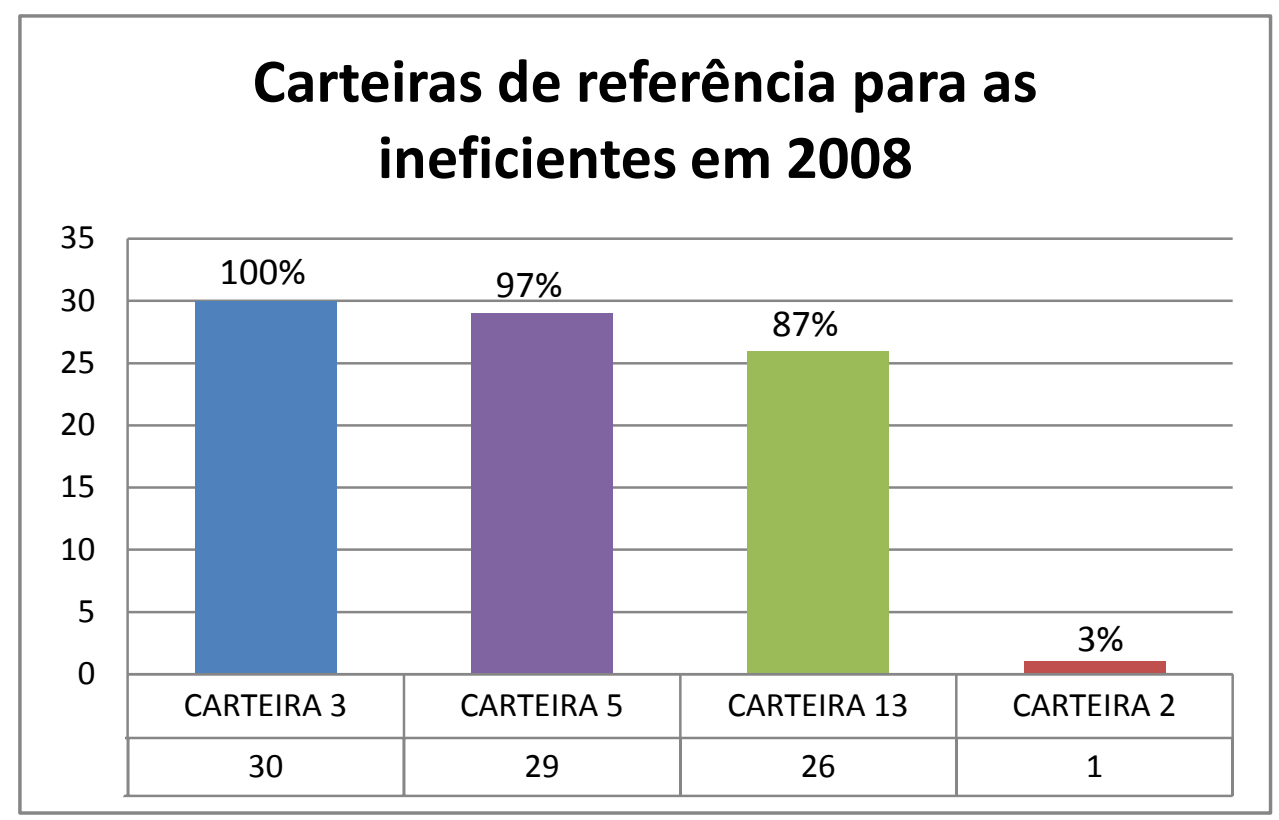

Gráfico 2 - Carteiras de referência para as ineficientes em 2008 Fonte: Elaborado pela autora

Com os dados do Gráfico 2, percebe-se que a carteira 3 é a unidade eficiente que mais aparece como referência para as demais. O número 30 indica que para um total de 30 carteiras ineficientes, a unidade 3 funciona como benchmarking para todas as ineficientes. Dado que são 5 carteiras eficientes, diante da amostra, 30 são ineficientes; isso explica o $100 \%$ de participação da carteira 3, pois ela é referência para todas as ineficientes. Cabe ressaltar que a carteira 23, apesar de eficiente em 2008, não está no Gráfico 2, pois ela não se apresenta como referência para nenhuma outra carteira, a não ser para ela mesma, isso indica que mesmo na fronteira de melhores práticas, a carteira 23 teve o P/L, riscos, retornos e LPA ótimos que não atenderam a mais nenhuma outra carteira. É importante ressaltar que as informações contidas no Gráfico 2 são independentes do modelo CCR ser OI ou $\mathrm{OO}$, pois o escore de eficiência é o mesmo e logo as carteiras de referência também.

Partindo para a análise das carteiras eficientes em 2009, no caso da carteira 6, de acordo com a Tabela 1 há aumento em todos seus outputs de 2008 para 2009 e redução da Volatilidade em $40,6 \%$ o que indica em parte a causa da eficiência. A situação desfavorável ocorreu com o aumento do P/L em quase $400 \%$ de 2008 para 2009. Analisando ainda os pesos das variáveis em cada ano, percebe-se a influência desses na definição da eficiência em 2009: 
Tabela 6 - Contribuição das Variáveis - Carteira 6

\begin{tabular}{l|r|r|l|r|r}
\hline \multicolumn{3}{c|}{ CCR - OI } & \multicolumn{3}{c}{ CCR - 00 } \\
\hline \multicolumn{1}{c}{ Carteira 6 } & $\mathbf{2 0 0 8}$ & $\mathbf{2 0 0 9}$ & \multicolumn{1}{c}{ Carteira 6 } & \multicolumn{1}{c}{$\mathbf{2 0 0 8}$} & \multicolumn{1}{c}{ 2009 } \\
\hline P/L & $77,1 \%$ & $53,3 \%$ & P/L & $77,1 \%$ & $97,2 \%$ \\
\hline BETA & $9,4 \%$ & $14,8 \%$ & BETA & $9,4 \%$ & $0,0 \%$ \\
\hline VOLATILIDADE & $0,0 \%$ & $12,4 \%$ & VOLATILIDADE & $0,0 \%$ & $1,4 \%$ \\
\hline Retorno 1 ano & $0,0 \%$ & $14,5 \%$ & Retorno 1 ano & $0,0 \%$ & $1,4 \%$ \\
\hline Retorno 3 anos & $0,0 \%$ & $0,1 \%$ & Retorno 3 anos & $0,0 \%$ & $0,0 \%$ \\
\hline Retorno 5 anos & $0,0 \%$ & $0,1 \%$ & Retorno 5 anos & $0,0 \%$ & $0,0 \%$ \\
\hline LPA & $13,5 \%$ & $4,8 \%$ & LPA & $13,5 \%$ & $0,0 \%$ \\
\hline
\end{tabular}

De 2008 para 2009, a redução da participação do P/L na orientação ao insumo contribuiu para a eficiência visto que nesse indicador a unidade se encontrava de maneira desfavorável, de acordo com os valores da Tabela 1. Além disso, o aumento da participação da Volatilidade e do Retorno de 1 também ajudaram a determinar a eficiência máxima dessa unidade, pois caracterizam-se como situações favoráveis.

Como variação de destaque a carteira 7 teve uma redução na Volatilidade de $58,6 \%$ passando de 65,5 para 27,1 de 2008 para 2009, conforme a Tabela 1 . Ao mesmo tempo esse indicador teve a segunda maior variação positiva na participação, representado pela linha Volatilidade na Tabela 7, sendo atribuído a ele então o fato de em 2009 essa carteira ser considerada eficiente.

Tabela 7 - Contribuição das Variáveis - Carteira 7

\begin{tabular}{l|r|r|l|r|r}
\hline \multicolumn{3}{c|}{ CCR - OI } & \multicolumn{3}{c}{ CCR - 00 } \\
\hline \multicolumn{1}{c|}{ Carteira 7 } & $\mathbf{2 0 0 8}$ & $\mathbf{2 0 0 9}$ & Carteira 7 & \multicolumn{1}{c|}{$\mathbf{2 0 0 8}$} & \multicolumn{1}{c}{$\mathbf{2 0 0 9}$} \\
\hline P/L & $80,7 \%$ & $0,1 \%$ & P/L & $80,7 \%$ & $0,1 \%$ \\
\hline Beta & $8,5 \%$ & $31,8 \%$ & Beta & $8,5 \%$ & $33,1 \%$ \\
\hline Volatilidade & $0,1 \%$ & $27,6 \%$ & Volatilidade & $0,0 \%$ & $29,7 \%$ \\
\hline Retorno 1 ano & $7,7 \%$ & $29,6 \%$ & Retorno 1 ano & $7,8 \%$ & $36,8 \%$ \\
\hline Retorno 3 anos & $0,1 \%$ & $0,1 \%$ & Retorno 3 anos & $0,0 \%$ & $0,1 \%$ \\
\hline Retorno 5 anos & $2,8 \%$ & $0,1 \%$ & Retorno 5 anos & $2,8 \%$ & $0,1 \%$ \\
\hline LPA & $0,1 \%$ & $10,7 \%$ & LPA & $0,0 \%$ & $0,1 \%$ \\
\hline
\end{tabular}

Percebe-se ainda na Tabela 7 que os indicadores Volatilidade e Retorno 1 ano aumentaram seus pesos, seguindo a tendência de outras Carteiras também eficientes.

Por fim a carteira 11 sofreu aumento de 54\% na eficiência devido principalmente, como expõe a Tabela 1 , à redução de $59,3 \%$ da Volatilidade e da elevação do LPA e dos retornos de 1 e 3 anos. Conjuntamente com esses dados, 
analisa-se a participação de cada variável na composição do escore na Tabela seguinte:

Tabela 8 - Contribuição das Variáveis - Carteira 11

\begin{tabular}{l|l|l|l|l|l}
\hline \multicolumn{3}{c|}{ CCR - OI } & \multicolumn{3}{c}{ CCR - O0 } \\
\hline \multicolumn{1}{c|}{ Carteira 11 } & $\mathbf{2 0 0 8}$ & $\mathbf{2 0 0 9}$ & \multicolumn{1}{c}{ Carteira 11 } & $\mathbf{2 0 0 8}$ & $\mathbf{2 0 0 9}$ \\
\hline P/L & $80,7 \%$ & $0,1 \%$ & P/L & $80,8 \%$ & $0,0 \%$ \\
\hline BETA & $8,5 \%$ & $31,8 \%$ & BETA & $8,5 \%$ & $3,2 \%$ \\
\hline VOLATILIDADE & $0,1 \%$ & $27,6 \%$ & VOLATILIDADE & $0,0 \%$ & $90,4 \%$ \\
\hline Retorno 1 ano & $7,6 \%$ & $29,6 \%$ & Retorno 1 ano & $7,8 \%$ & $0,0 \%$ \\
\hline Retorno 3 anos & $0,1 \%$ & $0,1 \%$ & Retorno 3 anos & $0,0 \%$ & $0,0 \%$ \\
\hline Retorno 5 anos & $2,9 \%$ & $0,1 \%$ & Retorno 5 anos & $2,8 \%$ & $0,0 \%$ \\
\hline LPA & $0,1 \%$ & $10,7 \%$ & LPA & $0,0 \%$ & $6,3 \%$ \\
\hline
\end{tabular}

Com essas participações, verifica-se que o indicador Volatilidade teve um maior aumento em sua participação; esse peso combinado com a redução citada acima ajudam a explicar a posição de máxima eficiência dessa carteira em 2009.

Finalmente, apresentam-se as carteiras eficientes que compõe o grupo de referência em 2009, indicando quantas vezes elas aparecem como benchmarking para as demais

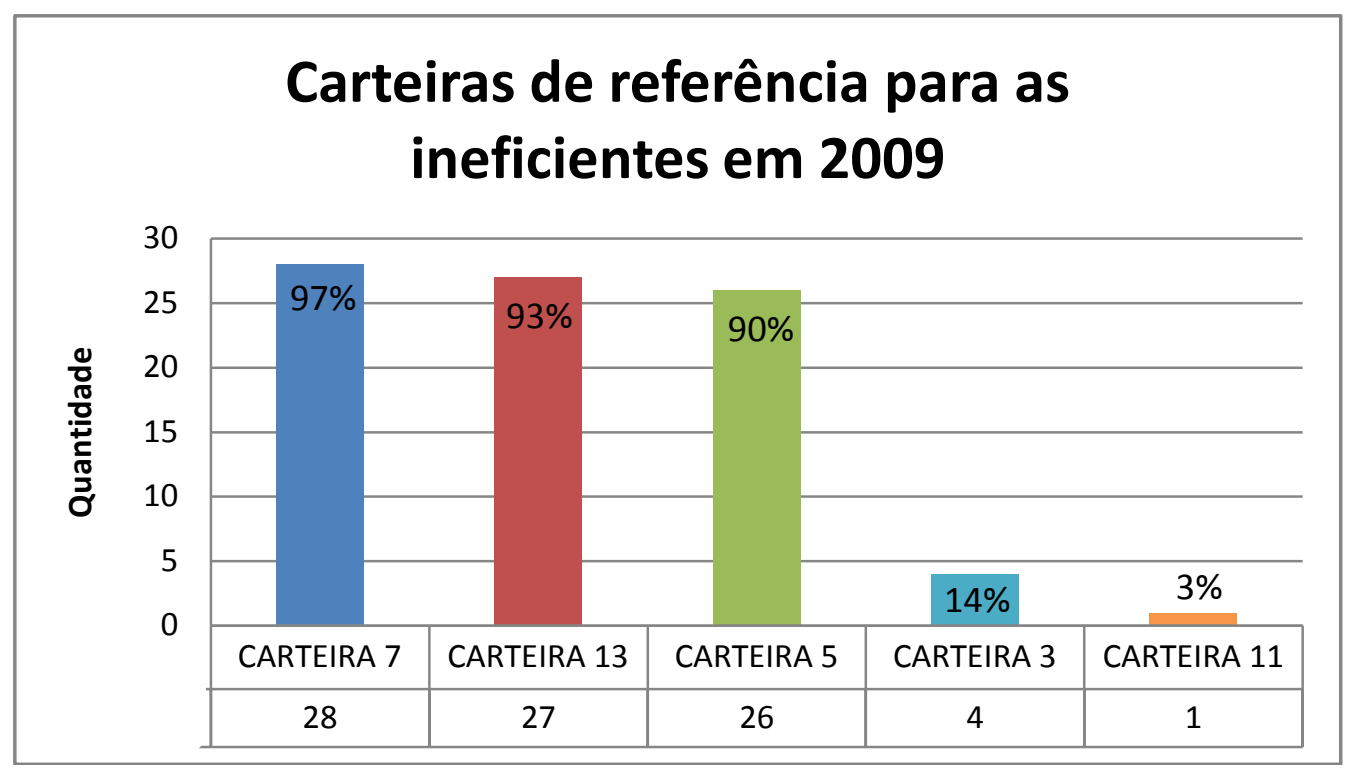

Gráfico 3 - Carteira de referência para as demais Fonte: Elaborado pela autora

Vê-se que a carteira 7 é a que se destaca como referência para as ineficientes, aparecendo 28 vezes, para um total de 30 ineficientes, e obtendo assim participação de $97 \%$ no quadro de referência. As carteiras 13 e 5 aparecem 27 e 26 
vezes com participação de $93 \%$ e $90 \%$ respectivamente. As unidades que menos aparecem como referência são as carteiras 3 e 11, esta última é referência só para uma ineficiente, obtendo participação de $3 \%$ no quadro de referência para as demais. Em contrapartida a carteira 6, que é eficiente em 2009, não aparece no Gráfico 3, pois ela é referência somente para si, ou seja, possui uma combinação de recursos e produtos que não atende mais nenhuma unidade do grupo.

Diante da análise das carteiras eficientes percebe-se que os indicadores P/L e Volatilidade destacaram-se dos demais, tanto na contribuição dos pesos quanto na variação observada na Tabela 1. Isso indica a importância dessas duas variáveis no momento de administrar carteiras de investimento. Esses dados se traduzem em informações estratégicas para os gestores auxiliando no processo de tomada de decisão, uma vez que serão preferíveis carteiras que possuam menores $P / L$ e Volatilidade possíveis, diante da alta contribuição dessas na eficiência. Do lado dos produtos o Retorno de 1 ano se mostrou o indicador mais participativo, o que sugere que dentre as séries históricas de retorno de carteiras, os recentes exercem maior influência na determinação da eficiência.

\subsection{Indicadores e Metas de Eficiência}

Feita a análise das DMUs eficientes pode-se proceder à investigação das carteiras ineficientes, analisando seus índices de ineficiências, variações assim como metas para torná-las produtivas. A ferramenta DEA permite calcular em quanto cada unidade precisa reduzir de insumo ou aumentar de produto para tornar-se eficiente, dado os escores de eficiência de cada uma. Sabe-se que esses escores para os modelos CCR-OI e CCR-OO são equivalentes, porém, o indicador de eficiência gerado por cada orientação no modelo CCR terá valores diferentes, já que um é o inverso do outro, como visto na seção 2.2.3.; essa situação é ilustrada quando se projetam as metas para cada carteira ineficiente em 2008 e 2009. Por ora serão contempladas as metas das 5 carteiras mais ineficientes em cada ano exibido na Tabela 9, a partir do escore de eficiência encontrado na Tabela 2. A lista completa pode ser encontrada no Apêndice B. 
Tabela 9 - Indicadores e Metas Radiais de Eficiência

\begin{tabular}{c|c|c|c|c}
\hline \multirow{2}{*}{ Carteiras } & \multicolumn{4}{|c}{$\mathbf{2 0 0 8}$} \\
\cline { 2 - 5 } & $\begin{array}{c}\text { Indicador de } \\
\text { Eficiência OI }\end{array}$ & $\begin{array}{c}\text { Meta } \\
\text { Insumo }\end{array}$ & $\begin{array}{c}\text { Indicador de } \\
\text { Eficiência OO }\end{array}$ & $\begin{array}{c}\text { Meta } \\
\text { Produto }\end{array}$ \\
\hline $\mathbf{3 3}$ & 0,52 & 0,48 & 1,93 & 0,93 \\
\hline $\mathbf{1 1}$ & 0,46 & 0,54 & 2,18 & 1,18 \\
\hline $\mathbf{2 0}$ & 0,45 & 0,55 & 2,25 & 1,25 \\
\hline $\mathbf{6}$ & 0,39 & 0,61 & 2,6 & 1,6 \\
\hline $\mathbf{1}$ & 0,13 & 0,87 & 7,92 & 6,92 \\
\hline \multicolumn{4}{|c}{$\mathbf{2 0 0 9}$} \\
\hline $\mathbf{4}$ & 0,41 & 0,59 & 2,46 & 1,46 \\
\hline $\mathbf{1 0}$ & 0,4 & 0,6 & 2,49 & 1,49 \\
\hline $\mathbf{3 1}$ & 0,39 & 0,61 & 2,55 & 1,54 \\
\hline $\mathbf{3 3}$ & 0,39 & 0,61 & 2,55 & 1,54 \\
\hline $\mathbf{2 0}$ & 0,18 & 0,82 & 5,69 & 4,69 \\
\hline
\end{tabular}

Como exposto na seção 2.2.3 do Referencial Teórico, o indicador de eficiência gerado na orientação aos insumos será sempre um valor entre 0 e 1, e na orientação aos produtos, o valor será sempre maior que 1 . A Tabela 9 confirma que quanto maior o indicador de orientação aos outputs maior é a ineficiência, e quanto menor o indicador orientado aos insumos, maior é a ineficiência. Essa Tabela ainda permite confirmar que o indicador de eficiência é o inverso do outro; como exemplo tem-se as carteiras em destaque que foram as mais ineficientes nos respectivos anos. A carteira 1, que foi a mais ineficiente em 2008, possui indicador de 0,13 para orientação aos insumos, o indicador inverso deve ser $1 / 0,13=7,92$, em média o que corrobora a utilização da recomendação vigente. Para ela ser eficiente precisa reduzir os insumos em $87 \%$ ou aumentar os produtos em $692 \%$, o que corresponde às colunas meta insumo e meta produto, respectivamente. Isso é explicado a partir de seus próprios indicadores. No caso dos insumos, como o indicador teve resultado 0,13 , para se chegar a 1 , que é a máxima eficiência, é preciso aumentar em $87 \%$ ou seja, $1-0,13=0,87$. A interpretação no caso dos produtos consiste em: para um índice de 7,92 é preciso aumentar $629 \%$ ou seja, 7,92 - 1=6,92. De maneira similar pode-se aplicar isso às outras unidades. Interessante notar que sob essa análise as carteiras eficientes possuem indicadores iguais a 1 e metas iguais a 0 .

Com a ajuda da Tabela 9, é possível saber em quanto é preciso aumentar os produtos ou reduzir os insumos de uma forma geral, porém uma análise mais detalhada pode ser feita a partir da projeção de cada variável para tornar a unidade eficiente. 


\subsection{Projeção das Ineficientes}

A ferramenta DEA possibilita também analisar a projeção que se deve fazer das ineficientes para torná-las eficientes, tomando como referência as melhores práticas. Essa projeção é apresentada na Tabela 10 para as 5 carteiras mais ineficientes em 2008, que ilustra de forma detalhada o quanto exatamente de cada insumo deve ser reduzido, a partir da orientação aos insumos e o quanto os produtos devem ser aumentados, a partir da orientação aos outputs. A lista completa com a projeção das carteiras ineficientes em 2008 se encontra no Apêndice C

Tabela 10 - Projeção radial das variáveis nas carteiras ineficientes em 2008

\begin{tabular}{c|c|c|c|c|c|c|c}
\hline \multirow{2}{*}{ CARTEIRAS } & \multicolumn{3}{|c|}{ Ol } & \multicolumn{4}{c}{ O0 } \\
\cline { 2 - 8 } & P/L & Beta & Volatilidade & $\begin{array}{c}\text { Retorno 1 } \\
\text { ano }\end{array}$ & $\begin{array}{c}\text { Retorno 3 } \\
\text { anos }\end{array}$ & $\begin{array}{c}\text { Retorno 5 } \\
\text { anos }\end{array}$ & LPA \\
\hline $\mathbf{3 3}$ & $-48 \%$ & $-48 \%$ & $-67 \%$ & $126 \%$ & $94 \%$ & $93 \%$ & $93 \%$ \\
\hline $\mathbf{1 1}$ & $-54 \%$ & $-54 \%$ & $-55 \%$ & $118 \%$ & $131 \%$ & $118 \%$ & $147 \%$ \\
\hline $\mathbf{2 0}$ & $-56 \%$ & $-56 \%$ & $-74 \%$ & $172 \%$ & $143 \%$ & $125 \%$ & $125 \%$ \\
\hline $\mathbf{6}$ & $-61 \%$ & $-61 \%$ & $-100 \%$ & $0 \%$ & $0 \%$ & $0 \%$ & $159 \%$ \\
\hline $\mathbf{1}$ & $-87 \%$ & $-87 \%$ & $-87 \%$ & $753 \%$ & $724 \%$ & $692 \%$ & $1191 \%$ \\
\hline
\end{tabular}

Os valores negativos das colunas P/L, Beta e Volatilidade da Tabela 10 apresentam o quanto em porcentagem é necessário reduzir de cada insumo a fim de atingir a meta de uma unidade eficiente. Do lado dos produtos, os valores indicam em quanto cada indicador deve aumentar para ser eficiente. Verifica-se nessa Tabela que do lado dos insumos, exceto a carteira 1, todas as outras possuem a mesma meta para os indicadores $\mathrm{P} / \mathrm{L}$ e Beta, no entanto a Volatilidade tem exigência de maior redução do que a meta estipulada, tanto na Tabela 9, quanto nessa. Essa diferença representa exatamente as folgas existentes nesse indicador. Esse resultado está de acordo com a revisão de literatura que trouxe a contribuição de Possamai (2006) ao afirmar que a partir dos escores de eficiência é possível identificar folgas, ou seja, excesso de insumos ou falta de produtos. Para compreender melhor essa situação, fez-se a análise gráfica da carteira 1: 


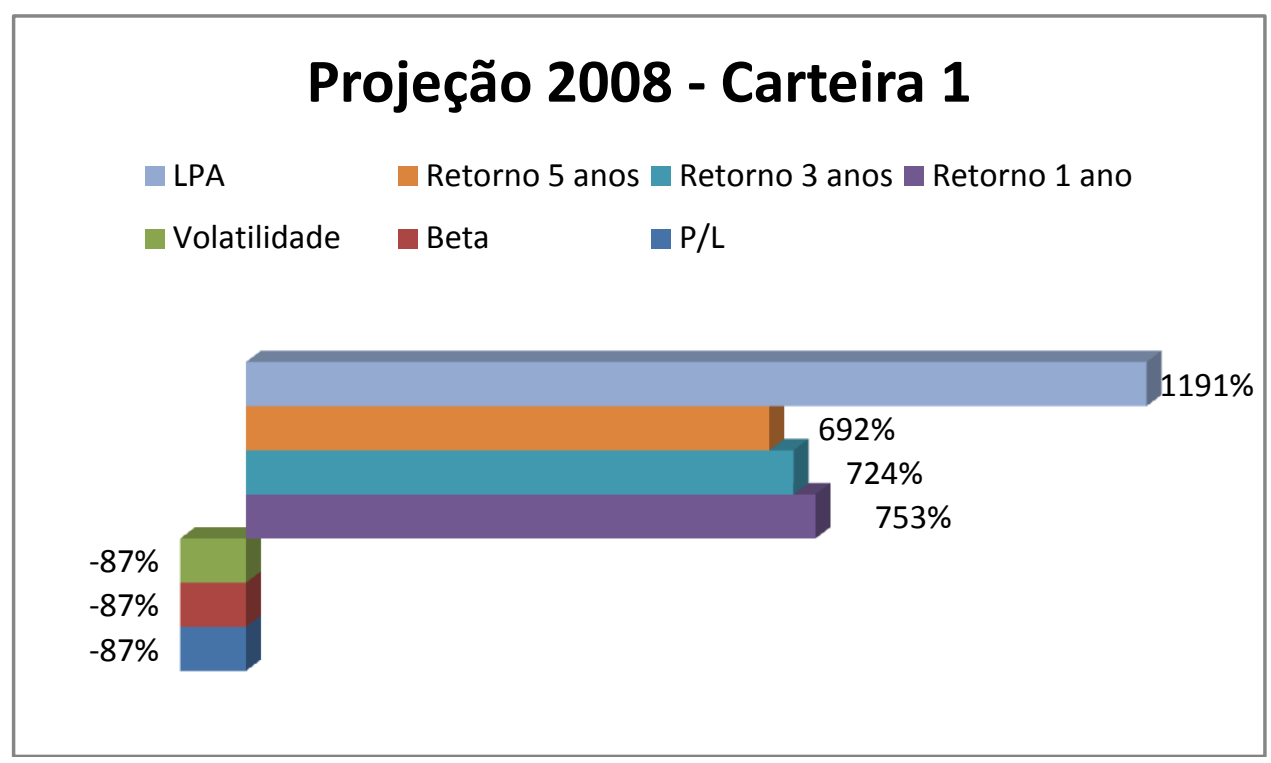

Gráfico 4 - Projeção da Carteira 1 em 2008

Fonte: Elaborado pela autora

Para alcançar a eficiência da carteira 1 viu-se na Tabela 9 que é preciso reduzir em $87 \%$ os insumos; com a Tabela 10 é possível verificar esse mesmo valor em cada insumo: o P/L, a Volatilidade e o Beta devem ser reduzidos em $87 \%$ confirmando a meta estipulada na Tabela 9 , o que indica que nos insumos não existem folgas. Do lado dos produtos, verifica-se que as variáveis Retorno 1 ano, Retorno 3 anos e o LPA tem projeção de 753\%, 724\% e 1191\%, respectivamente; ou seja, deve aumentar seus produtos mais do que a meta mínima de $692 \%$ na Tabela 10. Isso significa que essas variáveis possuem folgas e que para alcançar a eficiência precisam aumentar $61 \%, 32 \%$ e $499 \%$, respectivamente, além do aumento estipulado pela meta, que foi de $692 \%$ para essa carteira. Essas folgas podem ser visualizadas no Gráfico 4, diante da dispersão existente entre as linhas dos produtos. O mesmo procedimento pode ser feito para ter as projeções das carteiras ineficientes para o ano de 2009. A Tabela 11 traz as projeção das 5 mais ineficientes em 2009, a lista completa está disponível no Apêndice D.

Tabela 11 - Projeção radial das variáveis ineficientes em 2009

\begin{tabular}{c|c|c|c|c|c|c|c}
\hline \multirow{2}{*}{ CARTEIRAS } & \multicolumn{3}{|c|}{ Ol } & \multicolumn{4}{c}{ OO } \\
\cline { 2 - 8 } & $\mathbf{P} / \mathbf{L}$ & Beta & Volatilidade & $\begin{array}{c}\text { Retorno 1 } \\
\text { ano }\end{array}$ & $\begin{array}{c}\text { Retorno 3 3 } \\
\text { anos }\end{array}$ & $\begin{array}{c}\text { Retorno 5 } \\
\text { anos }\end{array}$ & LPA \\
\hline $\mathbf{4}$ & $-65 \%$ & $-59 \%$ & $-59 \%$ & $146 \%$ & $244 \%$ & $248 \%$ & $146 \%$ \\
\hline $\mathbf{1 0}$ & $-65 \%$ & $-60 \%$ & $-60 \%$ & $149 \%$ & $245 \%$ & $249 \%$ & $149 \%$ \\
\hline $\mathbf{3 1}$ & $-91 \%$ & $-61 \%$ & $-61 \%$ & $155 \%$ & $262 \%$ & $237 \%$ & $155 \%$ \\
\hline $\mathbf{3 3}$ & $-91 \%$ & $-61 \%$ & $-61 \%$ & $155 \%$ & $262 \%$ & $237 \%$ & $155 \%$ \\
\hline $\mathbf{2 0}$ & $-100 \%$ & $-82 \%$ & $-82 \%$ & $0 \%$ & $624 \%$ & $469 \%$ & $492 \%$ \\
\hline
\end{tabular}


Em 2009 verifica-se que, diferentemente de 2008, a predominância das folgas dentre os insumos se encontra com o indicador $P / L$, e não a Volatilidade; e dentre os produtos os Retornos de 3 e 5 anos são os que apresentam folgas em todas as carteiras sob análise na Tabela 11. Da mesma forma, fez-se a projeção gráfica da carteira mais ineficiente em 2009:

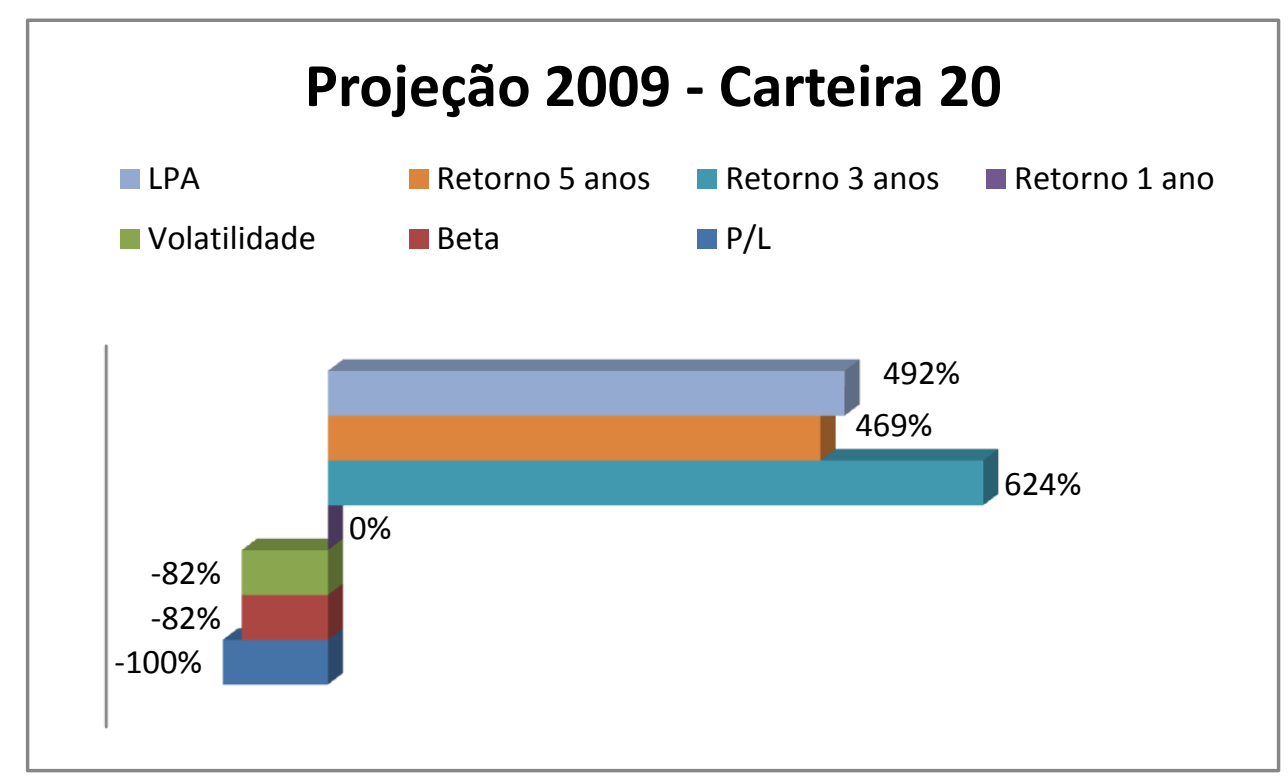

Gráfico 5 - Projeção da Carteira 20 em 2009

Fonte: Elaborado pela autora

Analisando a carteira 20, a Tabela 9 mostra que suas metas são redução de $82 \%$ e aumento de $469 \%$ para insumos e produtos, respectivamente. Considerando a Tabela 11 e o Gráfico 5, verifica-se a existência de folgas na variável P/L, Retorno 3 anos e LPA, pois esses indicadores têm projeção diferente da estipulada pela meta. O Retorno de 1 ano tem $0 \%$ pois possui valor de entrada igual a zero nessa carteira. Além disso, é possível fazer um detalhamento dessa projeção para se conhecer as carteiras de referência para a unidade 20 , funcionalidade disponibilizada pela ferramenta DEA.

Tabela 12 - Projeção radial para a carteira 20

\begin{tabular}{c|l|c|c|c|c|c}
\hline Metas Radiais & \multicolumn{1}{|c|}{ Variáveis } & Dados & Projeção & Diferença & $\%$ & Referência \\
\hline \multirow{5}{*}{0,82} & P/L & 0,04 & 0 & $-0,04$ & -1 & \\
\cline { 2 - 6 } & Beta & 0,68 & 0,12 & $-0,56$ & $-0,82$ & \\
\cline { 2 - 6 } & Volatilidade & 0,83 & 0,15 & $-0,68$ & $-0,82$ & \multirow{3}{*}{ Carteiras 3 e 5 } \\
\hline \multirow{5}{*}{4,69} & Retorno 1 ano & 0 & 0,05 & 0,05 & -- & \\
\cline { 2 - 6 } & Retorno 3 anos & 0,49 & 3,55 & 3,06 & 6,24 & \\
\cline { 2 - 6 } & Retorno 5 anos & 0,68 & 3,87 & 3,19 & 4,69 & \\
\cline { 2 - 6 } & LPA & 0,66 & 3,91 & 3,25 & 4,92 & \\
\hline
\end{tabular}


Pela Tabela 12, verifica-se que as carteiras eficientes 3 e 5 , juntas, determinam qual a projeção para a carteira 20 tornar-se eficiente. Essa projeção é obtida por uma combinação a partir dos valores de entrada das variáveis 3 e 5 no DEA, esses valores foram obtidos após a padronização e normalização de Powers e McMullen (2000) aplicados na Tabela 1.

\subsubsection{Projeção Não Orientada}

A combinação das orientações aos insumos e aos produtos resulta na chamada projeção não orientada abordada na seção 2.2.2. do Referencial Teórico. Essa análise possibilita identificar uma combinação de insumos e produtos a fim de encontrar um meio termo. Continuando como exemplo a carteira 20 , fez a projeção radial não orientada em 2009, obtendo os valores expostos na Tabela seguinte:

Tabela 13 - Projeção radial não orientada para a carteira 20

\begin{tabular}{c|l|c|c|c|c|c}
\hline Metas Radiais & Variáveis & Dados & $\begin{array}{c}\text { Projeção Não } \\
\text { Orientada }\end{array}$ & Diferença & Projeção \% & \multirow{2}{*}{ Referência } \\
\hline \multirow{3}{*}{0,41} & P/L & 0,04 & 0,00 & $-0,04$ & $-100 \%$ & \\
\cline { 2 - 6 } & Beta & 0,68 & 0,40 & $-0,28$ & $-41 \%$ & \\
\cline { 2 - 6 } & Volatilidade & 0,83 & 0,49 & $-0,34$ & $-41 \%$ & \multirow{3}{*}{ Carteiras } \\
\hline \multirow{3}{*}{2,35} & Retorno 1 ano & 0 & 0,03 & 0,03 & -- & \\
\cline { 2 - 6 } & Retorno 3 anos & 0,49 & 2,09 & 1,60 & $326 \%$ & \\
\cline { 2 - 6 } & Retorno 5 anos & 0,68 & 2,28 & 1,60 & $235 \%$ & \\
\cline { 2 - 6 } & LPA & 0,66 & 2,30 & 1,64 & $248 \%$ & \\
\hline
\end{tabular}

$\mathrm{Na}$ Tabela 13 a coluna 4 representa a projeção não orientada, obtida pela média simples das projeções orientadas aos insumos e aos produtos dessa carteira, a coluna 5 mostra a diferença entre o dado atual e a projeção estimada; esse valor em porcentagem é representado na coluna 6 . Procedendo para a análise Gráfica tem-se a seguinte situação: 


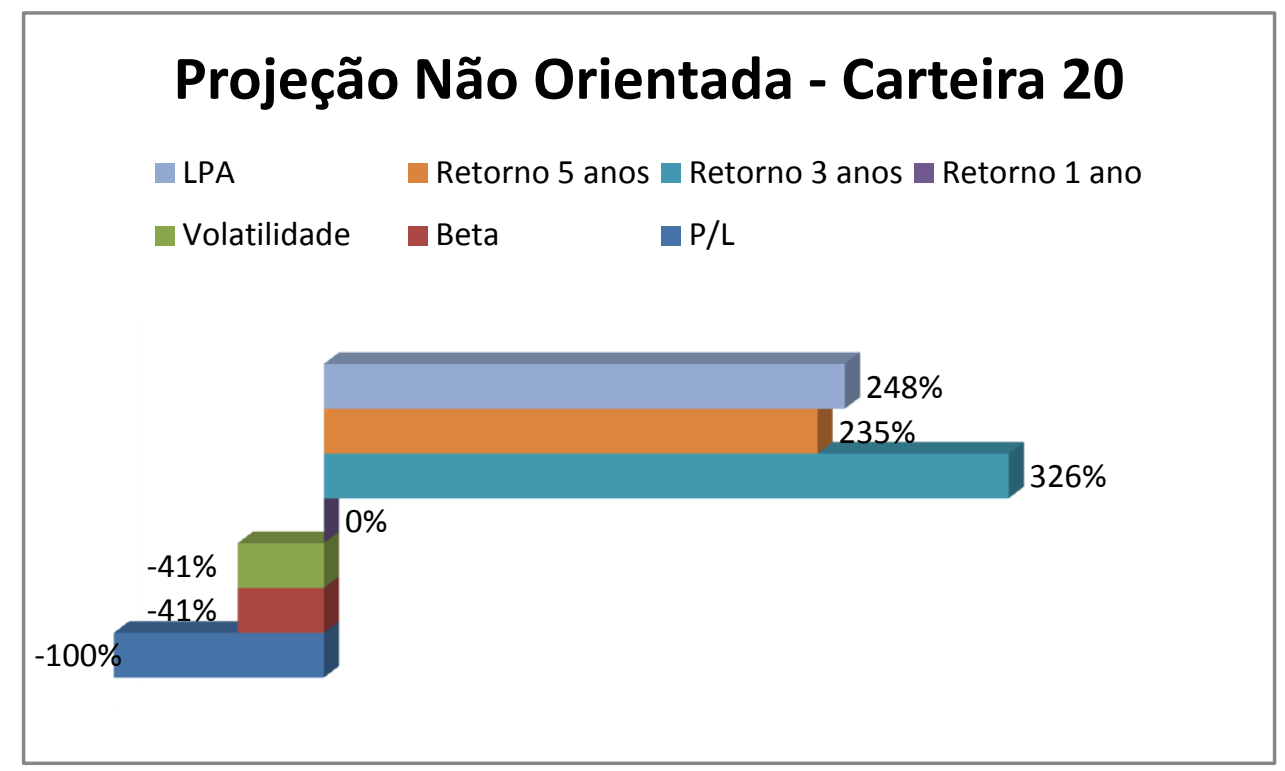

Gráfico 6 - Projeção não orientada da Carteira 20

Fonte: Elaborado pela autora

Nesse Gráfico observa-se que diferentemente da Projeção vista no Gráfico 5 para reduzir os insumos em $82 \%$ ou aumentar os produtos em $469 \%$, no caso da projeção não orientada a meta radial é: reduzir os insumos em $41 \%$ e ao mesmo tempo aumentar os produtos em 235\%. Ainda com ajuda do Gráfico 6 vê-se a existência de folgas nas variáveis P/L, LPA e Retorno 3 anos. Esse tipo de análise não orientada é uma alternativa para encontrar outra solução ótima para as carteiras: os gestores podem optar por uma alternativa que combine a existência de risco maior com a possibilidade de retorno menor, ao invés de priorizar risco zero com retorno mínimo ou risco alto com retorno baixo. Essa análise envolve um meio termo, o que no contexto de mercado financeiro seria um procedimento interessante face à instabilidade nessa área.

\subsection{Participação das Variáveis}

Até o momento foi possível identificar as carteiras ineficientes e suas características: quais possuem folgas, qual a meta de eficiência para cada uma, entre outras. Porém para saber o quanto cada variável contribui para a maior ineficiência, ou seja, qual variável é mais relevante no estudo, utiliza-se outra informação disponibilizada pelo DEA. Trata-se dos pesos específicos vi e ur de cada 
insumo $i$ e produto $r$ conforme visto na revisão de literatura, seção 2.2.3 O DEA apresenta os pesos em valores nominais, para melhor compreensão fez-se a análise em valores percentuais. Os pesos das variáveis em 2008 atribuídos pelo DEA estão disponibilizados nos Apêndices E e F. O Gráfico 7 mostra os pesos em valores percentuais calculados pelo modelo DEA CCR para os insumos nos 2 anos.

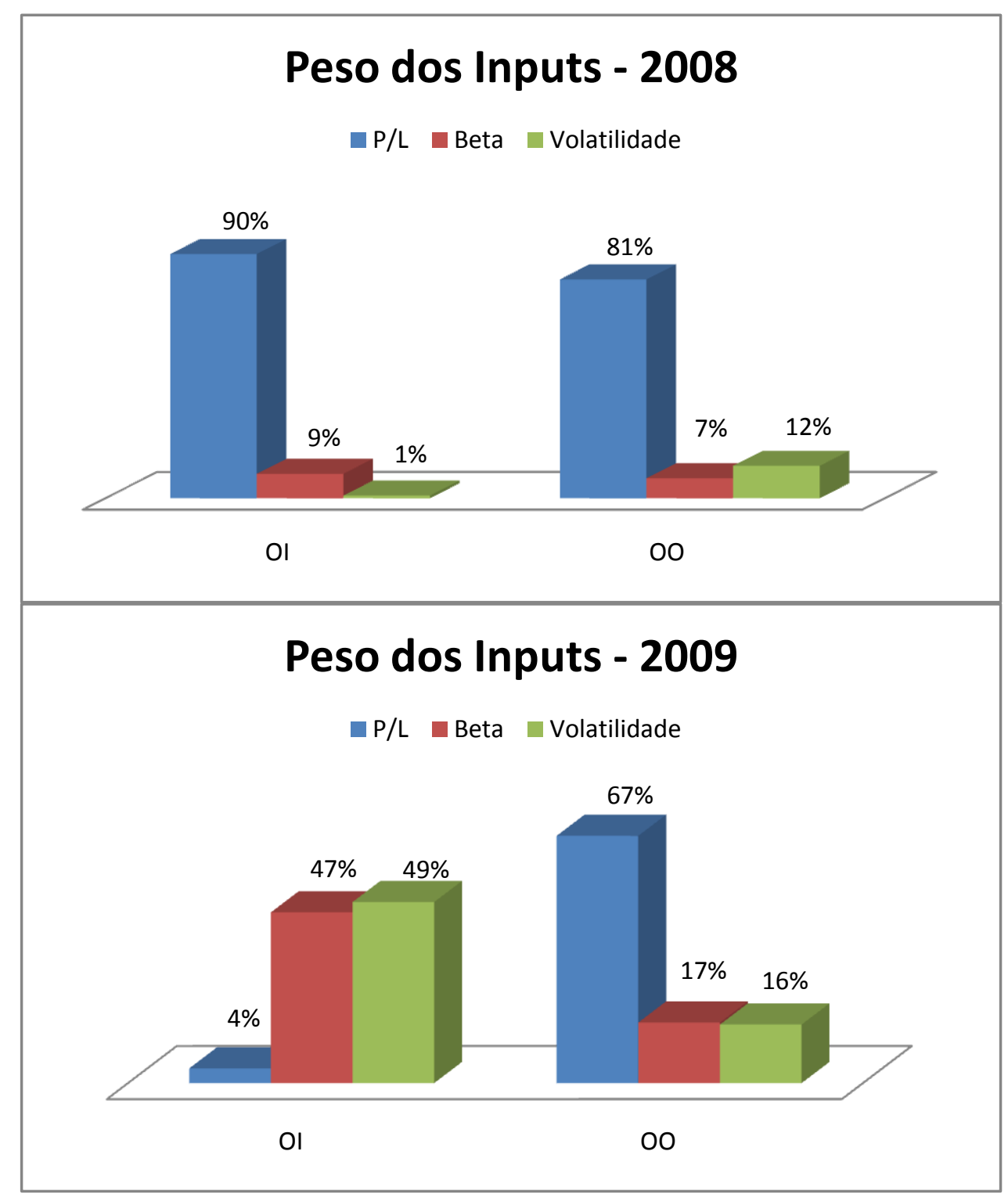

Gráfico 7 - Pesos dos Inputs Fonte: Elaborado pela autora

Com os pesos atribuídos, é possível identificar os insumos mais relevantes no estudo. Para os 2 anos destaca-se a variável P/L, posto que, em 2008, para as duas orientações esse indicador representa mais de $80 \%$ na contribuição dos escores de eficiência. Cabe ressaltar que as unidades eficientes 2, 3, 5, 13 e 23 possuem altos 
pesos para a variável $P / L$, o que já foi visto diante da análise das carteiras eficientes. Em 2009, o Gráfico 7 evidencia o destaque do indicador P/L para a definição da eficiência apenas quando se procede a orientação aos outputs. E nesse mesmo ano há maior contribuição dos indicadores Beta e Volatilidade, principalmente quando se tem orientação aos insumos. As contribuições mostram que, de maneira geral, o P/L é o indicador que se destaca tanto em 2008 quanto em 2009, seguido da Volatilidade que se torna a segunda variável mais relevante nos 2 anos. Essas análises permitem concluir que a eficiência das carteiras está intimamente ligada com sua medida de risco (volatilidade) e com o $\mathrm{P} / \mathrm{L}$, indicando que o gestor deve ter preferência primeiramente por carteiras que possuam o menor tempo para se recuperar o capital investido, e só depois verificar a tendência de risco daquela escolha.

Para a análise da contribuição dos produtos procedeu-se da mesma maneira realizada para os insumos. Os valores originais dos pesos das variáveis em 2009 estão nos Apêndices $\mathrm{G}$ e H. Os resultados encontrados estão disponibilizados no Gráfico 8 


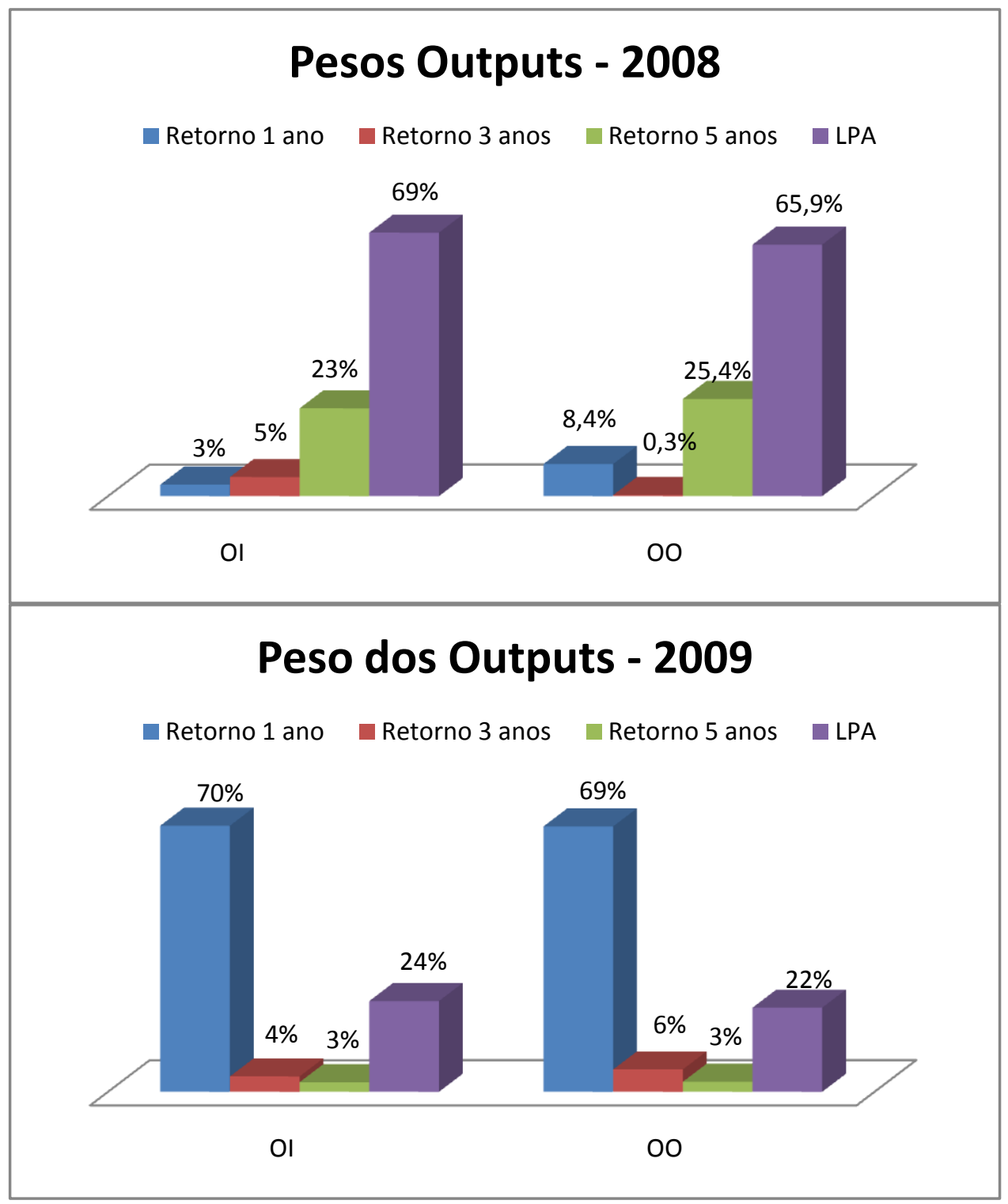

Gráfico 8 - Pesos dos Produtos

Fonte: Elaborado pela autora

Em 2008 verifica-se a maior participação do indicador LPA em ambas as orientações, seguida do Retorno de 5 anos. Isso indica que nesse ano maior relevância foi dada ao lucro por ação da carteira e também a análise de retorno histórica, revelando credibilidade em séries históricas de 5 anos anteriores ao período das carteiras. Já em 2009 o indicador predominante foi o Retorno de 1 ano seguido do LPA, este se manteve como uma variável importante para a tomada de decisão, porém com menos intensidade existente em 2008. O crescimento da participação do indicador Retorno 1 ano é notável e tem um significado importante, pois enquanto em 2008 havia a predominância de análises históricas, em 2009 diante do contexto de instabilidade, incerteza e consequências da crise do ano 
anterior, os investidores passaram a considerar retornos mais recentes para a tomada de decisão.

\subsection{Análise Conjunta}

Outra forma interessante de interpretar os resultados DEA é por meio da análise dos anos 2008 e 2009 juntos, ou seja, realizando uma avaliação média do comportamento das carteiras. Para isso, foi feita a média dos indicadores da Tabela 1 ; os valores obtidos foram padronizados e normalizados, de acordo com os procedimentos de Powers e McMullen (2000) explicitados na seção 3.3, e aplicados no software DEA-SEAD. Os resultados para o escore de eficiência foram os apresentados na Tabela 14

Tabela 14 - Comparação dos escores entre as eficientes

\begin{tabular}{c|c|c|c}
\hline \multirow{2}{*}{ Carteiras } & \multicolumn{3}{|c}{ Escores de Eficiência } \\
\cline { 2 - 4 } & $\mathbf{2 0 0 8}$ & $\mathbf{2 0 0 9}$ & Média \\
\hline $\mathbf{2}$ & $100 \%$ & $54 \%$ & $18 \%$ \\
\hline $\mathbf{3}$ & $100 \%$ & $100 \%$ & $100 \%$ \\
\hline $\mathbf{5}$ & $100 \%$ & $100 \%$ & $100 \%$ \\
\hline $\mathbf{6}$ & $39 \%$ & $100 \%$ & $100 \%$ \\
\hline $\mathbf{7}$ & $75 \%$ & $100 \%$ & $79 \%$ \\
\hline $\mathbf{1 1}$ & $46 \%$ & $100 \%$ & $34 \%$ \\
\hline $\mathbf{1 3}$ & $100 \%$ & $100 \%$ & $98 \%$ \\
\hline $\mathbf{2 3}$ & $100 \%$ & $92 \%$ & $92 \%$ \\
\hline
\end{tabular}

Com ajuda da Tabela anterior tem-se que mesclando as análises de 2008 e 2009 permaneceram eficientes apenas as carteiras 3, 5 e 6 . Interessante notar que as carteiras 3 e 5 foram eficientes em todas as análises, enquanto a carteira 6 era ineficiente em 2008, mas eficiente em 2009 e na Média. Por outro lado a carteira 13 que tinha escore 100\% tanto em 2008 quanto em 2009, teve na análise Média, escore de 98\%. Esses resultados permitem concluir que, excepcionalmente no caso da carteira 6, a ineficiência em 2008 não teve um peso forte para a determinação da eficiência média; para as outras carteiras foi predominante a situação de ineficiência, posto que somente 3 carteiras foram eficientes considerando a média dos 2 anos. 
Considerando as 5 carteiras mais ineficientes e os resultados de forma comparada com 2008 e 2009 tem-se as Tabelas 15 e 16:

Tabela 15 - Comparação dos escores entre as ineficientes

\begin{tabular}{c|c|c|c|c|c}
\hline \multicolumn{2}{c|}{2008} & \multicolumn{2}{c|}{2009} & \multicolumn{2}{c}{ Média 2 anos } \\
\hline Carteira & Escore & Carteira & Escore & Carteira & Escore \\
\hline $\mathbf{3 3}$ & $52 \%$ & $\mathbf{4}$ & $41 \%$ & $\mathbf{8}$ & $25 \%$ \\
\hline $\mathbf{1 1}$ & $46 \%$ & $\mathbf{1 0}$ & $40 \%$ & $\mathbf{2 9}$ & $23 \%$ \\
\hline $\mathbf{2 0}$ & $45 \%$ & $\mathbf{3 1}$ & $39 \%$ & $\mathbf{2}$ & $18 \%$ \\
\hline $\mathbf{6}$ & $39 \%$ & $\mathbf{3 3}$ & $39 \%$ & $\mathbf{3 0}$ & $8 \%$ \\
\hline $\mathbf{1}$ & $13 \%$ & $\mathbf{2 0}$ & $18 \%$ & $\mathbf{1}$ & $3 \%$ \\
\hline
\end{tabular}

Tabela 16 - Comparação dos resultados

\begin{tabular}{l|c|c|c}
\hline \multicolumn{1}{c|}{ Resultados } & $\mathbf{2 0 0 8}$ & $\mathbf{2 0 0 9}$ & Média 2 anos \\
\hline Média & 71 & 66 & 55 \\
\hline Desvio Padrão & 19 & 23 & 26 \\
\hline Mínimo & 13 & 18 & 3 \\
\hline Máximo & 100 & 100 & 100 \\
\hline Carteiras Eficientes & 5 & 6 & 3 \\
\hline $\begin{array}{l}\text { Carteiras com } \\
\text { ineficiência > 50\% }\end{array}$ & 4 & 12 & 15 \\
\hline
\end{tabular}

$\mathrm{Na}$ Tabela 15, o escore da Média dos 2 anos indica que o desempenho das carteiras foi pior quando se procedeu a essa análise. Verifica-se que carteiras que antes tinham maior eficiência agora possuem maior ineficiência. Como exemplo, a carteira 1 que era a mais ineficiente em 2008, manteve essa posição na análise média, porém com um escore de 10 unidades percentuais menor. A Tabela 16 confirma isso, pois se pode ver que comparado com os anos 2008 e 2009, a análise média teve apenas 3 carteiras eficientes, 15 com eficiência menor que $50 \%$ e fazendo uma média dos escores, obteve-se 55\%, o que representa um retrocesso comparado aos 2 anos. Por essa análise conjunta é possível concluir que o desempenho das carteiras ficou aquém se comparado com cada análise anualmente. A ineficiência das carteiras foi muito mais influente nos resultados do que a eficiência, apontando assim para esse efeito menos desejado.

Além disso, os pesos encontrados com a análise média confirmam a predominância de alguns indicadores na contribuição da eficiência. 


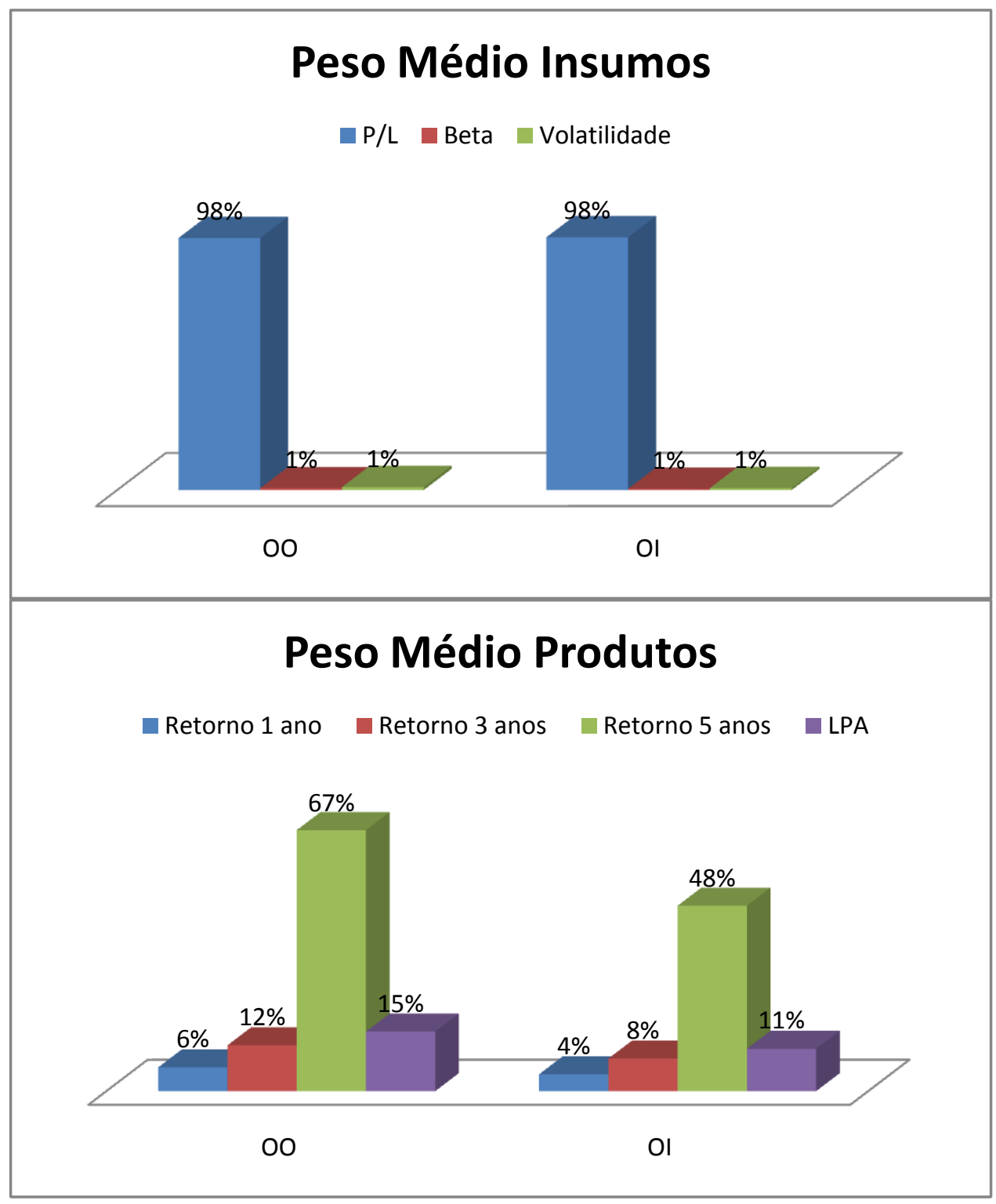

Gráfico 9 - Peso Médio das Variáveis Fonte: Elaborado pela autora

Com o Gráfico 9 verifica-se a supremacia do indicador P/L para a definição da eficiência, seguindo a tendência constatada em 2008 e 2009. Do lado dos produtos, diferentemente das análises individuais de cada ano em que predominaram o LPA e o Retorno de 1 ano, na análise média o indicador de destaque foi o Retorno 5 anos. Isso indica que essa variável, junto com o $\mathrm{P} / \mathrm{L}$ foram as que mais contribuíram para a definição dos baixos escores de eficiência nessa análise. 


\section{CONCLUSÕES E RECOMENDAÇÕES}

Uma das razões para se avaliar o desempenho de Carteiras de Investimento no mercado financeiro envolve a relevância desse assunto, como já discutido, principalmente, pelo alto volume de negócios que esse mercado movimenta e também pelo seu alcance, envolvendo a economia local e mundial. Essa dimensão deve ser marcada por ferramentas confiáveis de análise e de controle para se obter resultados desejáveis e otimizados constantemente. Com os resultados encontrados é possível concluir que a ferramenta DEA se mostrou útil para a determinação da eficiência nesse contexto de carteiras de investimento, considerando riscos, retornos e outras variáveis pertinentes ao desempenho financeiro.

Esse trabalho teve por objetivo principal evidenciar as potencialidades da ferramenta DEA no desempenho de carteiras de investimento no mercado variável brasileiro. Algumas dessas características foram detectadas a partir da capacidade que o DEA tem de identificar ineficiências e ao mesmo tempo sugerir melhorias. Essas características podem auxiliar sobre quais ativos escolher para compor suas carteiras, a partir dos indicadores técnicos e fundamentalistas disponibilizados no mercado de renda variável; e também apontam quais unidades não funcionam como parâmetro de eficiência. Isso foi verificado dentre as carteiras de referência que funcionam como benchmarking para as demais, já que compara umas com as outras e aponta dentre as melhores, a melhor, e dentre as piores, a pior. Dessa forma, o DEA se apresenta como uma poderosa ferramenta para gestores e analistas de mercado financeiro na tomada de decisão sobre qual carteira escolher.

Outro aspecto relevante é que o mercado acionário é extremamente volátil e muitas vezes imprevisível, ou seja, ganhos passados não refletem necessariamente ganhos futuros; sendo necessárias ferramentas dinâmicas que auxiliem na escolha de ações e carteiras, assim os resultados apontam mais uma potencialidade: o DEA foi fiel à realidade analisada, dado que o período vigente esteve marcado por crise e instabilidade, o que foi possível retratar a partir dos diferentes escores de eficiência, e das dispersões encontradas nas projeções, nos pesos das variáveis e nas visualizações gráficas.

Foi possível comprovar ainda que um dos diferenciais do DEA envolve, além de simplesmente apontar as carteiras eficientes, indicar as possíveis causas dessa 
eficiência, dada, principalmente, pelos pesos das variáveis. A eficiência de cada carteira é definida de forma individual, considerando a atuação das demais carteiras, porém o DEA permite atribuir pesos aos indicadores de forma a maximizar a eficiência. Assim, pelos resultados encontrados, foi possível identificar quais indicadores foram determinantes para o desempenho das carteiras considerando o período e o contexto analisado.

Como insumo, o P/L se mostrou o indicador mais relevante nos 2 anos de análise. Esse indicador sugere, em momentos de euforia, quanto tempo é necessário para recuperar o capital investido, ou seja, relaciona o preço pago pela aquisição da ação e o seu lucro periódico. No contexto analisado os analistas de mercado buscavam escolher carteiras que continham ativos com o menor $P / L$, pois face às incertezas, as medidas de risco eram menos confiáveis, sendo preferível assim utilizar como parâmetro um índice como o P/L. Isso foi comprovado pela supremacia do indicador $\mathrm{P} / \mathrm{L}$ na análise $\mathrm{DEA}$, tendo alta contribuição em praticamente todas as carteiras em ambas orientações.

Para os produtos, em 2008 consideravam-se retornos mais distantes para a escolha das carteiras, ou seja, a análise de séries históricas se mostravam mais determinantes para a tomada de decisão. Já em 2009 marcado pela recessão e incerteza do mercado financeiro, os gestores optaram por análises mais recentes e estáveis, o que foi retratado pelo DEA dada a maior participação do indicador Retorno de 1 ano para a definição da eficiência das Carteiras.

Considerando esses resultados obtidos é possível responder a problemática inicial em que se questionava se o DEA é um bom indicativo para a avaliação do desempenho de Carteiras de Investimento. Os resultados expressam essa resposta como positiva, dado que as propriedades fornecidas pelo DEA e detectadas nas análises refletem que essa ferramenta foi capaz de medir o desempenho das carteiras de investimento de acordo com a realidade analisada.

As análises permitem concluir que essa pesquisa possibilitou avaliar a eficiência de cada carteira de maneira detalhada, explorando as características que o DEA disponibiliza. Os principais conceitos para avaliação de desempenho, critérios de seleção de carteiras e ferramentas de decisão foram evidenciados ao longo do trabalho, como forma a comparar com o DEA e apresentar diferentes visões nessa área, nesse sentido indo ao encontro dos objetivos específicos. Por fim foram apresentados os conceitos relacionados com a ferramenta DEA, apontando seu 
histórico, surgimento, diferentes modelos existentes e particularidades de cada um. Aspectos como folgas, possibilidade de benchmarking, melhorias, diferentes orientações e respectivas formas de cálculo foram explicitadas e aplicadas nos resultados obtidos, relacionando assim a teoria com a prática e atingindo os objetivos específicos.

A insuficiência de tempo para uma análise mais elaborada e detalhada contendo mais carteiras na amostra e outros indicadores que representem o desempenho financeiro se apresenta como uma limitação nesse estudo. Além disso, muitas carteiras da empresa estudada eram compostas por ações que não tinham os dados disponíveis a respeito dos indicadores; ou ainda muitas carteiras continham ações recentes e, portanto não possuíam análises de 5 anos atrás, fato que foi necessário para se obter o Retorno 5 anos da carteira. Esses fatores se mostraram como dificuldades para a definição da amostra, que apesar de estar adequada às regras descritas na literatura sobre DEA, foi definida, principalmente, por exclusão de carteiras que não possuíam dados suficientes. Outro entrave foi a obtenção dos indicadores analisados, pois eles foram obtidos por fontes secundárias, sendo alguns previamente calculados a partir de uma média histórica, limitando ainda mais a precisão dos dados.

Trabalhos futuros apontam na direção de realizar análises mais pontuais, verificando o desempenho mensal ou trimestral das carteiras, por um período maior de tempo que não apenas 2 anos. Outros indicadores poderiam ser utilizados, além das medidas básicas de risco e retorno: poderia se considerar capital investido, euforia do mercado, contexto mundial, preferência do investidor, ética na tomada de decisão, variáveis macroeconômicas ou qualitativas, etc. Os indicadores poderiam ser escolhidos utilizando técnicas mais sofisticadas, além de médias de suas séries históricas.

$\mathrm{Na}$ discussão dos resultados foi possível perceber que o DEA se aplicou também no contexto do mercado financeiro, mostrando-se assim como uma ferramenta emergente de análise nessa área podendo ser utilizada como complemento a outros métodos já conhecidos como Teoria das Carteiras de Markowitz, Capital Asset Pricing Model (CAPM), análises técnicas e fundamentalistas de ações. Além disso, o desempenho gerado pelo DEA poderia ser comparado com padrões de referência no mercado financeiro, como por exemplo o Ibovespa. Ou ainda caberia ser aplicado conjuntamente com outras técnicas, 
métodos e análises apresentados no Quadro 1 a fim de se obter resultados mais precisos e com diferentes visões de desempenho, como forma a aumentar a compreensão dos fatores determinantes para a eficiência das carteiras de investimento. 


\section{REFERÊNCIAS}

ANDRADE, M. M. Introdução à metodologia do trabalho científico: elaboração de trabalhos na graduação. 4. Ed. São Paulo: Atlas, 1999.

ASSAF NETO, A. Mercado financeiro. 8. Ed. São Paulo: Atlas, 2008.

BOLSA DE VALORES, MERCADORIAS E FUTUROS (BM\&FBOVESPA). Principal. Disponível em: <http://www.bmfbovespa.com.br/pt-br/educacional/perguntasfrequentes/perguntas-frequentes.aspx?idioma=pt-br\# >. Acesso em 9 mar 2010.

CERETTA, P. S.; COSTA Jr, N. C. A. Avaliação e seleção de fundos de investimento: um enfoque sobre múltiplos atributos. Revista de Administração Contemporânea, Curitiba, v. 5, n.1, p. 7-27, jan./abr.2001.

CHARNES, A. et al. Data envelopment analysis: theory, methodology, and application. 3. Ed. Massachusetts (USA): Kluwer, 1997.

COMISSÃO DE VALORES MOBILIÁRIOS (CVM). Portal do Investidor. Disponível em:< http://www.portaldoinvestidor.gov.br/Acadêmico/tabid/55/Default.aspx>. Acesso em: 9 mar. 2010.

COELLI, T. J. et al. An introduction to efficiency and productivity analysis. 2. Ed. New York (EUA): Springer, 2005.

COOPER, W. W.; SEIFORD, L. M.; ZHU, J. Data envelopment analysis: History, Models and Interpretations. In: COOPER, W. W.; SEIFORD, L. M.; ZHU, J (Eds.) Handbook on Data Envelopment Analysis. Boston: Kluwer Academic, 2004. p.139.

COOPER, W.W.; SEIFORD, L.M.; TONE, K.. Data Envelopment Analysis: a comprehensive text with models, applications, references and DEA-Solver Software. 2. Ed. New York (USA): Springer, 2007. cap. 11

ELING, M. Performance Measurement of Hedge Funds Using Data Envelopment Analysis. Financial Markets and Portfolio Management, Boston, v.20, n.4, p. 442471, 2006. 
KASSAI, S. Utilização da Análise por Envoltória de Dados (DEA) na Análise de Demonstrações Contábeis. 2002. 350f. Tese (Doutorado em Contabilidade e Controladoria). Departamento de Contabilidade e Atuária, Faculdade de Economia, Administração e Contabilidade da Universidade de São Paulo. São Paulo: USP, 2002.

LINS, M. P. E.; MEZA, L. A. Análise por Envoltória de Dados e Perspectivas de Integração no Meio Ambiente de Apoio à Decisão. Rio de Janeiro: Coppe, 2000.

LINS, A.G. et al. Formulação de Carteiras Hipotéticas de Ativos Financeiros Usando a Técnica de Análise de Cluster. In: ENCONTRO DA ASSOCIAÇÃO NACIONAL DE PÓS-GRADUAÇÃO E PESQUISA EM ADMINISTRAÇÃO, 31., 2007, Rio de Janeiro. Anais do XXXI EnANPAD. Rio de Janeiro: ANPAD, 2007. p. 1-14.

LINS, M. P. E; ALMEIDA, B. F; BARTHOLO Jr., R. Avaliação de desempenho na pós-graduação utilizando a análise envoltória de dados. Revista Brasileira de PósGraduação, Brasília: Capes, v. 2, n. 2, p. 41-56, 2004.

LOPES, A.L.M. et al. Data Envelopment Analysis - DEA como estratégia para seleção de carteiras de investimento: uma aplicação a 13 anos do mercado de ações brasileiro. In: ENCONTRO DA ASSOCIAÇÃO NACIONAL DE PÓSGRADUAÇÃO E PESQUISA EM ADMINISTRAÇÃO, 32., 2008, Rio de Janeiro. Anais do XXXII EnANPAD. Rio de Janeiro: ANPAD, 2008. p.1-16.

LOPES, A.L.M. et al. Utilizando Data Envelopment Analysis - DEA e o Modelo de Otimização de Markowitz na Seleção de Ativos no Mercado de Renda Variável Brasileiro. In: SIMPÓSIO BRASILEIRO DE PESQUISA OPERACIONAL, 41., 2009, Porto Seguro. Anais do XLI Simpósio Brasileiro de Pesquisa Operacional. Porto Seguro: SOBRAPO, 2009. p.1-12.

LOPES, A.L.M. et al. Desempenho de Carteiras de Ações Compostas por Ações Selecionadas por Análise Envoltória de Dados de Indicadores. In: ENCONTRO BRASILEIRO DE FINANÇAS, 6., 2006, Vitória/ES. Anais do VI Encontro Brasileiro de Finanças. Vitória: SBFIN, 2006. p.1-10.

MACEDO, M. A. S.; CASA NOVA, S. P C.; ALMEIDA, K. Mapeamento e análise bibliométrica da utilização da análise envoltória de dados (DEA) em estudos das áreas de Contabilidade e Administração. In: ENCONTRO DA ASSOCIAÇÃO NACIONAL DE PÓS-GRADUAÇÃO E PESQUISA EM ADMINISTRAÇÃO, 31., 2007, Rio de Janeiro. Anais do XXXI EnANPAD. Rio de Janeiro: ANPAD, 2007. p.1-16. 
MARKOWITZ, H. M. Portfolio selection. Journal of Finance, v. 7(1), p. 77-91, 1952.

MATSUMOTO, A.S.; PINHEIRO, A.A.O.; SANTOS, C.E.G. Seleção de Carteiras com Base na Utilidade do Investidor. In: ENCONTRO DA ASSOCIAÇÃO NACIONAL DE PÓS-GRADUAÇÃO E PESQUISA EM ADMINISTRAÇÃO, 31., 2007, Rio de Janeiro. Anais do XXXI EnANPAD. Rio de Janeiro: ANPAD, 2007. p.1-16.

ONUSIC, L.M.; CASA NOVA, S. P. C.; ALMEIDA, F. C. Modelos de Previsăo de Insolvência Utilizando a Análise por Envoltória de Dados: Aplicação a Empresas Brasileiras. Revista de Administração Contemporânea, Curitiba, v.11, 2a. Edição Especial. p.77-97, 2007.

ORO, I. M.; BEUREN, I. M.; HEIN, N. Análise da eficiência de empresas familiares brasileiras. RAE-eletrônica, São Paulo, v. 8, n. 2, art. 11, jul./dez. 2009. Disponível em: <http://www16.fgv.br/rae/artigos/5517.pdf> Acesso em: 16 mar. 2010.

PORTUGAL NETO, R. F. A inclusão da micro, pequena e média empresa no mercado brasileiro de valores mobiliários. 2005. 90f. Monografia (Especialização em regulação do mercado de capitais) - Instituto de economia da Universidade Federal do Rio de Janeiro - UFRJ, Rio de Janeiro, 2005.

POSSAMAI, R. P. Avaliação de eficiência técnica em concessionárias de rodovias utilizando análise envoltória de dados. 2006. 169f. Dissertação (Mestrado em Engenharia de Produção) - Escola de Engenharia da Universidade Federal do Rio Grande do Sul - UFRGS, Porto Alegre, 2006.

POWERS, J.; McMULLEN, P. R., Using data envelopment analysis to select efficient large market cap securities. Journal of Business and Management, Toronto, v.7, n. 2, p.31-42, outono 2000.

ROSANO, C. P. Um Modelo de Avaliação da Eficiência da Administração Pública Através do Método Análise Envoltória de Dados (DEA). Revista de Administração Contemporânea, Curitiba, v. 12, n.1, p. 83-106, jan./mar. 2008.

SANTOS, A.; CASA NOVA, S.P.C. Proposta de um Modelo Estruturado de Análise de Demonstrações Contábeis. RAE Eletrônica, São Paulo, v.4, n.1, art. 8, jan/jul. 2005. Disponível em: <http://www.scielo.br/pdf/raeel/v4n1/v4n1a04.pdf>. Acesso em: 18 mar. 2010.

SENRA, L. F. A. C. et al. Estudo sobre Métodos de Seleção de Variáveis em DEA. Pesquisa Operacional, Rio de Janeiro, v. 27, n. 2, p.191-207, maio/ago. 2007. 
SILVA, L. A. F. A verificação das relações entre estratégias de investimento e as hipóteses de eficiência de mercado: um estudo na bolsa de valores de São Paulo. 2003. 100f. Tese (Doutorado em Engenharia de Produção) - Escola Politécnica da Universidade de São Paulo, São Paulo, 2003.

SILVA, E. L.; MENEZES, E. M. Metodologia da pesquisa e elaboração de dissertação. 3. ed. rev.e aum. Florianópolis: Laboratório de Ensino a Distância da Universidade Federal de Santa Catarina - UFSC, 2001, p. 1-121.

SURCO, D.F.; WILHELM, V. E. Desenvolvimento de uma ferramenta computacional para avaliação da eficiência técnica baseada em DEA. SISTEMAS \& GESTÃO, Niterói/RJ, v.1, n.1, p. 42-57, jan./abr. 2006.

VERGARA, S.C. Começando a definir a metodologia. In: Projetos e relatórios de pesquisa em Administração. 3.ed. São Paulo: Atlas, 2000. cap.4.

VIDOTTO, R. S.; MIGLIATO, A. L. T.; ZAMBOM, A. C.; O Moving Average Convergence-Divergence como ferramenta para a decisão de investimentos no mercado de ações. Revista de Administração Contemporânea, Curitiba, v. 13, n.2, p. 291-309, abr./jun. 2009. 


\section{APÊNDICES}

\section{Apêndice A - Carteiras de Investimento}

\begin{tabular}{|c|c|c|c|c|c|c|c|}
\hline 1 & BRFS3 & & & & & & \\
\hline 2 & FIBR3 & & & & & & \\
\hline 3 & UNIP6 & & & & & & \\
\hline 4 & PETR4 & & & & & & \\
\hline 5 & CMIG3 & & & & & & \\
\hline 6 & GOLL4 & & & & & & \\
\hline 7 & ETER3 & & & & & & \\
\hline 8 & GGBR4 & VALE5 & & & & & \\
\hline 9 & PETR4 & VALE5 & & & & & \\
\hline 10 & GGBR4 & PETR4 & & & & & \\
\hline 11 & BBDC4 & ITUB4 & & & & & \\
\hline 12 & CSNA3 & VALE5 & & & & & \\
\hline 13 & CNFB4 & CSNA3 & & & & & \\
\hline 14 & BBAS3 & PETR4 & VALE5 & & & & \\
\hline 15 & BBAS3 & GGBR4 & PETR4 & & & & \\
\hline 16 & ETER3 & PETR4 & VALE5 & & & & \\
\hline 17 & UNIP6 & VALE3 & VALE5 & & & & \\
\hline 18 & BBAS3 & PETR4 & VALE5 & & & & \\
\hline 19 & PETR3 & PETR4 & VALE5 & & & & \\
\hline 20 & EMBR3 & PETR4 & VALE5 & & & & \\
\hline 21 & CSNA3 & PETR4 & VALE5 & & & & \\
\hline 22 & BBDC4 & TLPP4 & VALE5 & & & & \\
\hline 23 & CESP3 & CMIG3 & BBDC4 & PETR4 & & & \\
\hline 24 & BBAS3 & CESP3 & GOLL4 & VALE5 & & & \\
\hline 25 & ETER3 & FIBR3 & PETR4 & VALE5 & & & \\
\hline 26 & CSNA3 & GGBR4 & PETR4 & VALE5 & & & \\
\hline 27 & BRFS3 & PETR4 & USIM5 & VALE5 & & & \\
\hline 28 & CSNA3 & BBDC4 & ELET3 & PETR4 & VALE5 & & \\
\hline 29 & GGBR4 & PETR4 & TNLP4 & USIM5 & VALE5 & & \\
\hline 30 & BRFS3 & CMIG4 & ELET3 & ELET6 & PETR4 & VALE5 & \\
\hline 31 & BBAS3 & EMBR3 & FIBR3 & GGBR4 & PETR4 & VALE5 & \\
\hline 32 & BBDC4 & CMIG3 & ELET6 & PETR4 & UNIP6 & USIM5 & \\
\hline 33 & BBAS3 & EMBR3 & FIBR3 & GGBR4 & PETR4 & VALE5 & \\
\hline 34 & BBDC4 & CSNA3 & ITSA4 & ITUB4 & PETR4 & USIM5 & VALE5 \\
\hline 35 & CSNA3 & ETER3 & FIBR3 & GGBR4 & PETR4 & USIM5 & VALE5 \\
\hline
\end{tabular}


Apêndice B - Indicadores e metas de eficiência

\begin{tabular}{|c|c|c|c|c|c|c|c|c|}
\hline \multirow[b]{2}{*}{ CARTEIRAS } & \multicolumn{4}{|c|}{2008} & \multicolumn{4}{|c|}{2009} \\
\hline & $\begin{array}{l}\text { Indicador de } \\
\text { Eficiência OI }\end{array}$ & $\begin{array}{c}\text { Meta } \\
\text { Insumo }\end{array}$ & $\begin{array}{l}\text { Indicador de } \\
\text { Eficiência OO }\end{array}$ & $\begin{array}{c}\text { Meta } \\
\text { Produto }\end{array}$ & $\begin{array}{l}\text { Indicador de } \\
\text { Eficiência Ol }\end{array}$ & $\begin{array}{c}\text { Meta } \\
\text { Insumo }\end{array}$ & $\begin{array}{l}\text { Indicador de } \\
\text { Eficiência OO }\end{array}$ & $\begin{array}{c}\text { Meta } \\
\text { Produto }\end{array}$ \\
\hline 1 & 0,13 & 0,87 & 7,92 & 6,92 & 0,69 & 0,31 & 1,45 & 0,45 \\
\hline 2 & 1,00 & 0,00 & 1,00 & 0,00 & 0,54 & 0,46 & 1,86 & 0,86 \\
\hline 3 & 1,00 & 0,00 & 1,00 & 0,00 & 1,00 & 0,00 & 1,00 & 0,00 \\
\hline 4 & 0,77 & 0,23 & 1,29 & 0,29 & 0,41 & 0,59 & 2,46 & 1,46 \\
\hline 5 & 1,00 & 0,00 & 1,00 & 0,00 & 1,00 & 0,00 & 1,00 & 0,00 \\
\hline 6 & 0,39 & 0,61 & 2,60 & 1,60 & 1,00 & 0,00 & 1,00 & 0,00 \\
\hline 7 & 0,75 & 0,25 & 1,33 & 0,33 & 1,00 & 0,00 & 1,00 & 0,00 \\
\hline 8 & 0,64 & 0,36 & 1,57 & 0,57 & 0,43 & 0,57 & 2,33 & 1,33 \\
\hline 9 & 0,74 & 0,26 & 1,36 & 0,36 & 0,50 & 0,50 & 2,00 & 1,00 \\
\hline 10 & 0,77 & 0,23 & 1,30 & 0,30 & 0,40 & 0,60 & 2,49 & 1,49 \\
\hline 11 & 0,46 & 0,54 & 2,18 & 1,18 & 1,00 & 0,00 & 1,00 & 0,00 \\
\hline 12 & 0,70 & 0,30 & 1,42 & 0,42 & 0,57 & 0,43 & 1,74 & 0,74 \\
\hline 13 & 1,00 & 0,00 & 1,00 & 0,00 & 1,00 & 0,00 & 1,00 & 0,00 \\
\hline 14 & 0,71 & 0,29 & 1,40 & 0,40 & 0,52 & 0,48 & 1,91 & 0,91 \\
\hline 15 & 0,65 & 0,35 & 1,53 & 0,53 & 0,56 & 0,44 & 1,79 & 0,79 \\
\hline 16 & 0,70 & 0,30 & 1,43 & 0,43 & 0,59 & 0,41 & 1,70 & 0,70 \\
\hline 17 & 0,80 & 0,20 & 1,25 & 0,25 & 0,86 & 0,14 & 1,16 & 0,16 \\
\hline 18 & 0,67 & 0,33 & 1,50 & 0,50 & 0,78 & 0,22 & 1,29 & 0,29 \\
\hline 19 & 0,71 & 0,29 & 1,42 & 0,42 & 0,48 & 0,52 & 2,08 & 1,08 \\
\hline 20 & 0,45 & 0,55 & 2,25 & 1,25 & 0,18 & 0,82 & 5,69 & 4,69 \\
\hline 21 & 0,74 & 0,26 & 1,35 & 0,35 & 0,46 & 0,54 & 2,19 & 1,19 \\
\hline 22 & 0,66 & 0,34 & 1,51 & 0,51 & 0,87 & 0,13 & 1,15 & 0,15 \\
\hline 23 & 1,00 & 0,00 & 1,00 & 0,00 & 0,92 & 0,08 & 1,09 & 0,09 \\
\hline 24 & 0,67 & 0,33 & 1,50 & 0,50 & 0,78 & 0,22 & 1,29 & 0,29 \\
\hline 25 & 0,72 & 0,28 & 1,38 & 0,38 & 0,86 & 0,14 & 1,16 & 0,16 \\
\hline 26 & 0,72 & 0,28 & 1,39 & 0,39 & 0,47 & 0,53 & 2,13 & 1,13 \\
\hline 27 & 0,80 & 0,20 & 1,26 & 0,26 & 0,57 & 0,43 & 1,75 & 0,75 \\
\hline 28 & 0,77 & 0,23 & 1,30 & 0,30 & 0,43 & 0,57 & 2,33 & 1,33 \\
\hline 29 & 0,69 & 0,31 & 1,46 & 0,46 & 0,45 & 0,55 & 2,22 & 1,22 \\
\hline 30 & 0,74 & 0,26 & 1,36 & 0,36 & 0,53 & 0,47 & 1,89 & 0,89 \\
\hline 31 & 0,52 & 0,48 & 1,93 & 0,93 & 0,39 & 0,61 & 2,55 & 1,54 \\
\hline 32 & 0,92 & 0,08 & 1,08 & 0,08 & 0,88 & 0,12 & 1,14 & 0,14 \\
\hline 33 & 0,52 & 0,48 & 1,93 & 0,93 & 0,39 & 0,61 & 2,55 & 1,54 \\
\hline 34 & 0,61 & 0,39 & 1,63 & 0,63 & 0,65 & 0,35 & 1,54 & 0,55 \\
\hline 35 & 0,71 & 0,29 & 1,41 & 0,41 & 0,78 & 0,22 & 1,28 & 0,28 \\
\hline
\end{tabular}




\section{Apêndice C - Projeção das variáveis para as unidades ineficientes em 2008}

\begin{tabular}{|c|c|c|c|c|c|c|c|}
\hline \multirow[b]{2}{*}{ CARTEIRAS } & \multicolumn{3}{|c|}{ Ol } & \multicolumn{4}{|c|}{00} \\
\hline & $\mathbf{P} / \mathbf{L}$ & Beta & Volatilidade & $\begin{array}{c}\text { Retorno } 1 \\
\text { ano }\end{array}$ & $\begin{array}{c}\text { Retorno } 3 \\
\text { anos }\end{array}$ & $\begin{array}{c}\text { Retorno } 5 \\
\text { anos }\end{array}$ & LPA \\
\hline 1 & $-87 \%$ & $-87 \%$ & $-87 \%$ & $753 \%$ & $724 \%$ & $692 \%$ & $1191 \%$ \\
\hline 4 & $-23 \%$ & $-23 \%$ & $-48 \%$ & $78 \%$ & $58 \%$ & $29 \%$ & $29 \%$ \\
\hline 6 & $-61 \%$ & $-61 \%$ & $-100 \%$ & $0 \%$ & $0 \%$ & $0 \%$ & $159 \%$ \\
\hline 7 & $-25 \%$ & $-25 \%$ & $-26 \%$ & $33 \%$ & $42 \%$ & $33 \%$ & $77 \%$ \\
\hline 8 & $-36 \%$ & $-36 \%$ & $-75 \%$ & $83 \%$ & $71 \%$ & $57 \%$ & $57 \%$ \\
\hline 9 & $-26 \%$ & $-26 \%$ & $-58 \%$ & $99 \%$ & $71 \%$ & $36 \%$ & $36 \%$ \\
\hline 10 & $-23 \%$ & $-23 \%$ & $-49 \%$ & $77 \%$ & $58 \%$ & $30 \%$ & $30 \%$ \\
\hline 11 & $-54 \%$ & $-54 \%$ & $-55 \%$ & $118 \%$ & $131 \%$ & $118 \%$ & $147 \%$ \\
\hline 12 & $-29 \%$ & $-29 \%$ & $-68 \%$ & $111 \%$ & $83 \%$ & $42 \%$ & $42 \%$ \\
\hline 14 & $-29 \%$ & $-29 \%$ & $-48 \%$ & $97 \%$ & $75 \%$ & $40 \%$ & $40 \%$ \\
\hline 15 & $-35 \%$ & $-35 \%$ & $-62 \%$ & $99 \%$ & $81 \%$ & $53 \%$ & $53 \%$ \\
\hline 16 & $-30 \%$ & $-30 \%$ & $-42 \%$ & $78 \%$ & $64 \%$ & $43 \%$ & $43 \%$ \\
\hline 17 & $-20 \%$ & $-20 \%$ & $-86 \%$ & $39 \%$ & $30 \%$ & $27 \%$ & $25 \%$ \\
\hline 18 & $-33 \%$ & $-33 \%$ & $-48 \%$ & $125 \%$ & $95 \%$ & $50 \%$ & $50 \%$ \\
\hline 19 & $-29 \%$ & $-29 \%$ & $-62 \%$ & $110 \%$ & $76 \%$ & $42 \%$ & $42 \%$ \\
\hline 20 & $-56 \%$ & $-56 \%$ & $-74 \%$ & $172 \%$ & $143 \%$ & $125 \%$ & $125 \%$ \\
\hline 21 & $-26 \%$ & $-26 \%$ & $-59 \%$ & $91 \%$ & $69 \%$ & $35 \%$ & $35 \%$ \\
\hline 22 & $-34 \%$ & $-34 \%$ & $-62 \%$ & $84 \%$ & $74 \%$ & $51 \%$ & $51 \%$ \\
\hline 24 & $-33 \%$ & $-33 \%$ & $-61 \%$ & $117 \%$ & $68 \%$ & $50 \%$ & $50 \%$ \\
\hline 25 & $-28 \%$ & $-28 \%$ & $-28 \%$ & $42 \%$ & $45 \%$ & $38 \%$ & $66 \%$ \\
\hline 26 & $-28 \%$ & $-28 \%$ & $-64 \%$ & $95 \%$ & $73 \%$ & $39 \%$ & $39 \%$ \\
\hline 27 & $-20 \%$ & $-20 \%$ & $-88 \%$ & $130 \%$ & $95 \%$ & $26 \%$ & $26 \%$ \\
\hline 28 & $-23 \%$ & $-23 \%$ & $-54 \%$ & $81 \%$ & $60 \%$ & $30 \%$ & $30 \%$ \\
\hline 29 & $-31 \%$ & $-31 \%$ & $-76 \%$ & $97 \%$ & $77 \%$ & $46 \%$ & $46 \%$ \\
\hline 30 & $-26 \%$ & $-26 \%$ & $-96 \%$ & $61 \%$ & $62 \%$ & $37 \%$ & $36 \%$ \\
\hline 31 & $-48 \%$ & $-48 \%$ & $-67 \%$ & $126 \%$ & $94 \%$ & $93 \%$ & $93 \%$ \\
\hline 32 & $-8 \%$ & $-8 \%$ & $-70 \%$ & $13 \%$ & $13 \%$ & $16 \%$ & $8 \%$ \\
\hline 33 & $-48 \%$ & $-48 \%$ & $-67 \%$ & $126 \%$ & $94 \%$ & $93 \%$ & $93 \%$ \\
\hline 34 & $-39 \%$ & $-39 \%$ & $-61 \%$ & $99 \%$ & $88 \%$ & $63 \%$ & $63 \%$ \\
\hline 35 & $-29 \%$ & $-29 \%$ & $-29 \%$ & $45 \%$ & $48 \%$ & $41 \%$ & $57 \%$ \\
\hline Média & $-34 \%$ & $-34 \%$ & $-62 \%$ & $109 \%$ & $92 \%$ & $69 \%$ & $95 \%$ \\
\hline
\end{tabular}




\section{Apêndice D - Projeção das variáveis para as unidades ineficientes em 2009}

\begin{tabular}{|c|c|c|c|c|c|c|c|}
\hline \multirow[b]{2}{*}{ CARTEIRAS } & \multicolumn{3}{|c|}{ Ol } & \multicolumn{4}{|c|}{00} \\
\hline & $P / L$ & Beta & Volatilidade & $\begin{array}{c}\text { Retorno } 1 \\
\text { ano }\end{array}$ & $\begin{array}{c}\text { Retorno } 3 \\
\text { anos }\end{array}$ & $\begin{array}{c}\text { Retorno } 5 \\
\text { anos }\end{array}$ & LPA \\
\hline 1 & $-97 \%$ & $-31 \%$ & $-31 \%$ & $45 \%$ & $45 \%$ & $53 \%$ & $465 \%$ \\
\hline 2 & $-90 \%$ & $-46 \%$ & $-46 \%$ & $86 \%$ & $254 \%$ & $266 \%$ & $86 \%$ \\
\hline 4 & $-65 \%$ & $-59 \%$ & $-59 \%$ & $146 \%$ & $244 \%$ & $248 \%$ & $146 \%$ \\
\hline 8 & $-91 \%$ & $-57 \%$ & $-57 \%$ & $133 \%$ & $164 \%$ & $166 \%$ & $133 \%$ \\
\hline 9 & $-78 \%$ & $-50 \%$ & $-50 \%$ & $100 \%$ & $174 \%$ & $180 \%$ & $100 \%$ \\
\hline 10 & $-65 \%$ & $-60 \%$ & $-60 \%$ & $149 \%$ & $245 \%$ & $249 \%$ & $149 \%$ \\
\hline 12 & $-77 \%$ & $-43 \%$ & $-43 \%$ & $74 \%$ & $118 \%$ & $131 \%$ & $74 \%$ \\
\hline 14 & $-56 \%$ & $-48 \%$ & $-48 \%$ & $91 \%$ & $187 \%$ & $188 \%$ & $91 \%$ \\
\hline 15 & $-79 \%$ & $-44 \%$ & $-44 \%$ & $79 \%$ & $162 \%$ & $164 \%$ & $79 \%$ \\
\hline 16 & $-68 \%$ & $-41 \%$ & $-41 \%$ & $70 \%$ & $118 \%$ & $121 \%$ & $70 \%$ \\
\hline 17 & $-66 \%$ & $-14 \%$ & $-14 \%$ & $16 \%$ & $25 \%$ & $107 \%$ & $16 \%$ \\
\hline 18 & $-48 \%$ & $-22 \%$ & $-22 \%$ & $29 \%$ & $113 \%$ & $115 \%$ & $29 \%$ \\
\hline 19 & $-79 \%$ & $-52 \%$ & $-52 \%$ & $108 \%$ & $183 \%$ & $190 \%$ & $108 \%$ \\
\hline 20 & $-100 \%$ & $-82 \%$ & $-82 \%$ & $0 \%$ & $624 \%$ & $469 \%$ & $492 \%$ \\
\hline 21 & $-71 \%$ & $-54 \%$ & $-54 \%$ & $119 \%$ & $197 \%$ & $204 \%$ & $119 \%$ \\
\hline 22 & $-89 \%$ & $-13 \%$ & $-13 \%$ & $15 \%$ & $27 \%$ & $28 \%$ & $15 \%$ \\
\hline 23 & $-55 \%$ & $-8 \%$ & $-8 \%$ & $9 \%$ & $41 \%$ & $35 \%$ & $9 \%$ \\
\hline 24 & $-76 \%$ & $-22 \%$ & $-22 \%$ & $29 \%$ & $113 \%$ & $104 \%$ & $29 \%$ \\
\hline 25 & $-48 \%$ & $-14 \%$ & $-14 \%$ & $16 \%$ & $26 \%$ & $27 \%$ & $16 \%$ \\
\hline 26 & $-76 \%$ & $-53 \%$ & $-53 \%$ & $113 \%$ & $180 \%$ & $191 \%$ & $113 \%$ \\
\hline 27 & $-80 \%$ & $-43 \%$ & $-43 \%$ & $75 \%$ & $171 \%$ & $177 \%$ & $75 \%$ \\
\hline 28 & $-88 \%$ & $-57 \%$ & $-57 \%$ & $133 \%$ & $217 \%$ & $223 \%$ & $133 \%$ \\
\hline 29 & $-93 \%$ & $-55 \%$ & $-55 \%$ & $122 \%$ & $176 \%$ & $181 \%$ & $122 \%$ \\
\hline 30 & $-99 \%$ & $-47 \%$ & $-47 \%$ & $89 \%$ & $89 \%$ & $96 \%$ & $121 \%$ \\
\hline 31 & $-91 \%$ & $-61 \%$ & $-61 \%$ & $155 \%$ & $262 \%$ & $237 \%$ & $155 \%$ \\
\hline 32 & $-81 \%$ & $-12 \%$ & $-12 \%$ & $14 \%$ & $14 \%$ & $114 \%$ & $18 \%$ \\
\hline 33 & $-91 \%$ & $-61 \%$ & $-61 \%$ & $155 \%$ & $262 \%$ & $237 \%$ & $155 \%$ \\
\hline 34 & $-81 \%$ & $-35 \%$ & $-35 \%$ & $54 \%$ & $89 \%$ & $90 \%$ & $54 \%$ \\
\hline 35 & $-47 \%$ & $-22 \%$ & $-22 \%$ & $28 \%$ & $45 \%$ & $47 \%$ & $28 \%$ \\
\hline MÉDIA & $-77 \%$ & $-42 \%$ & $-42 \%$ & $78 \%$ & $157 \%$ & $160 \%$ & $110 \%$ \\
\hline
\end{tabular}




\section{Apêndice E - Pesos das variáveis CCR- OI 2008}

\begin{tabular}{|c|c|c|c|c|c|c|c|}
\hline \multirow[b]{2}{*}{ CARTEIRAS } & \multicolumn{3}{|c|}{ INSUMOS } & \multicolumn{4}{|c|}{ PRODUTOS } \\
\hline & $P / L$ & Beta & Volatilidade & $\begin{array}{c}\text { Retorno } 1 \\
\text { ano }\end{array}$ & $\begin{array}{c}\text { Retorno } 3 \\
\text { anos }\end{array}$ & $\begin{array}{c}\text { Retorno } 5 \\
\text { anos }\end{array}$ & LPA \\
\hline 1 & 0,942 & 0,041 & 0,105 & 0,004 & 0,004 & 0,115 & 0,004 \\
\hline 2 & 9,300 & 1,330 & 0,253 & 0,004 & 1,210 & 0,004 & 0,004 \\
\hline 3 & 13,300 & 1,610 & 0,004 & 0,004 & 0,004 & 0,004 & 2,310 \\
\hline 4 & 5,590 & 0,529 & 0,004 & 0,004 & 0,004 & 0,245 & 0,652 \\
\hline 5 & 7,690 & 0,935 & 0,004 & 0,004 & 0,004 & 0,004 & 1,330 \\
\hline 6 & 21,900 & 2,660 & 0,004 & 0,004 & 0,004 & 0,004 & 3,830 \\
\hline 7 & 5,700 & 0,600 & 0,004 & 0,546 & 0,004 & 0,201 & 0,004 \\
\hline 8 & 5,120 & 0,485 & 0,004 & 0,004 & 0,004 & 0,225 & 0,596 \\
\hline 9 & 5,310 & 0,502 & 0,004 & 0,004 & 0,004 & 0,233 & 0,618 \\
\hline 10 & 5,590 & 0,529 & 0,004 & 0,004 & 0,004 & 0,245 & 0,652 \\
\hline 11 & 3,510 & 0,369 & 0,004 & 0,332 & 0,004 & 0,125 & 0,004 \\
\hline 12 & 5,010 & 0,474 & 0,004 & 0,004 & 0,004 & 0,220 & 0,583 \\
\hline 13 & 7,700 & 0,264 & 0,970 & 0,004 & 0,004 & 1,030 & 0,004 \\
\hline 14 & 5,200 & 0,492 & 0,004 & 0,004 & 0,004 & 0,229 & 0,606 \\
\hline 15 & 5,020 & 0,475 & 0,004 & 0,004 & 0,004 & 0,221 & 0,584 \\
\hline 16 & 5,390 & 0,510 & 0,004 & 0,004 & 0,004 & 0,237 & 0,628 \\
\hline 17 & 8,960 & 1,090 & 0,004 & 0,004 & 0,004 & 0,004 & 1,560 \\
\hline 18 & 4,880 & 0,461 & 0,004 & 0,004 & 0,004 & 0,214 & 0,567 \\
\hline 19 & 5,090 & 0,481 & 0,004 & 0,004 & 0,004 & 0,224 & 0,592 \\
\hline 20 & 4,270 & 0,403 & 0,004 & 0,004 & 0,004 & 0,188 & 0,494 \\
\hline 21 & 5,310 & 0,502 & 0,004 & 0,004 & 0,004 & 0,233 & 0,618 \\
\hline 22 & 5,040 & 0,476 & 0,004 & 0,004 & 0,004 & 0,221 & 0,586 \\
\hline 23 & 8,030 & 0,702 & 0,472 & 0,004 & 0,499 & 0,590 & 0,004 \\
\hline 24 & 6,110 & 0,578 & 0,004 & 0,004 & 0,004 & 0,268 & 0,714 \\
\hline 25 & 5,560 & 0,193 & 0,696 & 0,004 & 0,004 & 0,741 & 0,004 \\
\hline 26 & 5,200 & 0,492 & 0,004 & 0,004 & 0,004 & 0,228 & 0,605 \\
\hline 27 & 4,960 & 0,469 & 0,004 & 0,004 & 0,004 & 0,218 & 0,577 \\
\hline 28 & 5,530 & 0,523 & 0,004 & 0,004 & 0,004 & 0,243 & 0,645 \\
\hline 29 & 5,060 & 0,478 & 0,004 & 0,004 & 0,004 & 0,222 & 0,588 \\
\hline 30 & 5,000 & 0,607 & 0,004 & 0,004 & 0,004 & 0,004 & 0,861 \\
\hline 31 & 5,070 & 0,480 & 0,004 & 0,004 & 0,004 & 0,223 & 0,591 \\
\hline 32 & 10,700 & 1,310 & 0,004 & 0,004 & 0,004 & 0,004 & 1,870 \\
\hline 33 & 5,070 & 0,480 & 0,004 & 0,004 & 0,004 & 0,223 & 0,591 \\
\hline 34 & 4,660 & 0,440 & 0,004 & 0,004 & 0,004 & 0,205 & 0,541 \\
\hline 35 & 7,310 & 0,207 & 0,151 & 0,004 & 0,004 & 0,727 & 0,004 \\
\hline MÉDIA & 6,402 & 0,634 & 0,079 & 0,029 & 0,053 & 0,238 & 0,698 \\
\hline
\end{tabular}




\section{Apêndice F - Pesos das variáveis CCR- 002008}

\begin{tabular}{|c|c|c|c|c|c|c|c|}
\hline \multirow[b]{2}{*}{ CARTEIRAS } & \multicolumn{3}{|c|}{ INSUMOS } & \multicolumn{4}{|c|}{ PRODUTOS } \\
\hline & $P / L$ & Beta & Volatilidade & $\begin{array}{c}\text { Retorno } 1 \\
\text { ano }\end{array}$ & $\begin{array}{c}\text { Retorno } 3 \\
\text { anos }\end{array}$ & $\begin{array}{c}\text { Retorno } 5 \\
\text { anos }\end{array}$ & LPA \\
\hline 1 & 7,470 & 0,256 & 0,941 & 0,004 & 0,004 & 1,000 & 0,004 \\
\hline 2 & 23,900 & 0,999 & 0,004 & 0,004 & 0,004 & 1,960 & 0,651 \\
\hline 3 & 12,500 & 0,004 & 49,900 & 1,630 & 0,004 & 0,004 & 0,004 \\
\hline 4 & 7,240 & 0,685 & 0,004 & 0,004 & 0,004 & 0,317 & 0,849 \\
\hline 5 & 7,690 & 0,991 & 0,004 & 0,998 & 0,004 & 0,004 & 0,004 \\
\hline 6 & 57,000 & 6,950 & 0,004 & 0,004 & 0,004 & 0,004 & 10,000 \\
\hline 7 & 7,600 & 0,801 & 0,004 & 0,732 & 0,004 & 0,267 & 0,004 \\
\hline 8 & 8,090 & 0,765 & 0,004 & 0,004 & 0,004 & 0,354 & 0,950 \\
\hline 9 & 7,230 & 0,683 & 0,004 & 0,004 & 0,004 & 0,317 & 0,847 \\
\hline 10 & 7,300 & 0,691 & 0,004 & 0,004 & 0,004 & 0,320 & 0,856 \\
\hline 11 & 7,670 & 0,808 & 0,004 & 0,739 & 0,004 & 0,269 & 0,004 \\
\hline 12 & 7,140 & 0,676 & 0,004 & 0,004 & 0,004 & 0,313 & 0,837 \\
\hline 13 & 8,540 & 0,808 & 0,004 & 0,004 & 0,004 & 0,374 & 1,000 \\
\hline 14 & 7,330 & 0,693 & 0,004 & 0,004 & 0,004 & 0,321 & 0,859 \\
\hline 15 & 7,720 & 0,731 & 0,004 & 0,004 & 0,004 & 0,338 & 0,906 \\
\hline 16 & 7,720 & 0,730 & 0,004 & 0,004 & 0,004 & 0,338 & 0,906 \\
\hline 17 & 11,200 & 1,360 & 0,004 & 0,004 & 0,004 & 0,004 & 1,950 \\
\hline 18 & 7,350 & 0,695 & 0,004 & 0,004 & 0,004 & 0,322 & 0,862 \\
\hline 19 & 7,230 & 0,683 & 0,004 & 0,004 & 0,004 & 0,317 & 0,847 \\
\hline 20 & 9,610 & 0,909 & 0,004 & 0,004 & 0,004 & 0,421 & 1,130 \\
\hline 21 & 7,180 & 0,679 & 0,004 & 0,004 & 0,004 & 0,315 & 0,841 \\
\hline 22 & 7,610 & 0,720 & 0,004 & 0,004 & 0,004 & 0,333 & 0,893 \\
\hline 23 & 8,750 & 1,030 & 0,004 & 0,365 & 0,004 & 0,801 & 0,004 \\
\hline 24 & 9,200 & 0,871 & 0,004 & 0,004 & 0,004 & 0,403 & 1,080 \\
\hline 25 & 7,700 & 0,264 & 0,970 & 0,004 & 0,004 & 1,030 & 0,004 \\
\hline 26 & 7,240 & 0,685 & 0,004 & 0,004 & 0,004 & 0,317 & 0,849 \\
\hline 27 & 6,290 & 0,595 & 0,004 & 0,004 & 0,004 & 0,276 & 0,736 \\
\hline 28 & 7,200 & 0,681 & 0,004 & 0,004 & 0,004 & 0,316 & 0,844 \\
\hline 29 & 7,410 & 0,701 & 0,004 & 0,004 & 0,004 & 0,325 & 0,869 \\
\hline 30 & 6,790 & 0,826 & 0,004 & 0,004 & 0,004 & 0,004 & 1,180 \\
\hline 31 & 9,790 & 0,926 & 0,004 & 0,004 & 0,004 & 0,428 & 1,150 \\
\hline 32 & 11,600 & 1,420 & 0,004 & 0,004 & 0,004 & 0,004 & 2,030 \\
\hline 33 & 9,790 & 0,926 & 0,004 & 0,004 & 0,004 & 0,428 & 1,150 \\
\hline 34 & 7,630 & 0,721 & 0,004 & 0,004 & 0,004 & 0,334 & 0,895 \\
\hline 35 & 10,300 & 0,288 & 0,216 & 0,004 & 0,004 & 1,030 & 0,004 \\
\hline MÉDIA & 10,057 & 0,921 & 1,490 & 0,131 & 0,004 & 0,397 & 1,029 \\
\hline
\end{tabular}




\section{Apêndice G - Pesos das variáveis CCR- OI 2009}

\begin{tabular}{|c|c|c|c|c|c|c|c|}
\hline \multirow[b]{2}{*}{ CARTEIRAS } & \multicolumn{3}{|c|}{ INSUMOS } & \multicolumn{4}{|c|}{ PRODUTOS } \\
\hline & $P / L$ & Beta & Volatilidade & $\begin{array}{c}\text { Retorno } 1 \\
\text { ano }\end{array}$ & $\begin{array}{c}\text { Retorno } 3 \\
\text { anos }\end{array}$ & $\begin{array}{c}\text { Retorno } 5 \\
\text { anos }\end{array}$ & LPA \\
\hline 1 & 0,004 & 0,965 & 2,580 & 0,047 & 0,746 & 0,004 & 0,004 \\
\hline 2 & 0,004 & 0,679 & 0,554 & 0,687 & 0,004 & 0,004 & 0,120 \\
\hline 3 & 0,004 & 1,590 & 1,430 & 1,780 & 0,004 & 0,004 & 0,004 \\
\hline 4 & 0,004 & 0,615 & 0,535 & 0,569 & 0,004 & 0,004 & 0,204 \\
\hline 5 & 0,004 & 1,060 & 4,610 & 0,004 & 0,004 & 0,004 & 1,080 \\
\hline 6 & 2,760 & 0,767 & 0,640 & 0,753 & 0,004 & 0,004 & 0,250 \\
\hline 7 & 0,004 & 1,270 & 1,100 & 1,180 & 0,004 & 0,004 & 0,427 \\
\hline 8 & 0,004 & 0,602 & 0,524 & 0,556 & 0,004 & 0,004 & 0,199 \\
\hline 9 & 0,004 & 0,706 & 0,614 & 0,654 & 0,004 & 0,004 & 0,235 \\
\hline 10 & 0,004 & 0,612 & 0,532 & 0,565 & 0,004 & 0,004 & 0,202 \\
\hline 11 & 0,004 & 1,430 & 3,220 & 1,120 & 0,004 & 0,004 & 0,871 \\
\hline 12 & 0,004 & 0,729 & 0,633 & 0,675 & 0,004 & 0,004 & 0,242 \\
\hline 13 & 0,004 & 1,620 & 1,650 & 0,963 & 0,004 & 0,603 & 0,004 \\
\hline 14 & 0,004 & 0,687 & 0,598 & 0,636 & 0,004 & 0,004 & 0,228 \\
\hline 15 & 0,004 & 0,668 & 0,581 & 0,619 & 0,004 & 0,004 & 0,222 \\
\hline 16 & 0,004 & 0,810 & 0,703 & 0,751 & 0,004 & 0,004 & 0,270 \\
\hline 17 & 0,004 & 1,460 & 1,190 & 1,480 & 0,004 & 0,004 & 0,276 \\
\hline 18 & 0,004 & 0,823 & 0,715 & 0,763 & 0,004 & 0,004 & 0,275 \\
\hline 19 & 0,004 & 0,693 & 0,602 & 0,642 & 0,004 & 0,004 & 0,230 \\
\hline 20 & 0,004 & 1,460 & 0,008 & 0,004 & 0,004 & 0,250 & 0,004 \\
\hline 21 & 0,004 & 0,654 & 0,569 & 0,606 & 0,004 & 0,004 & 0,217 \\
\hline 22 & 0,004 & 1,560 & 1,350 & 1,460 & 0,004 & 0,004 & 0,528 \\
\hline 23 & 0,004 & 1,790 & 1,550 & 1,670 & 0,004 & 0,004 & 0,608 \\
\hline 24 & 0,004 & 0,948 & 0,823 & 0,881 & 0,004 & 0,004 & 0,318 \\
\hline 25 & 0,004 & 1,110 & 0,962 & 1,030 & 0,004 & 0,004 & 0,373 \\
\hline 26 & 0,004 & 0,653 & 0,568 & 0,604 & 0,004 & 0,004 & 0,216 \\
\hline 27 & 0,004 & 0,664 & 0,577 & 0,614 & 0,004 & 0,004 & 0,220 \\
\hline 28 & 0,004 & 0,652 & 0,567 & 0,603 & 0,004 & 0,004 & 0,216 \\
\hline 29 & 0,004 & 0,646 & 0,562 & 0,598 & 0,004 & 0,004 & 0,214 \\
\hline 30 & 0,004 & 1,060 & 1,110 & 0,578 & 0,441 & 0,004 & 0,004 \\
\hline 31 & 0,004 & 0,684 & 0,595 & 0,633 & 0,004 & 0,004 & 0,227 \\
\hline 32 & 0,004 & 1,500 & 1,310 & 1,320 & 0,265 & 0,004 & 0,004 \\
\hline 33 & 0,004 & 0,684 & 0,595 & 0,633 & 0,004 & 0,004 & 0,227 \\
\hline 34 & 0,004 & 0,968 & 0,840 & 0,900 & 0,004 & 0,004 & 0,325 \\
\hline 35 & 0,004 & 1,010 & 0,877 & 0,939 & 0,004 & 0,004 & 0,339 \\
\hline Média & 0,083 & 0,967 & 1,025 & 0,786 & 0,045 & 0,028 & 0,268 \\
\hline
\end{tabular}




\section{Apêndice H - Pesos das variáveis CCR- OO 2009}

\begin{tabular}{|c|c|c|c|c|c|c|c|}
\hline \multirow[b]{2}{*}{ CARTEIRAS } & \multicolumn{3}{|c|}{ INSUMOS } & \multicolumn{4}{|c|}{ PRODUTOS } \\
\hline & $P / L$ & Beta & Volatilidade & $\begin{array}{c}\text { Retorno } 1 \\
\text { ano }\end{array}$ & $\begin{array}{c}\text { Retorno } 3 \\
\text { anos }\end{array}$ & $\begin{array}{c}\text { Retorno } 5 \\
\text { anos }\end{array}$ & LPA \\
\hline 1 & 0,004 & 1,410 & 3,770 & 0,066 & 1,090 & 0,004 & 0,004 \\
\hline 2 & 0,004 & 1,270 & 1,040 & 1,290 & 0,004 & 0,004 & 0,239 \\
\hline 3 & 99,700 & 3,790 & 0,004 & 1,780 & 0,004 & 0,004 & 0,004 \\
\hline 4 & 0,004 & 1,520 & 1,320 & 1,420 & 0,004 & 0,004 & 0,515 \\
\hline 5 & 82,200 & 6,250 & 0,004 & 0,004 & 1,210 & 0,004 & 0,004 \\
\hline 6 & 70,300 & 0,004 & 0,998 & 0,994 & 0,004 & 0,004 & 0,004 \\
\hline 7 & 0,004 & 1,270 & 1,140 & 1,410 & 0,004 & 0,004 & 0,004 \\
\hline 8 & 0,004 & 1,410 & 1,220 & 1,310 & 0,004 & 0,004 & 0,475 \\
\hline 9 & 0,004 & 1,420 & 1,230 & 1,330 & 0,004 & 0,004 & 0,480 \\
\hline 10 & 0,004 & 1,530 & 1,330 & 1,430 & 0,004 & 0,004 & 0,517 \\
\hline 11 & 0,004 & 0,676 & 19,100 & 0,004 & 0,004 & 0,004 & 1,340 \\
\hline 12 & 0,004 & 1,270 & 1,100 & 1,190 & 0,004 & 0,004 & 0,430 \\
\hline 13 & 6,080 & 1,780 & 1,410 & 1,870 & 0,004 & 0,004 & 0,387 \\
\hline 14 & 0,004 & 1,320 & 1,150 & 1,230 & 0,004 & 0,004 & 0,446 \\
\hline 15 & 0,004 & 1,210 & 1,050 & 1,120 & 0,004 & 0,004 & 0,406 \\
\hline 16 & 0,004 & 1,380 & 1,200 & 1,290 & 0,004 & 0,004 & 0,466 \\
\hline 17 & 0,004 & 1,700 & 1,390 & 1,730 & 0,004 & 0,004 & 0,324 \\
\hline 18 & 0,004 & 1,070 & 0,924 & 0,991 & 0,004 & 0,004 & 0,358 \\
\hline 19 & 0,004 & 1,450 & 1,250 & 1,350 & 0,004 & 0,004 & 0,489 \\
\hline 20 & 0,004 & 8,360 & 0,008 & 0,004 & 0,004 & 1,460 & 0,004 \\
\hline 21 & 0,004 & 1,440 & 1,250 & 1,340 & 0,004 & 0,004 & 0,486 \\
\hline 22 & 0,004 & 1,790 & 1,550 & 1,670 & 0,004 & 0,004 & 0,607 \\
\hline 23 & 0,004 & 1,960 & 1,690 & 1,830 & 0,004 & 0,004 & 0,664 \\
\hline 24 & 0,004 & 1,220 & 1,060 & 1,140 & 0,004 & 0,004 & 0,413 \\
\hline 25 & 0,004 & 1,290 & 1,120 & 1,200 & 0,004 & 0,004 & 0,434 \\
\hline 26 & 0,004 & 1,390 & 1,210 & 1,300 & 0,004 & 0,004 & 0,471 \\
\hline 27 & 0,004 & 1,170 & 1,020 & 1,090 & 0,004 & 0,004 & 0,394 \\
\hline 28 & 0,004 & 1,530 & 1,320 & 1,420 & 0,004 & 0,004 & 0,516 \\
\hline 29 & 0,004 & 1,440 & 1,250 & 1,340 & 0,004 & 0,004 & 0,486 \\
\hline 30 & 0,004 & 2,010 & 2,110 & 1,090 & 0,846 & 0,004 & 0,004 \\
\hline 31 & 0,004 & 1,750 & 1,520 & 1,630 & 0,004 & 0,004 & 0,593 \\
\hline 32 & 0,004 & 1,720 & 1,500 & 1,510 & 0,305 & 0,004 & 0,004 \\
\hline 33 & 0,004 & 1,750 & 1,520 & 1,630 & 0,004 & 0,004 & 0,593 \\
\hline 34 & 0,004 & 1,490 & 1,300 & 1,390 & 0,004 & 0,004 & 0,505 \\
\hline 35 & 0,004 & 1,290 & 1,120 & 1,200 & 0,004 & 0,004 & 0,435 \\
\hline MÉDIA & 7,383 & 1,809 & 1,748 & 1,217 & 0,102 & 0,046 & 0,386 \\
\hline
\end{tabular}




\section{Apêndice I - Valores padronizados de 2008}

\begin{tabular}{|c|c|c|c|c|c|c|c|}
\hline \multirow{2}{*}{$\begin{array}{c}\text { Carteiras } \\
2008\end{array}$} & \multicolumn{3}{|c|}{ INSUMOS } & \multicolumn{4}{|c|}{ PRODUTOS } \\
\hline & $P / L$ & Beta & Volatilidade & $\begin{array}{c}\text { Retorno } 1 \\
\text { ano }\end{array}$ & $\begin{array}{c}\text { Retorno } 3 \\
\text { anos }\end{array}$ & $\begin{array}{c}\text { Retorno } 5 \\
\text { anos }\end{array}$ & LPA \\
\hline 1 & 1,00 & 0,52 & 0,35 & 0,94 & 0,94 & 0,99 & 0,46 \\
\hline 2 & 0,02 & 0,52 & 0,48 & 0,40 & 0,82 & 0,44 & 0,20 \\
\hline 3 & 0,00 & 0,62 & 0,02 & 0,61 & 0,68 & 0,17 & 0,43 \\
\hline 4 & 0,12 & 0,62 & 0,32 & 0,82 & 0,96 & 0,96 & 0,81 \\
\hline 5 & 0,13 & 0,00 & 0,00 & 0,99 & 0,94 & 0,96 & 0,74 \\
\hline 6 & 0,02 & 0,21 & 0,68 & 0,00 & 0,00 & 0,00 & 0,00 \\
\hline 7 & 0,11 & 0,62 & 0,37 & 1,00 & 1,00 & 0,98 & 0,53 \\
\hline 8 & 0,13 & 0,68 & 1,00 & 0,84 & 0,95 & 0,95 & 0,69 \\
\hline 9 & 0,12 & 0,72 & 0,40 & 0,78 & 0,95 & 0,94 & 0,82 \\
\hline 10 & 0,12 & 0,62 & 0,34 & 0,82 & 0,96 & 0,96 & 0,80 \\
\hline 11 & 0,22 & 0,61 & 0,44 & 0,98 & 0,95 & 1,00 & 0,62 \\
\hline 12 & 0,11 & 0,94 & 0,72 & 0,79 & 0,97 & 0,95 & 0,83 \\
\hline 13 & 0,08 & 0,39 & 0,29 & 0,90 & 0,96 & 0,96 & 0,63 \\
\hline 14 & 0,12 & 0,76 & 0,38 & 0,80 & 0,95 & 0,95 & 0,80 \\
\hline 15 & 0,12 & 0,83 & 0,67 & 0,81 & 0,95 & 0,95 & 0,74 \\
\hline 16 & 0,12 & 0,69 & 0,39 & 0,84 & 0,96 & 0,95 & 0,74 \\
\hline 17 & 0,03 & 0,67 & 0,12 & 0,64 & 0,73 & 0,32 & 0,51 \\
\hline 18 & 0,11 & 1,00 & 0,48 & 0,76 & 0,94 & 0,94 & 0,80 \\
\hline 19 & 0,13 & 0,70 & 0,39 & 0,77 & 0,95 & 0,94 & 0,82 \\
\hline 20 & 0,15 & 0,89 & 0,21 & 0,73 & 0,84 & 0,64 & 0,64 \\
\hline 21 & 0,12 & 0,72 & 0,44 & 0,81 & 0,96 & 0,96 & 0,82 \\
\hline 22 & 0,15 & 0,51 & 0,34 & 0,86 & 0,93 & 0,94 & 0,76 \\
\hline 23 & 0,10 & 0,12 & 0,24 & 0,77 & 0,94 & 0,89 & 0,49 \\
\hline 24 & 0,10 & 0,67 & 0,54 & 0,61 & 0,84 & 0,80 & 0,62 \\
\hline 25 & 0,11 & 0,64 & 0,38 & 0,95 & 0,99 & 0,96 & 0,57 \\
\hline 26 & 0,12 & 0,76 & 0,55 & 0,81 & 0,96 & 0,96 & 0,81 \\
\hline 27 & 0,11 & 0,96 & 0,83 & 0,76 & 0,94 & 0,93 & 1,00 \\
\hline 28 & 0,12 & 0,64 & 0,34 & 0,82 & 0,96 & 0,95 & 0,82 \\
\hline 29 & 0,13 & 0,71 & 0,72 & 0,82 & 0,95 & 0,94 & 0,79 \\
\hline 30 & 0,15 & 0,41 & 0,22 & 0,96 & 0,95 & 0,89 & 0,84 \\
\hline 31 & 0,12 & 0,81 & 0,53 & 0,71 & 0,88 & 0,73 & 0,59 \\
\hline 32 & 0,02 & 0,60 & 0,06 & 0,66 & 0,71 & 0,27 & 0,49 \\
\hline 33 & 0,12 & 0,81 & 0,53 & 0,71 & 0,88 & 0,73 & 0,59 \\
\hline 34 & 0,15 & 0,68 & 0,49 & 0,86 & 0,95 & 0,96 & 0,75 \\
\hline 35 & 0,11 & 0,65 & 0,41 & 0,93 & 0,98 & 0,96 & 0,60 \\
\hline
\end{tabular}


Apêndice J - Valores padronizados de 2009

\begin{tabular}{|c|c|c|c|c|c|c|c|}
\hline \multirow{2}{*}{$\begin{array}{c}\text { Carteiras } \\
2009\end{array}$} & \multicolumn{3}{|c|}{ INSUMOS } & \multicolumn{4}{|c|}{ PRODUTOS } \\
\hline & $P / L$ & Beta & Volatilidade & $\begin{array}{c}\text { Retorno } 1 \\
\text { ano }\end{array}$ & $\begin{array}{c}\text { Retorno } 3 \\
\text { anos }\end{array}$ & $\begin{array}{c}\text { Retorno } 5 \\
\text { anos }\end{array}$ & LPA \\
\hline 1 & 1,00 & 0,63 & 0,15 & 0,18 & 0,90 & 0,92 & 0,22 \\
\hline 2 & 0,13 & 0,95 & 0,64 & 0,68 & 0,62 & 0,61 & 0,49 \\
\hline 3 & 0,01 & 0,00 & 0,70 & 0,56 & 0,68 & 0,00 & 0,00 \\
\hline 4 & 0,02 & 0,79 & 0,96 & 0,34 & 0,92 & 0,97 & 0,99 \\
\hline 5 & 0,00 & 0,16 & 0,18 & 0,00 & 0,82 & 0,91 & 0,92 \\
\hline 6 & 0,00 & 0,47 & 1,00 & 1,00 & 0,00 & 0,39 & 0,98 \\
\hline 7 & 0,01 & 0,79 & 0,00 & 0,70 & 0,97 & 1,00 & 0,39 \\
\hline 8 & 0,13 & 0,99 & 0,77 & 0,59 & 0,94 & 0,96 & 0,46 \\
\hline 9 & 0,04 & 0,72 & 0,80 & 0,44 & 0,93 & 0,96 & 0,85 \\
\hline 10 & 0,02 & 0,80 & 0,96 & 0,34 & 0,92 & 0,97 & 0,98 \\
\hline 11 & 0,05 & 0,63 & 0,03 & 0,31 & 0,89 & 0,94 & 0,74 \\
\hline 12 & 0,05 & 0,79 & 0,67 & 0,60 & 1,00 & 0,98 & 0,65 \\
\hline 13 & 0,01 & 0,21 & 0,40 & 0,45 & 0,91 & 0,93 & 0,39 \\
\hline 14 & 0,02 & 0,82 & 0,73 & 0,45 & 0,92 & 0,97 & 0,98 \\
\hline 15 & 0,05 & 1,00 & 0,57 & 0,58 & 0,93 & 0,97 & 0,84 \\
\hline 16 & 0,03 & 0,74 & 0,57 & 0,51 & 0,94 & 0,97 & 0,72 \\
\hline 17 & 0,03 & 0,13 & 0,68 & 0,55 & 0,73 & 0,19 & 0,14 \\
\hline 18 & 0,02 & 0,92 & 0,34 & 0,64 & 0,92 & 0,96 & 1,00 \\
\hline 19 & 0,04 & 0,73 & 0,82 & 0,42 & 0,93 & 0,96 & 0,87 \\
\hline 20 & 0,04 & 0,68 & 0,83 & 0,00 & 0,49 & 0,68 & 0,66 \\
\hline 21 & 0,03 & 0,78 & 0,86 & 0,42 & 0,94 & 0,97 & 0,88 \\
\hline 22 & 0,04 & 0,51 & 0,15 & 0,31 & 0,88 & 0,94 & 0,78 \\
\hline 23 & 0,01 & 0,28 & 0,32 & 0,22 & 0,81 & 0,91 & 0,89 \\
\hline 24 & 0,05 & 0,56 & 0,57 & 0,61 & 0,81 & 0,88 & 0,72 \\
\hline 25 & 0,02 & 0,78 & 0,14 & 0,66 & 0,96 & 0,98 & 0,46 \\
\hline 26 & 0,04 & 0,81 & 0,83 & 0,47 & 0,96 & 0,97 & 0,81 \\
\hline 27 & 0,06 & 0,88 & 0,72 & 0,61 & 0,92 & 0,94 & 0,83 \\
\hline 28 & 0,06 & 0,76 & 0,89 & 0,36 & 0,92 & 0,96 & 0,93 \\
\hline 29 & 0,14 & 0,86 & 0,79 & 0,50 & 0,93 & 0,95 & 0,66 \\
\hline 30 & 0,47 & 0,48 & 0,44 & 0,22 & 0,89 & 0,92 & 0,62 \\
\hline 31 & 0,08 & 0,87 & 0,68 & 0,38 & 0,69 & 0,78 & 0,63 \\
\hline 32 & 0,05 & 0,08 & 0,67 & 0,52 & 0,71 & 0,12 & 0,09 \\
\hline 33 & 0,08 & 0,87 & 0,68 & 0,38 & 0,69 & 0,78 & 0,63 \\
\hline 34 & 0,04 & 0,72 & 0,36 & 0,44 & 0,91 & 0,96 & 0,75 \\
\hline 35 & 0,02 & 0,79 & 0,23 & 0,64 & 0,96 & 0,98 & 0,51 \\
\hline
\end{tabular}




\section{Apêndice K - Valores padronizados da média de 2008 e 2009}

\begin{tabular}{|c|c|c|c|c|c|c|c|}
\hline \multirow{2}{*}{$\begin{array}{c}\text { Carteiras } \\
2008 \text { e } 2009\end{array}$} & \multicolumn{3}{|c|}{ INSUMOS } & \multicolumn{4}{|c|}{ PRODUTOS } \\
\hline & $P / L$ & Beta & Volatilidade & $\begin{array}{c}\text { Retorno } 1 \\
\text { ano }\end{array}$ & $\begin{array}{c}\text { Retorno } 3 \\
\text { anos }\end{array}$ & $\begin{array}{c}\text { Retorno } 5 \\
\text { anos }\end{array}$ & LPA \\
\hline 1 & 1,00 & 0,57 & 0,25 & 0,87 & 0,94 & 0,96 & 0,17 \\
\hline 2 & 0,09 & 0,78 & 0,56 & 0,38 & 0,78 & 0,47 & 0,00 \\
\hline 3 & 0,00 & 0,21 & 0,25 & 0,58 & 0,68 & 0,00 & 0,05 \\
\hline 4 & 0,04 & 0,73 & 0,59 & 0,77 & 0,96 & 0,97 & 0,86 \\
\hline 5 & 0,03 & 0,00 & 0,00 & 0,90 & 0,91 & 0,94 & 0,76 \\
\hline 6 & 0,00 & 0,31 & 0,87 & 0,00 & 0,00 & 0,10 & 0,00 \\
\hline 7 & 0,04 & 0,73 & 0,19 & 1,00 & 1,00 & 1,00 & 0,32 \\
\hline 8 & 0,12 & 0,88 & 1,00 & 0,81 & 0,95 & 0,96 & 0,52 \\
\hline 9 & 0,06 & 0,73 & 0,58 & 0,74 & 0,95 & 0,95 & 0,82 \\
\hline 10 & 0,04 & 0,73 & 0,61 & 0,77 & 0,96 & 0,97 & 0,85 \\
\hline 11 & 0,09 & 0,62 & 0,25 & 0,92 & 0,94 & 0,98 & 0,55 \\
\hline 12 & 0,06 & 0,88 & 0,75 & 0,77 & 0,98 & 0,97 & 0,75 \\
\hline 13 & 0,03 & 0,23 & 0,31 & 0,87 & 0,96 & 0,95 & 0,42 \\
\hline 14 & 0,04 & 0,82 & 0,53 & 0,76 & 0,95 & 0,96 & 0,85 \\
\hline 15 & 0,07 & 0,97 & 0,67 & 0,79 & 0,95 & 0,96 & 0,73 \\
\hline 16 & 0,05 & 0,73 & 0,47 & 0,81 & 0,96 & 0,97 & 0,68 \\
\hline 17 & 0,02 & 0,31 & 0,31 & 0,61 & 0,73 & 0,19 & 0,19 \\
\hline 18 & 0,04 & 1,00 & 0,42 & 0,74 & 0,94 & 0,95 & 0,86 \\
\hline 19 & 0,06 & 0,73 & 0,58 & 0,72 & 0,95 & 0,96 & 0,82 \\
\hline 20 & 0,07 & 0,78 & 0,45 & 0,63 & 0,76 & 0,63 & 0,55 \\
\hline 21 & 0,05 & 0,77 & 0,63 & 0,76 & 0,96 & 0,97 & 0,82 \\
\hline 22 & 0,07 & 0,49 & 0,23 & 0,80 & 0,93 & 0,94 & 0,73 \\
\hline 23 & 0,03 & 0,14 & 0,23 & 0,70 & 0,91 & 0,89 & 0,48 \\
\hline 24 & 0,06 & 0,60 & 0,57 & 0,58 & 0,84 & 0,83 & 0,55 \\
\hline 25 & 0,04 & 0,73 & 0,25 & 0,94 & 0,99 & 0,98 & 0,39 \\
\hline 26 & 0,06 & 0,81 & 0,70 & 0,78 & 0,97 & 0,97 & 0,79 \\
\hline 27 & 0,07 & 0,95 & 0,85 & 0,74 & 0,94 & 0,94 & 1,00 \\
\hline 28 & 0,07 & 0,72 & 0,57 & 0,77 & 0,95 & 0,96 & 0,84 \\
\hline 29 & 0,13 & 0,82 & 0,80 & 0,79 & 0,95 & 0,95 & 0,70 \\
\hline 30 & 0,38 & 0,42 & 0,28 & 0,90 & 0,94 & 0,90 & 0,74 \\
\hline 31 & 0,08 & 0,87 & 0,62 & 0,66 & 0,84 & 0,74 & 0,48 \\
\hline 32 & 0,04 & 0,25 & 0,27 & 0,62 & 0,72 & 0,12 & 0,15 \\
\hline 33 & 0,08 & 0,87 & 0,62 & 0,66 & 0,84 & 0,74 & 0,48 \\
\hline 34 & 0,06 & 0,71 & 0,44 & 0,82 & 0,94 & 0,97 & 0,70 \\
\hline 35 & 0,04 & 0,74 & 0,32 & 0,92 & 0,98 & 0,98 & 0,44 \\
\hline
\end{tabular}

